SAND95-2629 • UC-706

Unlimited Release

Printed November 1995
RECEIVED

JAN 30 IYYS6

OSTI

\title{
Inverse-Synthetic-Aperture Imaging of Trees over a Ground Plane
}

David H. Zittel, Billy C. Brock, John H. Littlejohn, Ward E. Patitz

\author{
Prepared by \\ Sandia National Laboratories \\ Albuquerque, New Mexico 87185 and Livermore, California 94550 \\ for the United States Department of Energy \\ under Contract DE-AC04-94AL85000
}

Approved for public release djstribution is unlimited.
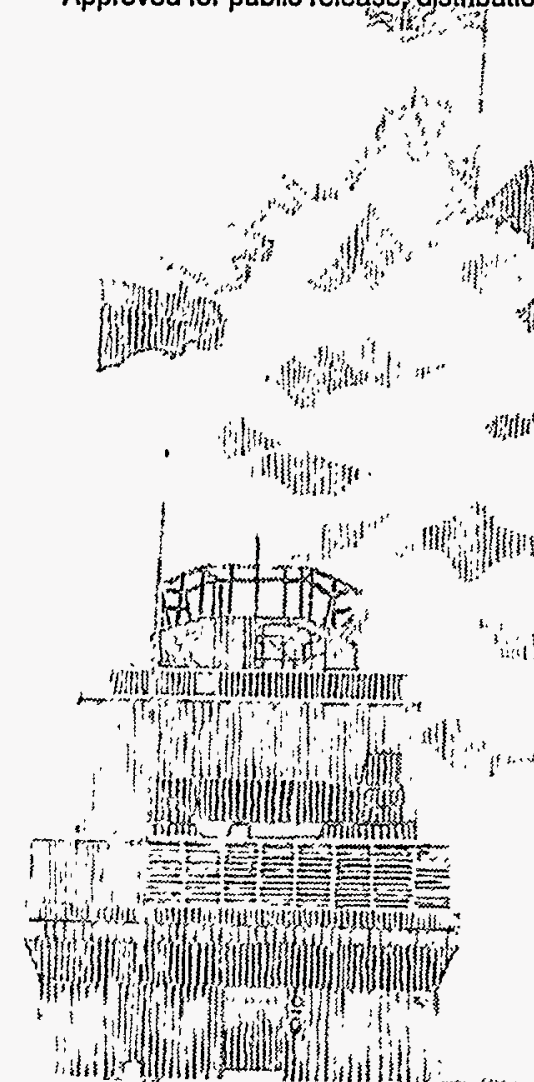

SF2900O(8.81)

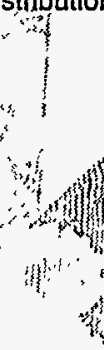


Issued by Sandia National Laboratories, operated for the United States Department of Energy by Sandia Corporation.

NOTICE: This report was prepared as an account of work sponsored by an agency of the United States Government. Neither the United States Government nor any agency thereof, nor any of their employees, nor any of their contractors, subcontractors, or their employees, makes any warranty, express or implied, or assumes any legal liability or responsibility for the accuracy, completeness, or usefulness of any information, apparatus, product, or process disclosed, or represents that its use would not infringe privately owned rights. Reference herein to any specific commercial product, process, or service by trade name, trademark, manufacturer, or otherwise, does not necessarily constitute or imply its endorsement, recommendation, or favoring by the United States Government, any agency thereof or any of their contractors or subcontractors. The views and opinions expressed herein do not necessarily state or reflect those of the United States Government, any agency thereof or any of their contractors.

Printed in the United States of America. This report has been reproduced directly from the best available copy.

Available to DOE and DOE contractors from Office of Scientific and Technical Information

PO Box 62

Oak Ridge, TN 37831

Prices available from (615) 576-8401, FTS 626-8401

Available to the public from

National Technical Information Service

US Department of Commerce

5285 Port Royal Rd

Springfield, VA 22161

NTIS price codes

Printed copy: A04

Microfiche copy:A01 
SAND95-2629

Unlimited Release

Distribution

Printed November 1995

\title{
Inverse-Synthetic-Aperture Imaging
}

\section{of \\ Trees over a Ground Plane}

\author{
David H. Zittel \\ Billy C. Brock \\ John H. Littlejohn \\ Ward E. Patitz \\ Radar/Antenna Department \\ Sandia National Laboratories \\ Albuquerque, New Mexico 87185-0533
}

\begin{abstract}
Recent data collections with the Sandia VHF-UHF synthetic-aperture radar have yielded surprising results; trees appear brighter in the images than expected! In an effort to understand this phenomenon, various small trees have been measured on the Sandia folded compact range with the inverse-synthetic-aperture imaging system. A compilation of these measurements is contained in this report.
\end{abstract}

\section{MASTER}


This page intentionally Blank 


\section{Contents}

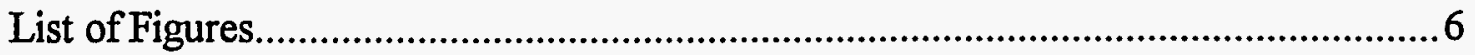

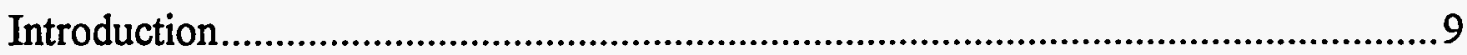

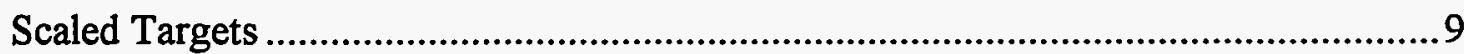

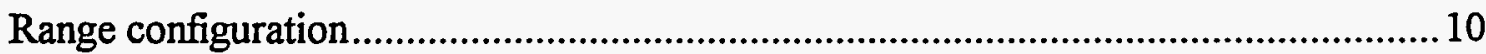

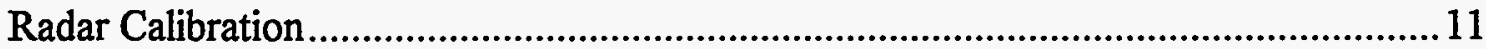

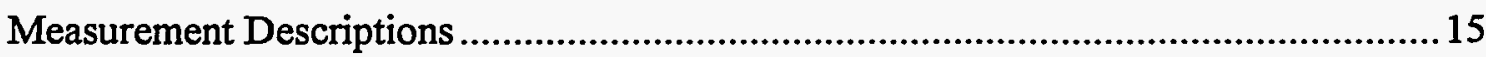

Empty Ground plane ..............................................................................

Black Hills Spruce Tree.....................................................................................16

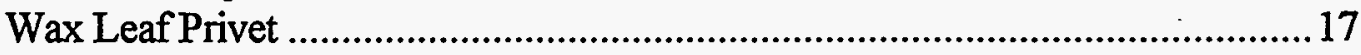

Juniper Tree ...........................................................................................

Royal Purple Smoke Tree................................................................................ 18

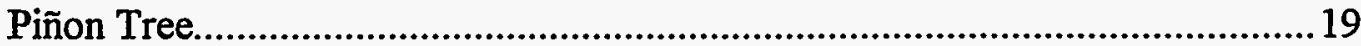

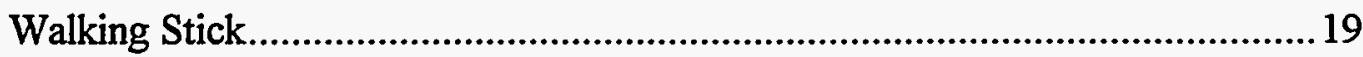

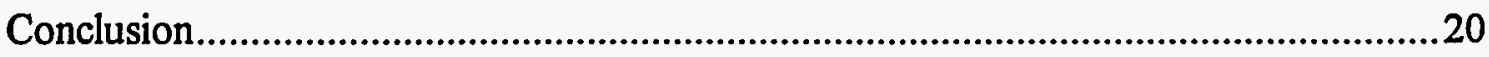

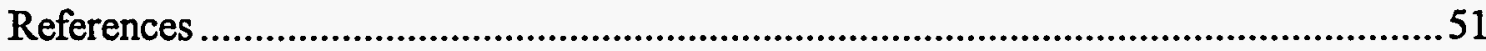




\section{List of Figures}

Fig. 1 Scaled height (feet) as a function of target height (inches) for the low- and highfrequency measurements when scaled to center frequencies of $380 \mathrm{MHz}$ and 750 $\mathrm{MHz}$.

Fig. 2 Folded Compact Range.........................................................................................11

Fig. 3 Diagram showing the four ray paths associated with scattering from a sphere over a conducting plane.

Fig. 4 Geometry indicating the increase in path length for the forward bistatic rays (corner-reflector mode) when compared to the direct ray path. 14

Fig. 5 Ground Plane Cover on Sample Holder........................................................................22

Fig. 6 Calibration Trihedral on Ground plane ....................................................................22

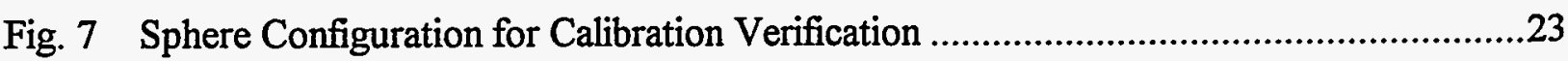

Fig. 8 Sphere Down-range High-frequency Response H-H Polarization .................................23

Fig. 9 ISAR Image of Sphere High-frequency Response H-H Polarization ...............................24

Fig. 10 Sphere Down-range High-frequency Response V-V Polarization ..................................24

Fig. 11 ISAR Image of Sphere High-frequency Response V-V Polarization ..............................25

Fig. 12 Sphere Down Range Low-frequency Response H-H Polarization ................................25

Fig. 13 Sphere Down Range Low-frequency Response V-V Polarization..................................26

Fig. 14 High Frequency ISAR Image of Ground Plane H-H Polarization..................................26

Fig. 15 High Frequency ISAR Image of Ground Plane V-V Polarization ....................................27

Fig. 16 Low Frequency ISAR Image of Ground Plane H-H Polarization ..................................27

Fig. 17 Low Frequency ISAR Image of Ground Plane V-V Polarization ..................................28

Fig. 18 Black Hills Spruce Tree .............................................................................................28

Fig. 19 High Frequency ISAR Image of Black Hills Spruce Tree H-H Polarization ...................29

Fig. 20 High Frequency ISAR Image of Black Hills Spruce Tree V-V Polarization ....................29

Fig. 21 Low Frequency ISAR Image of Black Hills Spruce Tree H-H Polarization......................30

Fig. 22 Low Frequency ISAR Image of Black Hills Spruce Tree V-V Polarization.....................30

Fig. 23 Wax Leaf Privet...................................................................................................... 31

Fig. 24 High Frequency ISAR Image of Wax Leaf Privet H-H Polarization ................................31

Fig. 25 High Frequency ISAR Image of Wax Leaf Privet V-V Polarization................................32

Fig. 26 Low Frequency ISAR Image of Wax Leaf Privet H-H Polarization ................................32

Fig. 27 Low Frequency ISAR Image of Wax Leaf Privet V-V Polarization ...............................33

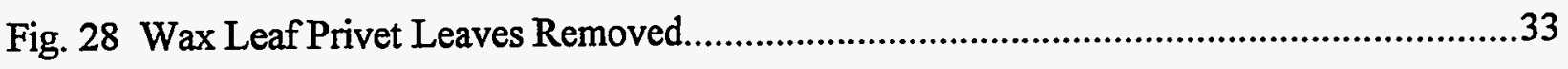


Fig. 29 High Frequency ISAR Image of Wax Leaf Privet Leaves Removed H-H Polarization.

Fig. 30 High Frequency ISAR Image of Wax Leaf Privet Leaves Removed V-V Polarization.

Fig. 31 Low Frequency ISAR Image of Wax Leaf Privet Leaves Removed H-H Polarization.

Fig. 32 Low Frequency ISAR Image of Wax Leaf Privet Leaves Removed V-V Polarization. .35

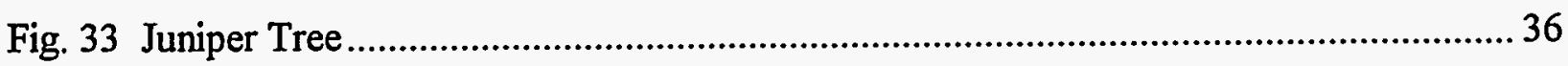

Fig. 34 High Frequency ISAR Image of Juniper Tree H-H Polarization .................................... 36

Fig. 35 High Frequency ISAR Image of Juniper Tree V-V Polarization .................................... 37

Fig. 36 Low Frequency ISAR Image of Juniper Tree H-H Polarization....................................... 37

Fig. 37 Low Frequency ISAR Image of Juniper Tree V-V Polarization..................................... 38

Fig. 38 Royal Purple Smoke Tree............................................................................................ 38

Fig. 39 High Frequency ISAR Image of Royal Purple Smoke Tree H-H Polarization................. 39

Fig. 40 High Frequency ISAR Image of Royal Purple Smoke Tree V-V Polarization................. 39

Fig. 41 Low Frequency ISAR Image of Royal Purple Smoke Tree H-H Polarization ................. 40

Fig. 42 Low Frequency ISAR Image of Royal Purple Smoke Tree V-V Polarization ................. 40

Fig. 43 Royal Purple Smoke Tree, Leaves Removed ................................................................ 41

Fig. 44 High Frequency ISAR Image of Royal Purple Smoke Tree No Leaves H-H

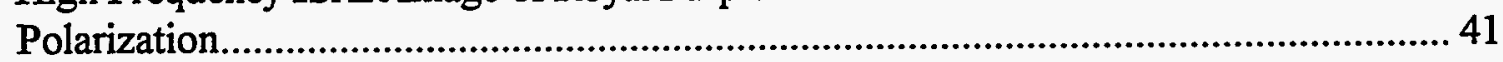

Fig. 45 High Frequency ISAR Image of Royal Purple Smoke Tree No Leaves V-V Polarization...

Fig. 46 Low Frequency ISAR Image of Royal Purple Smoke Tree No Leaves H-H

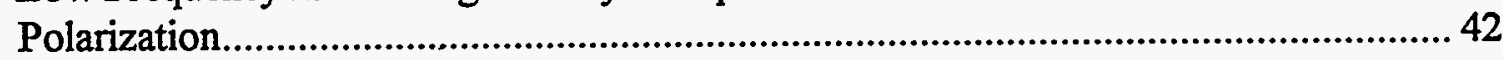

Fig. 47 Low Frequency ISAR Image of Royal Purple Smoke Tree No Leaves V-V Polarization............................................................................................................. 43

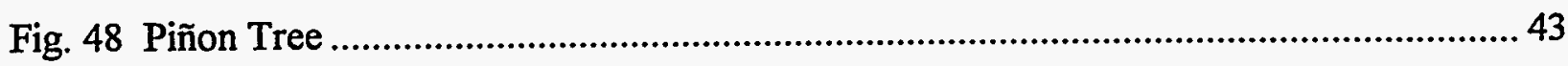

Fig. 49 High Frequency ISAR Image of Piñon Tree H-H Polarization ..................................... 44

Fig. 50 High Frequency ISAR Image of Piñon Tree V-V Polarization ..................................... 44

Fig. 51 Low Frequency ISAR Image of Piñon Tree H-H Polarization....................................... 45

Fig. 52 Low Frequency ISAR Image of Piñon Tree V-V Polarization....................................... 45

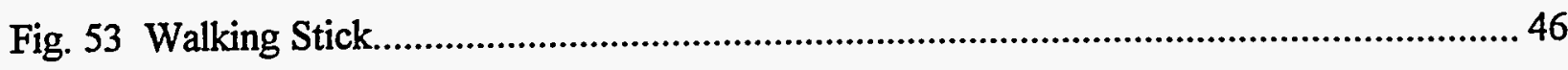

Fig. 54 High Frequency ISAR Image of Walking Stick, Vertical Position, H-H

Polarization. 46 
Fig. 55 High Frequency ISAR Image of Walking Stick, Vertical Position, V-V Polarization.

Fig. 56 Low Frequency ISAR Image of Walking Stick, Vertical Position, H-H

Polarization

Fig. 57 Low Frequency ISAR Image of Walking Stick, Vertical Position, V-V

Polarization

Fig. 58 High Frequency ISAR Image of Walking Stick, Tilted 6.8 Degrees, H-H

Polarization

Fig. 59 High Frequency ISAR Image of Walking Stick, Tilted 6.8 Degrees, V-V

Polarization

Fig. 60 Low Frequency ISAR Image of Walking Stick, Tilted 6.8 Degrees, H-H

Polarization

Fig. 61 Low Frequency ISAR Image of Walking Stick, Tilted 6.8 Degrees, V-V

Polarization 


\section{Introduction}

Sandia Laboratories operates a low-frequency synthetic-aperture radar (LFSAR), which is a linear-FM, synthetic-aperture radar capable of operation from 125 to $950 \mathrm{MHz}$ [1]. Recent data collections with the Sandia LFSAR have yielded surprising results; some trees appear brighter in the images than expected! In particular, data collected at a center frequency of $380 \mathrm{MHz}$ show bright trees, with the horizontal-transmit / horizontal-receive $(\mathrm{H}-\mathrm{H})$ response being brighter than the vertical-transmit / vertical-receive (V-V) response. In an effort to understand this phenomenon, various small trees have been measured on the Sandia folded compact range with the inverse-synthetic-aperture radar (ISAR) imaging system.

The ISAR imaging technique gets its name from the fact that the target is moved while the radar is held motionless, the opposite configuration from conventional synthetic-aperture radar (SAR). Although it is called inverse-synthetic-aperture imaging, the process is essentially identical to the conventional spotlight SAR mode, where the radar moves in an arc at a constant distance from the scene center. The principles are the same in all of the SAR imaging modes; phase change (or Doppler frequency shift) is used to obtain high resolution by sharpening the antenna pattern in the cross-range dimension, while high-bandwidth pulse compression is used to obtain high resolution in the range dimension. This process allows a two-dimensional mapping (image) of the radar scatterers to be formed.

Utilizing the ISAR system allows a somewhat more controlled environment than that available when imaging with the LFSAR on the Sandia Twin Otter aircraft. A major advantage is the ability to image a single, isolated target in a relatively benign clutter environment. However, since the Sandia indoor folded compact range is limited in the size of the objects which can be measured, and since the radar is limited to frequencies above $2 \mathrm{GHz}$, scaled measurements at higher frequencies are used to model the response from the UHF radar.

\section{Scaled Targets}

The targets of interest, trees, are not perfect conductors. In fact, they are composed of lossy dielectric materials which are frequency dependent, so their scattering properties will be different at different frequencies. However, it is not practical to fashion scale models of trees from materials whose dielectric properties are also scaled to appropriate values at the higher frequencies. Our approach, instead, is to use small, live trees and bushes to represent scale models of the full-sized trees. Although the dielectric properties are not scaled, we believe this approach will achieve useful results. The following small trees and bushes have been chosen to represent certain types of larger trees at the scaled frequencies:

1) Black Hills spruce tree ( $48^{\prime \prime}$ height), which represents a ponderosa pine,

2) wax leaf privet $\left(28.5^{\prime \prime}\right.$ height), which represents a cottonwood,

3) royal purple smoke tree ( $32^{n}$ height), which represents a cottonwood,

4) juniper tree ( $37^{n}$ height), which represents a large juniper tree,

5) piñon tree ( $37^{n}$ height), which represents a large piñon tree,

and

6) wooden walking stick ( $32^{n}$ height), which represents a telephone pole. 
When the measurements at center frequencies of $5 \mathrm{GHz}$ and $12 \mathrm{GHz}$ are scaled to center frequencies of $380 \mathrm{MHz}$ and $750 \mathrm{MHz}$, the scaled heights of the targets range from about 16 feet to over 100 feet, as indicated in Fig. 1. Unfortunately, the dimensions of the leaves, needles, and branches also scale accordingly. Since the scaled trees and bushes have unrealistic leaf and needle cross sections, the signal penetration into the foliage will not scale properly. The result is more attenuation of the penetrating signal than would occur in properly scaled trees. Thus, effects which depend on penetration of the signal into the tree will be somewhat attenuated in these tests.

The low-frequency $(5 \mathrm{GHz})$ measurement has a bandwidth of $6 \mathrm{GHz}$, and the high-frequency (12 $\mathrm{GHz}$ ) measurement has a bandwidth of $12 \mathrm{GHz}$. These bandwidths correspond to the scaled bandwidths shown in Table 1 at the LFSAR frequencies of $380 \mathrm{MHz}$ and $750 \mathrm{MHz}$.

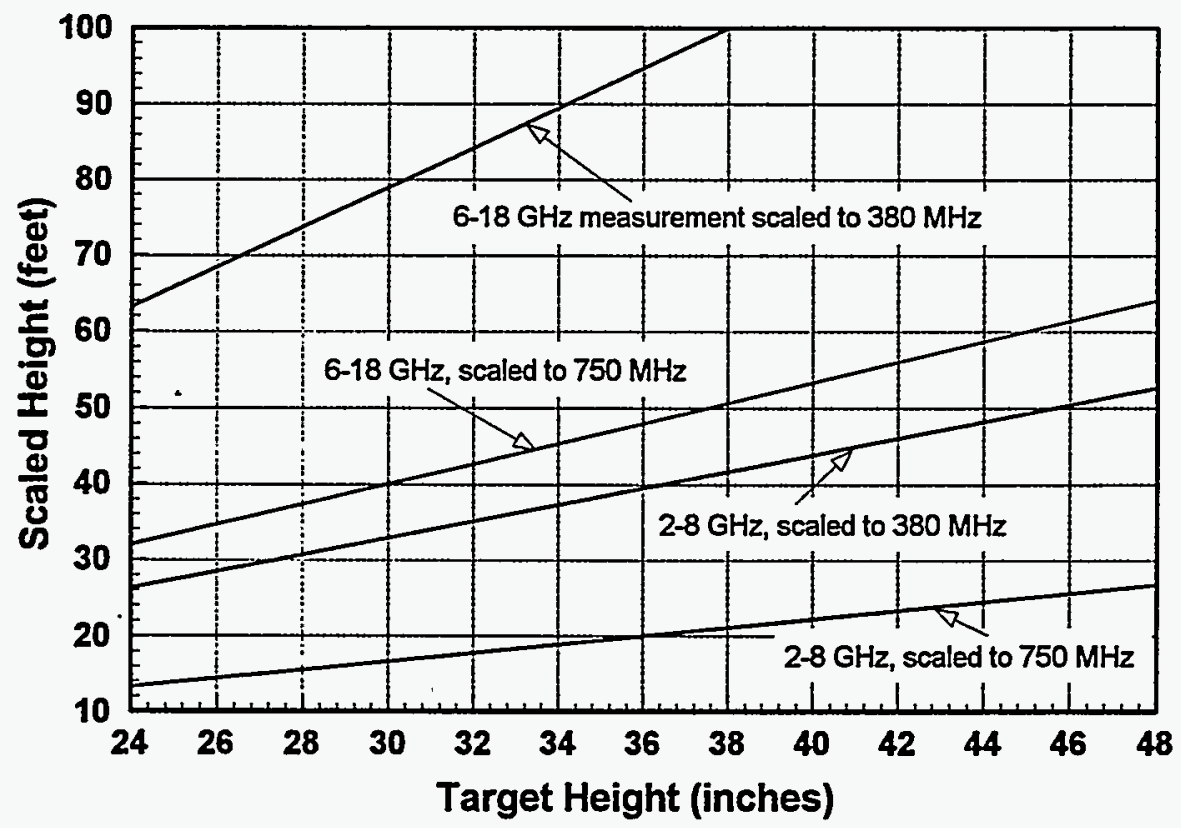

Fig. 1 Scaled height (feet) as a function of target height (inches) for the low- and highfrequency measurements when scaled to center frequencies of $380 \mathrm{MHz}$ and $750 \mathrm{MHz}$

\begin{tabular}{|c|c|c|}
\hline \multicolumn{3}{|c|}{ Table 1 Equivalent LFSAR Bandwidths } \\
\hline & \multicolumn{2}{|c|}{ LFSAR Center Frequency } \\
\hline Measurement Range & $380 \mathrm{MHz}$ & $750 \mathrm{MHz}$ \\
\hline Low-Frequency & $152-608 \mathrm{MHz}$ & $300-1,200 \mathrm{MHz}$ \\
\hline High-Frequency & $190-570 \mathrm{MHz}$ & $375-1,125 \mathrm{MHz}$ \\
\hline
\end{tabular}

\section{Range configuration}

The range configuration for this test is shown in Fig. 2. The range is a standard compact range, but reconfigured into a folded compact range by the addition of a secondary reflector. This configuration was developed at Sandia by the Radar/Antenna Department to be used for performing indoor, environmentally-controlled, far-field simulations of synthetic-aperture radar (SAR) coherent change-detection (CCD) measurements. A complete description of this range configuration and field-probe measurements on the folded range can be found in [2]. 


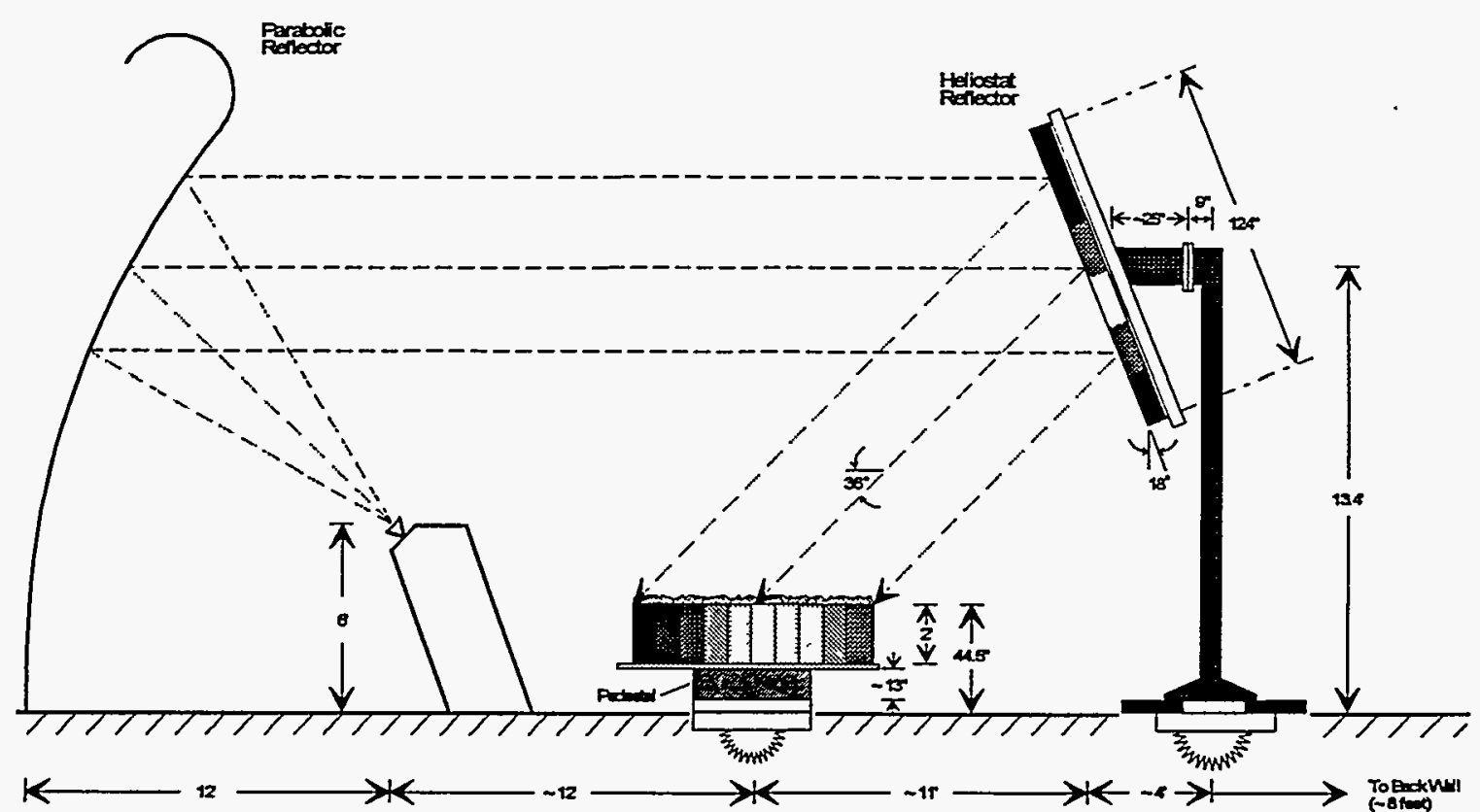

Fig. 2 Folded Compact Range

The trees and bushes used in these measurements were obtained from a local nursery, and were left in their containers in order to maintain the root system to keep the plants alive. To simulate the ground-trunk interface of trees actually growing in the ground, a metallized ground plane was fabricated to cover the sample holder and container on the turntable (Fig. 5). This ground plane extends 8 feet toward the radar in the down-range direction and 8 feet either side of the center of the sample holder in the cross-range direction. All foliage samples were placed behind the ground plane with their containers below the ground-plane surface. The area of the sample holder not covered by the ground plane was covered with microwave absorbing material.

\section{Radar Calibration}

Two separate calibrations were used in this set of measurements: a low-frequency and a highfrequency calibration. The calibration parameters are listed in Table 2 . The radar is calibrated by placing a trihedral of known radar cross section on the ground-plane along the centerline at the point defined to be the zero relative-range reference, and performing a reference-target measurement. The zero relative-range reference is approximately the point where the trunk intersects the ground-plane (Fig. 6). The calibration was checked by placing a 6 inch sphere on top of a Styrofoam column placed on the ground plane (Fig. 7), and measuring the return of the sphere. The results of the high-frequency measurement of the sphere are shown in

Fig. 8 Sphere Down-range High-frequency Response H-H Polarization,

Fig. 9 ISAR Image of Sphere High-frequency Response H-H Polarization,

Fig. 10 Sphere Down-range High-frequency Response V-V Polarization,

Fig. 11 ISAR Image of Sphere High-frequency Response V-V Polarization, and the data for the low-frequency measurement of the sphere are plotted in

Fig. 12 Sphere Down Range Low-frequency Response H-H Polarization,

Fig. 13 Sphere Down Range Low-frequency Response V-V Polarization. 
The radar cross section of the 6 inch sphere should be $-17.4 \mathrm{dBsm}$. Examination of the highfrequency range response in Fig. 8 and Fig. 10 shows the direct sphere response (at -1 ns) about $3 \mathrm{~dB}$ low. In the low-frequency calibration, the sphere was placed closer to the radar, relative to the zero-range reference point, and the direct response occurs at $-2.1 \mathrm{~ns}$. In this data, plotted in Fig. 12 and Fig. 13, the measured value of the sphere is higher and more nearly matches the theoretical value.

\begin{tabular}{|c|c|c|}
\hline \multicolumn{3}{|c|}{ Table 2 Radar Test Parameters } \\
\hline Test Frequency Range & Low Frequency & High Frequency \\
\hline Number of steps: & 251 & 251 \\
\hline Start: & $2.000 \mathrm{GHz}$ & $6.000 \mathrm{GHz}$ \\
\hline Stop: & $8.000 \mathrm{GHz}$ & $18.000 \mathrm{GHz}$ \\
\hline Increment: & $24 \mathrm{MHz}$ & $48 \mathrm{MHz}$ \\
\hline Alias-free range: & $41.67 \mathrm{~ns}$ & $20.83 \mathrm{~ns}$ \\
\hline Primary Axis: & Theta & Theta \\
\hline Direction: & Clockwise & Clockwise \\
\hline Motion: & Step & Step \\
\hline Start: & $-37.00^{\circ}$ & $-31.00^{\circ}$ \\
\hline Stop: & $37.00^{\circ}$ & $31.00^{\circ}$ \\
\hline Increment: & $0.15^{\circ}$ & 0.150 \\
\hline \multicolumn{3}{|l|}{ Calibration Status: } \\
\hline $\mathrm{H}-\mathrm{H}:$ & Fully Calibrated & Fully Calibrated \\
\hline $\mathrm{V}-\mathrm{V}:$ & Fully Calibrated & Fully Calibrated \\
\hline \multicolumn{3}{|l|}{ Reference Position: } \\
\hline Theta: & $0.00^{\circ}$ & $0.00^{\circ}$ \\
\hline Calibration Target: & Square Trihedral & Square Trihedral \\
\hline Length: & 4.53 inches & 4.53 inches \\
\hline
\end{tabular}

Absolute radar cross section is not important here, but proper interpretation of these sphere results is necessary in order to properly understand the set of tree measurements. The rangeresponse data shown in Fig. 8, Fig. 10, Fig. 12, and Fig. 13 show three strong responses. The first response, at about $-1 \mathrm{~ns}$ in the high-frequency data and $-2.1 \mathrm{~ns}$ in the low-frequency data, is the direct return from the sphere. The two strong, later responses are a result of the interaction of the sphere with the ground plane. The fact that the second response (at about $0.6 \mathrm{~ns}$ and $-0.4 \mathrm{~ns}$ ) is about $6 \mathrm{~dB}$ larger than the direct response of the sphere is somewhat surprising, but it is due to an interaction of the sphere with the ground plane, and is easily explained. The presence of the third response at about $1.8 \mathrm{~ns}$ and $1.1 \mathrm{~ns}$ is due to a different interaction of the sphere with the ground plane.

Consider the simple ray diagram in Fig. 3, which shows the four possible ray paths for plane-wave scattering from a sphere over a conducting ground plane. The ray designated (A) is the direct return from the sphere that would be present if the sphere were in free space. The rays $(B),\left(C_{1}\right.$, and (D) are bistatic returns. Ray (B) represents the scattering from the sphere due to the illumination first hitting the ground plane and then reflecting to the sphere, before scattering back to the radar. Ray (C) represents a similar path, but the illumination first hits the sphere and then reflects back to the radar from the ground plane. Because of the similarity to the paths of rays scattered from a corner reflector, scattering due to ray paths similar to (B) and (C) will be referred to as the corner- 
corner reflector, scattering due to ray paths similar to (B) and (C) will be referred to as the cornerreflector mode. Ray (D) is a bistatic return where scattering from the sphere illuminates the ground plane directly beneath the sphere where it is reflected back to the sphere, and, through the bistatic scattering from the sphere, is returned to the radar. Scattering where the ray paths are similar to ray (D) will be referred to as the bistatic mode, even though the corner-reflector mode is also a bistatic scattering process.

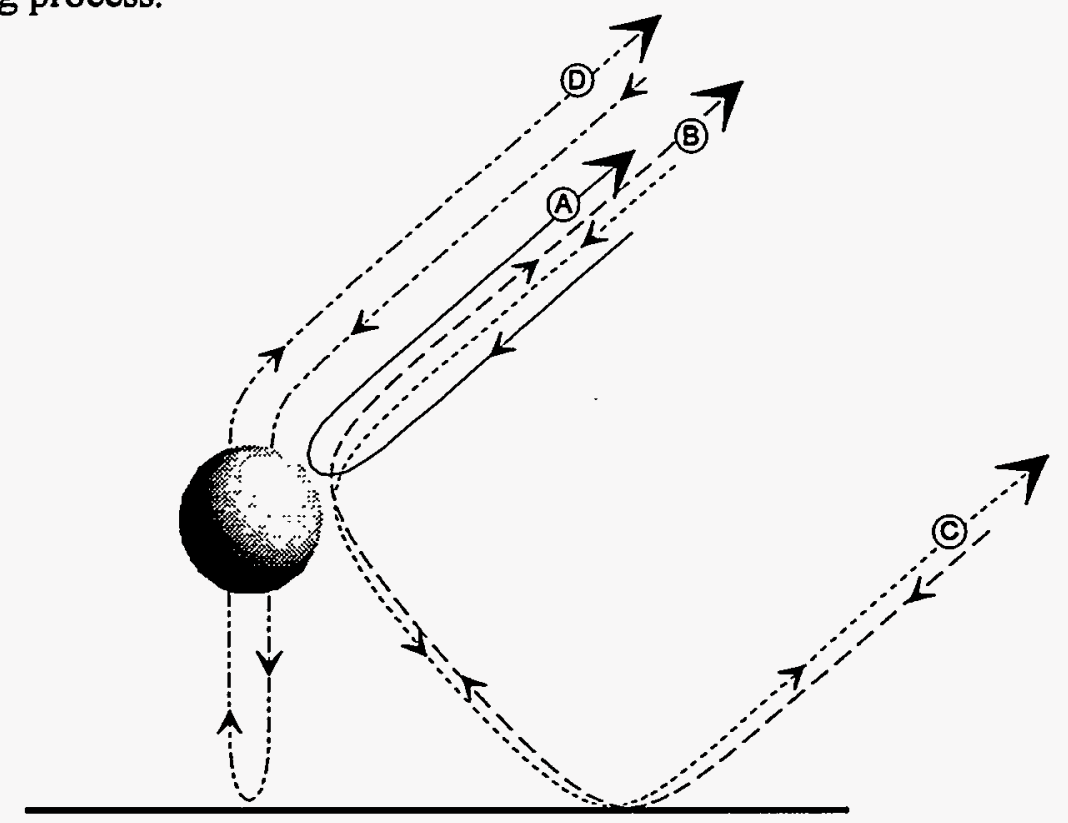

Fig. 3 Diagram showing the four ray paths associated with scattering from a sphere over a conducting plane.

The center of the sphere is about 16 inches above the ground plane, and the plane wave is incident at an angle of about $\theta=32^{\circ}$ from the horizontal. Since the sphere is higher than the range zeroreference position, the direct return from the sphere should occur about $0.7 \mathrm{~ns}$ earlier than an object on the zero-reference position. This is the first peak in the response data shown in Fig. 8 and Fig. 10. Rays (B) and (C) follow paths of identical lengths, and thus they add in-phase. Since the bistatic cross section of a sphere is very nearly the same as the monostatic cross section, the combining of these two rays results in a return about $6 \mathrm{~dB}$ larger than the return from the sphere in free space. These two rays follow a longer path than the direct ray $\oplus^{\oplus}$, illustrated in detail in Fig. 4. As can be seen, the additional path length for rays (B) and $(\subset)$ is $\delta=\delta_{1}-\delta_{2}$, where

and

$$
\delta_{1}=\frac{h}{\sin \theta}
$$

$$
\delta_{2}=\delta_{1} \cos (2 \theta) \text {. }
$$

In this case, the return should occur about $1.4 \mathrm{~ns}$ after the direct return. This corresponds to the second peak, which, as expected, is about $6 \mathrm{~dB}$ larger than the first peak. Ray (D) follows a path $2 h$ longer than the direct path and should be delayed by about $2.7 \mathrm{~ns}$ from the direct path. This corresponds to the third peak. Thus, the measured range response of the sphere over a 
conducting plane illustrated in Fig. 8 and Fig. 10 agree with the three returns that are expected from the analysis of a ray-trace model.

If the range delay is measured relative to the zero-range reference, the time delays associated with the direct, corner-reflector, and bistatic modes are

$$
\begin{gathered}
\tau_{\text {direa }}=-2 \frac{h}{c} \sin \theta, \\
\tau_{\text {comer-reflector }}=\frac{h}{c} \frac{\left(1-\cos (2 \theta)-2 \sin ^{2} \theta\right)}{\sin \theta}=0,
\end{gathered}
$$

and

$$
\tau_{\text {bistatic }}=2 \frac{h}{c}(1-\sin \theta),
$$

where $c$ is the speed of light. Note that the response from the corner-reflector mode occurs at precisely the same time as the response from a point scatterer located at the zero-range reference.

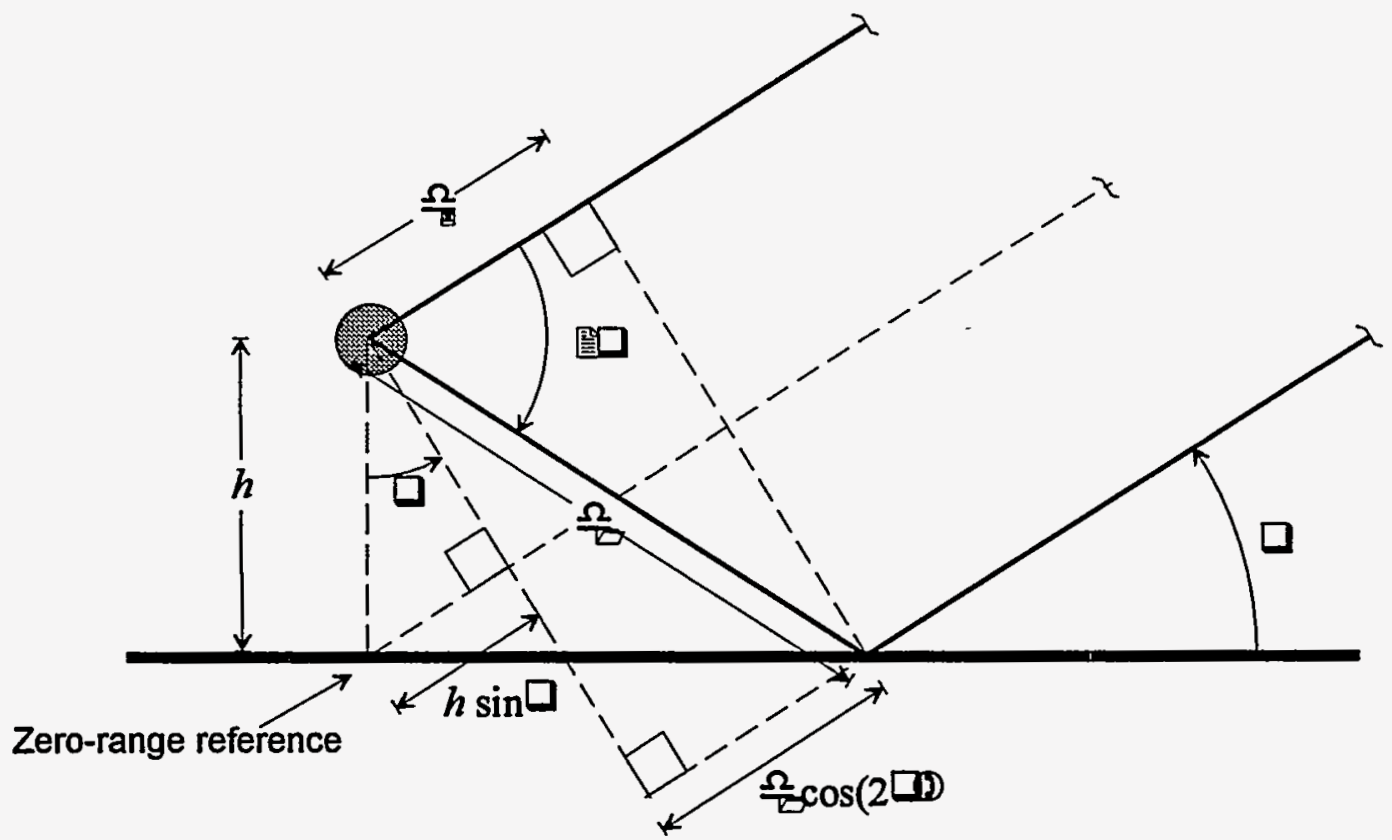

Fig. 4 Geometry indicating the increase in path length for the forward bistatic rays (cornerreflector mode) when compared to the direct ray path.

Another point to note is the presence of a cross-range response at the zero down-range position in all V-V polarization ISAR plots. This is particularly noticeable in the low-frequency measurements, for example the empty ground-plane measurement in Fig. 17, but it is also clearly present in the high-frequency V-V ISAR image of the sphere, Fig. 14. This response is due to diffraction from the back edge of the ground plane. Due to the presence of this diffraction return, the down-range plots of the sphere returns were obtained using target-background subtraction (actually a change-detection measurement). This effectively eliminates the diffraction return in the range plots for the sphere. However, all ISAR image plots are from measurements without target-background subtraction. 
Note that the range response in the ISAR images, Fig. 9 and Fig. 11, is measured in distance (feet). The ISAR software maps delay into two-way path length. However, the one-dimensional range plots (Fig. 8 and Fig. 10) plot the response against the actual delay time. Because of this difference, care must be exercised when comparing the range plots with the corresponding ISAR images. The distance, $r_{I S A R}$, and time delay, $\tau_{\text {delay }}$, in the two plots are related by

$$
r_{I S A R}=\frac{c \tau_{\text {delay }}}{2} \text {. }
$$

It is interesting to see that the direct return from the sphere (about - 6 inch down-range) appears to be smeared into an arc. This is explained by the fact that the sphere is located very near to the axis of rotation of the turntable. Because of the symmetry of the sphere, the point at which the direct scattering appears to come from remains near the same place in space as the table is turned. Therefore, its scattered phase will remain essentially constant as the table is turned. The imaging algorithm will map such an object into an arc. Indeed, the two-dimensional image of a sphere, or a cylinder rotated about its axis, will be a circle. In Fig. 9 and Fig. 11, the radius of the arc is larger than that of the sphere. This is caused by the height of the sphere above the zero-range reference point. The sphere actually appears closer to the radar than if it were at the zero-range reference point. However, since the rotation is about the axis of the sphere, its phase does not change as the table turns. Neglecting amplitude differences, to the ISAR algorithm, the small sphere at some height above the ground plane appears as a larger sphere located at the zero-range reference, thereby mapping to a larger radius arc.

\section{Measurement Descriptions}

The ray-trace model described for the sphere indicates that multiple returns can occur from even a simple target when imaged over a ground plane. The tree and bush measurements can exhibit the same multiple-return phenomena as the sphere. However, because the bandwidths used in these measurements are sufficient to resolve small details, many returns will already be present in the image due to scattering from individual leaves, branches, and trunks. Nevertheless, because of the range delay associated with the interaction with the ground plane, the direct, corner-reflectormode, and bistatic-mode scattering will be apparent in the data. The locations of the direct, corner-reflector-mode, and bistatic-mode scattering from a point target have been computed from the heights of the targets, and are listed in Table 3. These locations assume that the target is located at the zero-range reference position.

Table 3 Location of Scattering Returns Relative to Zero-Range Reference for a Point Target

\begin{tabular}{|c|c|c|c|}
\hline Tree/Bush & $\begin{array}{c}\text { Direct Scatter } \\
\text { (ft) }\end{array}$ & $\begin{array}{c}\text { Corner-Reflector Mode } \\
\text { (ft) }\end{array}$ & $\begin{array}{c}\text { Bistatic } \\
\text { Mode } \\
\text { (ft) }\end{array}$ \\
\hline sphere & -0.7 & 0 & 0.6 \\
\hline Black Hills spruce & -2.1 & 0 & 1.9 \\
\hline wax leaf privet & -1.3 & 0 & 1.1 \\
\hline royal purple smoke tree & -1.4 & 0 & 1.3 \\
\hline juniper & -1.6 & 0 & 1.4 \\
\hline piñon & -1.6 & 0 & 1.4 \\
\hline walking stick & -1.4 & 0 & 1.3 \\
\hline
\end{tabular}




\section{Empty Ground plane}

The empty ground plane, shown in Fig. 5, was measured for both the high- and low-frequency conditions. Images from these measurements are shown in

Fig. 14 High Frequency ISAR Image of Ground Plane H-H Polarization,

Fig. 15 High Frequency ISAR Image of Ground Plane V-V Polarization,

Fig. 16 Low Frequency ISAR Image of Ground Plane H-H Polarization,

and

Fig. 17 Low Frequency ISAR Image of Ground Plane V-V Polarization.

The empty ground plane exhibits its least clutter in the high-frequency data. This supports the view that most of the return is due to diffraction from discontinuities, since diffraction is more significant at the lower frequencies. In the low-frequency images, the back edge of the circular turntable is visible, although microwave absorber is used to reduce this return. In the V-V polarized low-frequency image, Fig. 17, the front surface of the turntable is beginning to be visible, and the diffraction from the edge of the ground plane at the center of the image is quite noticeable. However, none of this ground-plane clutter is sufficient to interfere with the evaluation of the measurements of the trees.

\section{Black Hills Spruce Tree}

The Black Hills spruce tree, Fig. 18, stands 48 inches above the ground plane. A significant portion of this height is bare trunk. Images from the measurement are shown in

Fig. 19 High Frequency ISAR Image of Black Hills Spruce Tree H-H Polarization, Fig. 20 High Frequency ISAR Image of Black Hills Spruce Tree V-V Polarization, Fig. 21 Low Frequency ISAR Image of Black Hills Spruce Tree H-H Polarization, and

Fig. 22 Low Frequency ISAR Image of Black Hills Spruce Tree V-V Polarization.

There appear to be three well-defined regions in the image, very similar to the three peak responses from the sphere. The direct scattering is the weakest, with the corner-reflector mode dominating the image. The bistatic mode is also significant. The direct scattering return extends to about -2.1 feet in the high-frequency images, implying that we are seeing the top of the tree. However, the extent is not as great in the low-frequency images, indicating that more penetration of the tree occurs. Since the brightest return appears to come from near the nominal cornerreflector-mode scattering location, the implication is that not only is the corner-reflector-mode scattering dominant, but that this scattering is coming from near the center of the tree, and is probably due to the interaction between the trunk and the ground plane. This appears to be the case in both the high- and low-frequency images.

The high-frequency $\mathrm{H}-\mathrm{H}$ response peaks at about $5 \mathrm{~dB}$ larger than the $\mathrm{V}-\mathrm{V}$ response. However, the low-frequency responses appear to be much more closely matched in amplitude, with the H-H response only slightly larger. The peak response appears near the location of the trunk of the plant, and is due to the corner-reflector mode. 


\section{Wax Leaf Privet}

This tree stands 28.5 inches above the ground plane. Measurements were taken with the tree in full foliage (Fig. 23) and with leaves removed (Fig. 28). Images obtained with full foliage are shown in

Fig. 24 High Frequency ISAR Image of Wax Leaf Privet H-H Polarization,

Fig. 25 High Frequency ISAR Image of Wax Leaf Privet V-V Polarization, and,

Fig. 26 Low Frequency ISAR Image of Wax Leaf Privet H-H Polarization,

Fig. 27 Low Frequency ISAR Image of Wax Leaf Privet V-V Polarization. The images from the tree with the leaves removed (Fig. 28) are

Fig. 29 High Frequency ISAR Image of Wax Leaf Privet Leaves Removed $\mathrm{H}-\mathrm{H}$ Polarization,

Fig. 30 High Frequency ISAR Image of Wax Leaf Privet Leaves Removed V-V Polarization,

Fig. 31 Low Frequency ISAR Image of Wax Leaf Privet Leaves Removed H-H Polarization,

and

Fig. 32 Low Frequency ISAR Image of Wax Leaf Privet Leaves Removed V-V Polarization.

The fully foliated privet exhibits a clear direct response, which is diffuse, and a corner-reflectormode response, which is more compact and is stronger. The bistatic-mode response is also present, and there is a hint of the back edge of the turntable near +2 feet. This return from the turntable edge is stronger in the low-frequency images. It is interesting to note that the strongest return (located near the nominal location for the corner-reflector mode) changes position with both center frequency and polarization.

When the leaves are removed, the direct response is reduced, and the scattering appears to come from a location deeper in the bush. The $\mathrm{H}-\mathrm{H}$ polarization seems to show less of the direct response than does the $\mathrm{V}-\mathrm{V}$ polarization. In all cases, the bistatic response is present, and the peak response is near the nominal corner-reflector-mode position. It is interesting that the peak radar cross section changes little between the foliated and defoliated bush for $\mathrm{H}-\mathrm{H}$ polarization. However, the cross section increased about $5 \mathrm{~dB}$ for the defoliated bush over the foliated bush with V-V polarization. Even though the foliated bush is slightly brighter in the high-frequency image set with $\mathrm{H}-\mathrm{H}$ polarization than with $\mathrm{V}-\mathrm{V}$ polarization, $\mathrm{V}-\mathrm{V}$ dominates the low-frequency image set for the foliated bush and both the high- and low-frequency image sets for the defoliated bush.

\section{Juniper Tree}

The juniper, shown in Fig. 33, stands 37 inches above the ground plane. Measurement results are shown in

Fig. 34 High Frequency ISAR Image of Juniper Tree H-H Polarization,

Fig. 35 High Frequency ISAR Image of Juniper Tree V-V Polarization, Fig. 36 Low Frequency ISAR Image of Juniper Tree H-H Polarization,

and 
Fig. 37 Low Frequency ISAR Image of Juniper Tree V-V Polarization.

In these images, the direct, corner-reflector-mode, and bistatic-mode returns are all present but the corner-reflector-mode scattering is clearly dominant. However, in this case, there does not appear to be a single trunk causing the scattering. It appears more like an uneven wall is present, consistent with the photographic image (Fig. 33) which shows a wall of many small trunks. In both the low- and high-frequency images, the $\mathrm{H}-\mathrm{H}$ polarization is the brightest. The lowfrequency $\mathrm{H}-\mathrm{H}$ image exhibits smaller regions of direct and bistatic-mode scattering, implying more penetration of the signal into the tree. This effect, though present in the low-frequency V-V image, is most obvious with the $\mathrm{H}-\mathrm{H}$ image. The implication is that the horizontal polarization penetrates the juniper much better than vertical polarization.

\section{Royal Purple Smoke Tree}

This tree stands 32 inches above the ground plane. Measurements were performed both with the plant in full foliage, shown in Fig. 38, and with the defoliated plant, shown in Fig. 43. Images obtained with full foliage are shown in

Fig. 39 High Frequency ISAR Image of Royal Purple Smoke Tree H-H Polarization,

Fig. 40 High Frequency ISAR Image of Royal Purple Smoke Tree V-V Polarization,

Fig. 41 Low Frequency ISAR Image of Royal Purple Smoke Tree H-H Polarization, and

Fig. 42 Low Frequency ISAR Image of Royal Purple Smoke Tree V-V Polarization. Images obtained with leaves removed are shown in

Fig. 44 High Frequency ISAR Image of Royal Purple Smoke Tree No Leaves H-H Polarization,

Fig. 45 High Frequency ISAR Image of Royal Purple Smoke Tree No Leaves V-V Polarization,

Fig. 46 Low Frequency ISAR Image of Royal Purple Smoke Tree No Leaves H-H Polarization,

and

Fig. 47 Low Frequency ISAR Image of Royal Purple Smoke Tree No Leaves V-V Polarization.

The foliated tree does not exhibit as clearly defined corner-reflector-mode scattering as the other trees, or as the defoliated tree. Scattering from the direct and bistatic-mode regions is clearly present, and the image is somewhat uniform. The high-frequency H-H image seems to be slightly brighter than the V-V image, but the V-V image is clearly brighter in the low-frequency data.

The defoliated tree exhibits clearly defined corner-reflector-mode scattering, unlike the foliated tree. This implies that there is less signal penetration into the foliated tree. Also, the images of the defoliated tree are consistently bright, and the direct bistatic-mode scattering has been reduced. There is little difference in the brightness of the $\mathrm{V}-\mathrm{V}$ and $\mathrm{H}-\mathrm{H}$ images for the highfrequency data, but the low-frequency V-V image is considerably brighter than the low-frequency $\mathrm{H}-\mathrm{H}$ image. The bright region of the $\mathrm{V}-\mathrm{V}$ image is fairly large, and appears to be a combination of corner-reflector-mode scattering and bistatic-mode scattering from about midway up into the tree. 


\section{Piñon Tree}

The piñon, shown in Fig. 48, stands 37 inches above the ground plane. Measurements results are shown in

Fig. 49 High Frequency ISAR Image of Piñon Tree H-H Polarization, Fig. 50 High Frequency ISAR Image of Piñon Tree V-V Polarization, and

Fig. 51 Low Frequency ISAR Image of Piñon Tree H-H Polarization,

Fig. 52 Low Frequency ISAR Image of Piñon Tree V-V Polarization.

The direct and bistatic-mode scattering is clearly present, but the corner-reflector-mode scattering is not as clear. The high-frequency V-V image has its brightest region in the bistatic-mode region, but the $\mathrm{H}-\mathrm{H}$ image has bright spots near where corner-reflector-mode scattering would appear if the scattering is due to those portions of the tree leaning to the left in Fig. 48. These regions do not seem to produce strong corner-reflector-mode scattering in the high-frequency V-V image. Over all, the $\mathrm{H}-\mathrm{H}$ high-frequency image is brighter than the V-V image.

The low-frequency $\mathrm{H}-\mathrm{H}$ and $\mathrm{V}-\mathrm{V}$ images are similar to each other in brightness, with somewhat distributed bright regions in both images. It appears that direct, corner-reflector-mode, and bistatic-mode scattering are all present, but the corner-reflector-mode scattering may be several parts of the tree at different down-range locations. There is no obvious return due to a trunk as exhibited with the Black Hills spruce tree.

\section{Walking Stick}

A bare walking stick, with a diameter of about $1 \frac{1}{8}$ inch and extending 32 inches above the ground plane (Fig. 53), was measured to simulate a telephone pole. The walking stick was measured in the vertical position and again tilted $6.8^{\circ}$ from the vertical. The measurement results with the walking stick in the vertical position are shown in

Fig. 54 High Frequency ISAR Image of Walking Stick, Vertical Position, H-H Polarization,

Fig. 55 High Frequency ISAR Image of Walking Stick, Vertical Position, V-V Polarization,

Fig. 56 Low Frequency ISAR Image of Walking Stick, Vertical Position, H-H Polarization,

and

Fig. 57 Low Frequency ISAR Image of Walking Stick, Vertical Position, V-V Polarization.

The measurement results with the walking stick tilted $68^{\circ}$ from the vertical position are shown in

Fig. 58 High Frequency ISAR Image of Walking Stick, Tilted 6.8 Degrees, $\mathrm{H}-\mathrm{H}$ Polarization,

Fig. 59 High Frequency ISAR Image of Walking Stick, Tilted 6.8 Degrees, V-V Polarization,

Fig. 60 Low Frequency ISAR Image of Walking Stick, Tilted 6.8 Degrees, H-H Polarization,

and 
Fig. 61 Low Frequency ISAR Image of Walking Stick, Tilted 6.8 Degrees, V-V Polarization.

As expected, the vertical walking-stick image shows a much more localized response. The response is clearly due to the corner-reflector-mode scattering. There is no significant differences between the $\mathrm{H}-\mathrm{H}$ and $\mathrm{V}-\mathrm{V}$ polarizations in either low- or high-frequency images. When the walking stick is tilted, the high-frequency $\mathrm{H}-\mathrm{H}$ and $\mathrm{V}-\mathrm{V}$ images are considerably dimmer, but are similar to each other. The low-frequency images are also dimmer for the tilted walking stick, but the reduction in brightness is not as great as in the high-frequency case. However, the lowfrequency $\mathrm{H}-\mathrm{H}$ image is clearly brighter than the V-V image. In all cases, the corner-reflectormode scattering appears to be the only significant contributor.

\section{Conclusion}

When imaged over ground, trees exhibit scattering from three well-defined modes:

1) direct scattering,

2) corner-reflector-mode scattering,

and

3) bistatic-mode scattering.

The direct scattering produces an early response and the bistatic-mode scattering produces a late response when compared to the time at which the corner-reflector-mode scattering appears. The corner-reflector-mode scattering essentially integrates scattering contributions from many points which lie in a vertical plane transverse to the SAR look direction. This has the potential to make the corner-reflector-mode very bright, and, in fact, this mode appears to be a dominant contributor in most of the tree images. However, in some images, the corner-reflector-mode scattering was not very obvious. It is important to note that the response from the cornerreflector mode occurs at precisely the same time as the response from a point scatterer located on the surface of the ground plane, directly under the vertically distributed scatters.

The direct scattering is generally always present, but is reduced in the low-frequency data, compared to the high-frequency data. The bistatic-mode scattering is also reduced in the lowfrequency data. These two modes also have reduced contributions in the defoliated-tree images when compared to the foliated-tree images. This implies that the leaves (at the measurement frequencies, at least) are responsible for producing significant direct and bistatic scattering, and that the leaves have greater effect at the higher frequencies, but have less effect at the low frequencies, as expected.

The corner-reflector-mode scattering is more apparent in the defoliated-tree images than in the fully-foliated-tree images. This supports the hypothesis that the brightness of the corner-reflectormode is due primarily to the vertical structures in the tree, and is thus enhanced when randomly oriented scatterers (such as leaves) are not present. Improved signal penetration into the tree seems to correlate with bright, well-defined corner-reflector-mode scattering regions.

The $\mathrm{H}-\mathrm{H}$ polarization seems to produce the brightest images of the coniferous evergreens in both the high- and low-frequency data. However, while the H-H image is still the brightest in the high- 
frequency data, the $\mathrm{V}-\mathrm{V}$ image dominates the low-frequency data from the fully-foliated deciduous plants. Also, V-V images are brighter in both the high- and low-frequency data for the defoliated plants.

Based on this study, it seems that trees appear bright in the LFSAR images because the improved foliage penetrating capability of UHF causes the corner-reflector-mode scattering to be enhanced. Also, there is evidence that $\mathrm{H}-\mathrm{H}$ polarization will produce brighter images of coniferous trees than will $\mathrm{V}-\mathrm{V}$ polarization. However, it appears that $\mathrm{V}-\mathrm{V}$ polarization will produce brighter images of deciduous plants similar to those tested here. This is likely due to the different structure of the plants; the coniferous trees tend to have many near-horizontal branches stacked vertically along the trunk, while the deciduous plants used in the study have a large number of near-vertical trunklike branches and fewer horizontal structures. 


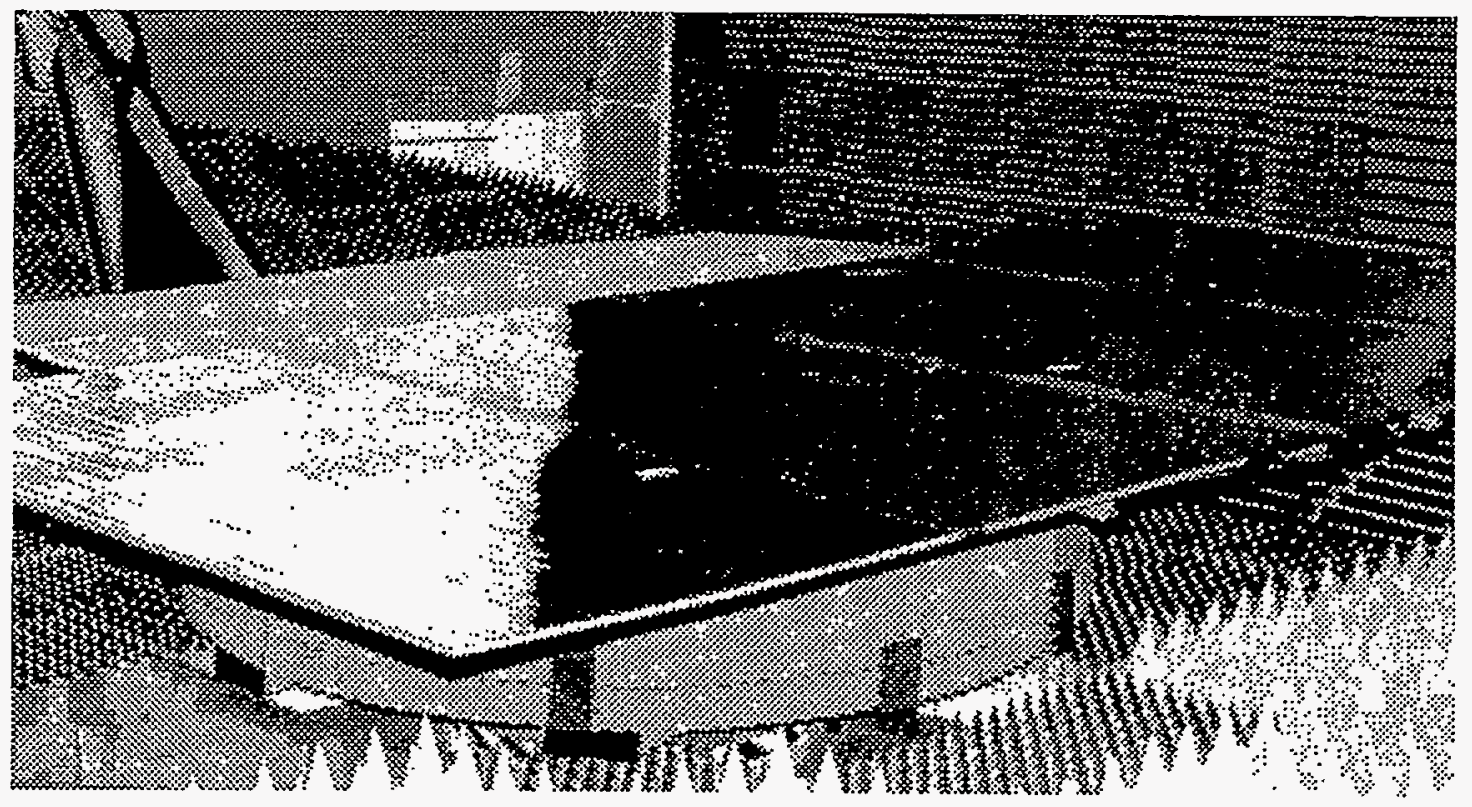

Fig. 5 Ground Plane Cover on Sample Holder

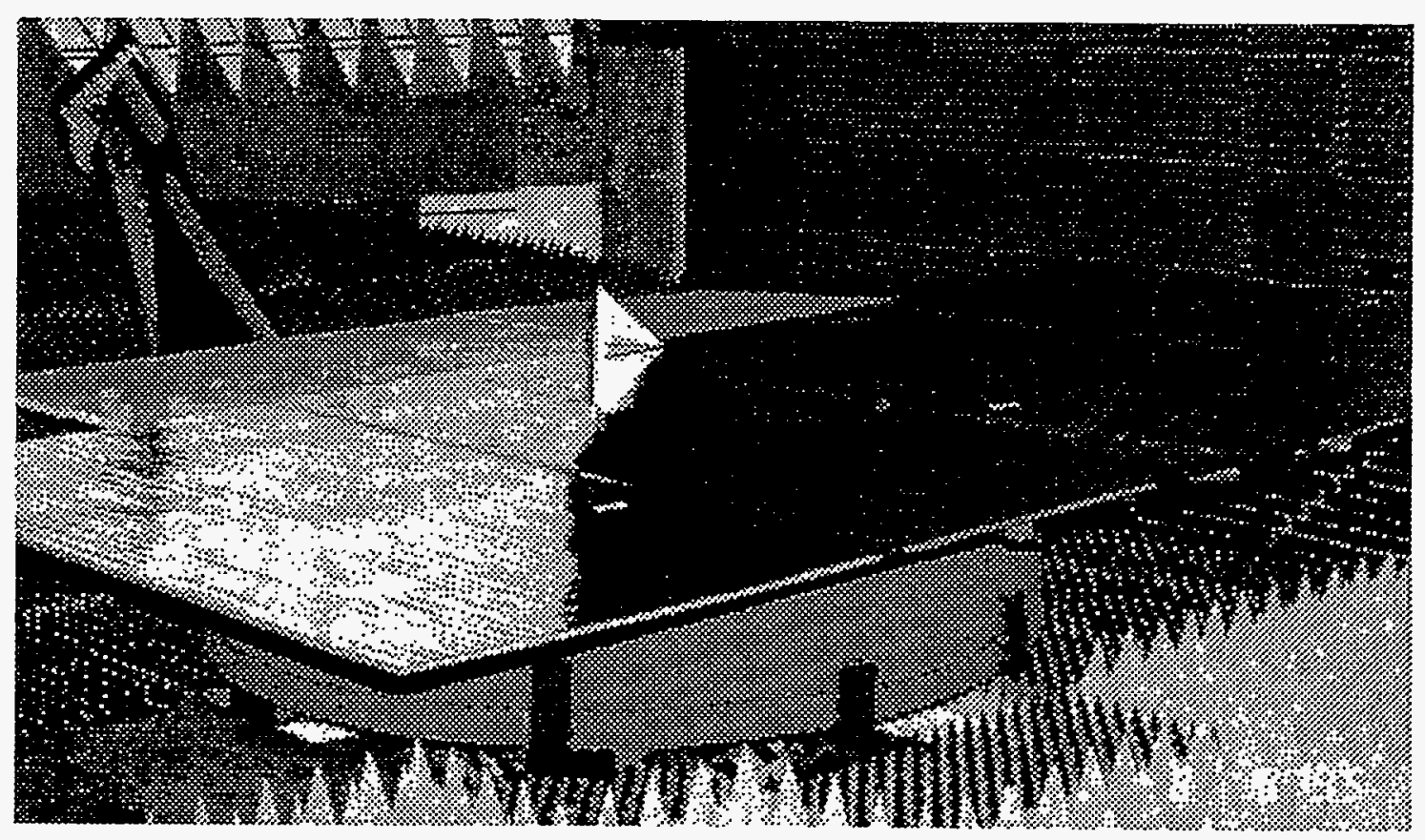

Fig. 6 Calibration Trihedral on Ground plane 


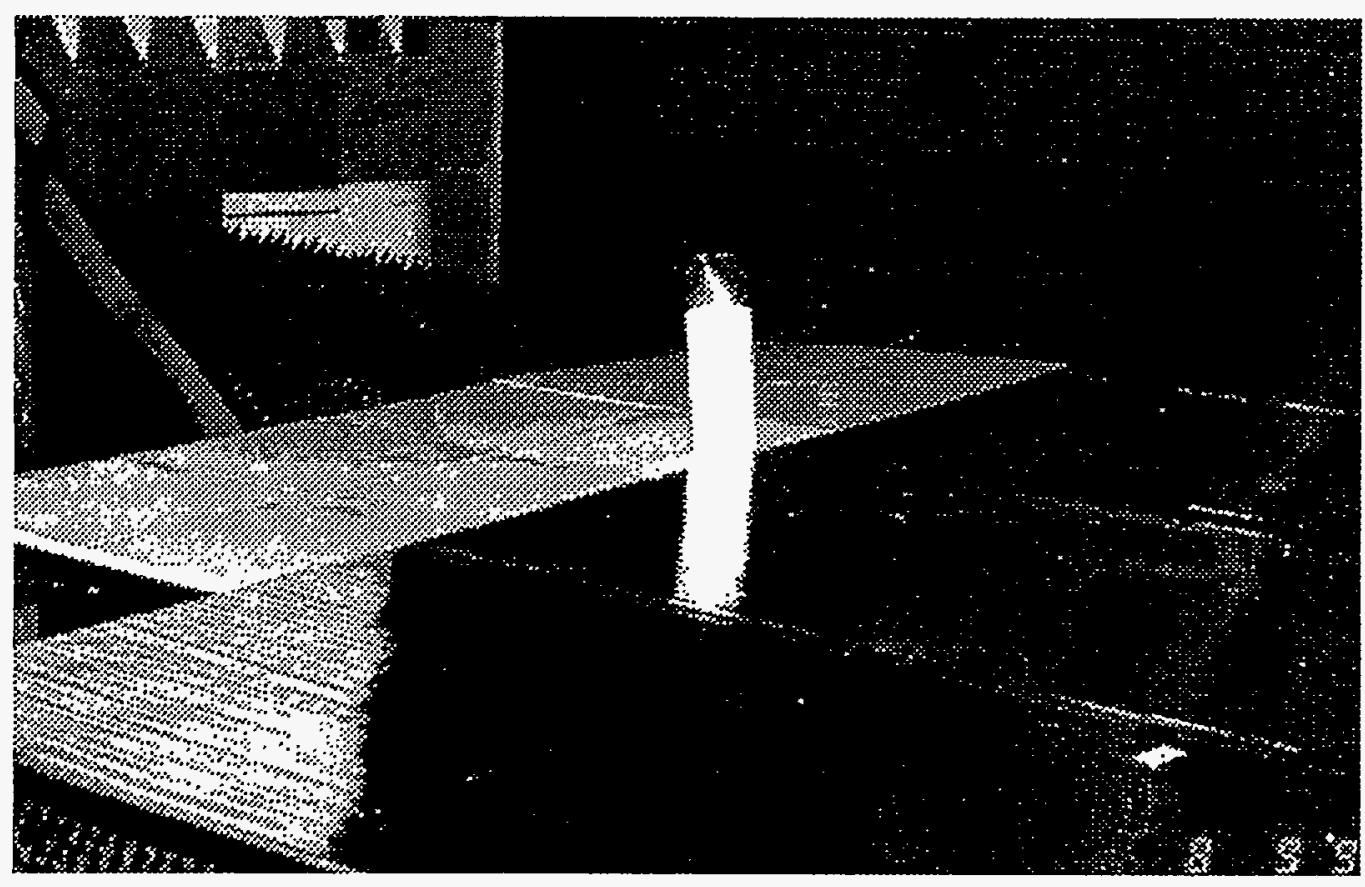

Fig. 7 Sphere Configuration for Calibration Verification

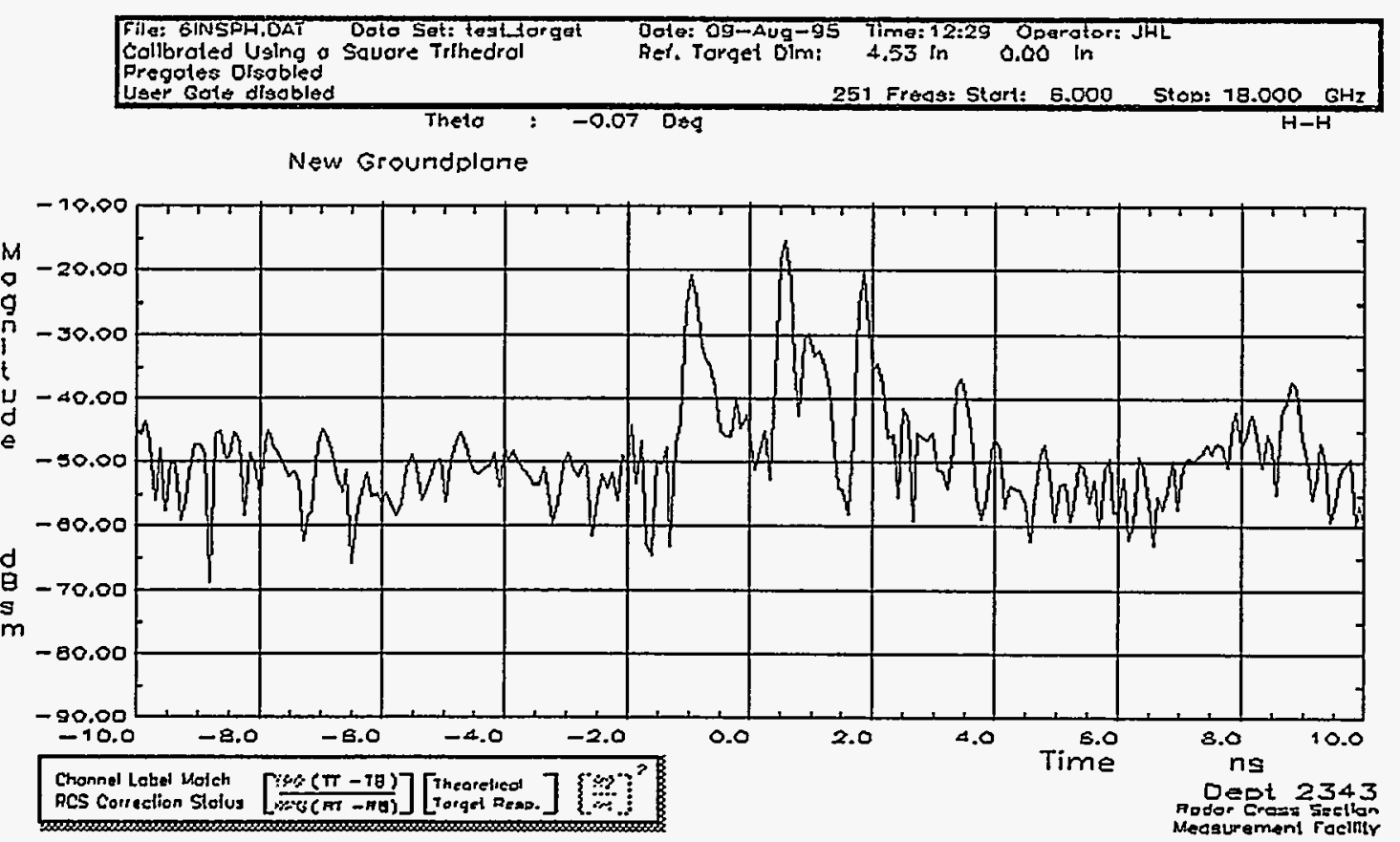

Fig. 8 Sphere Down-range High-frequency Response H-H Polarization 


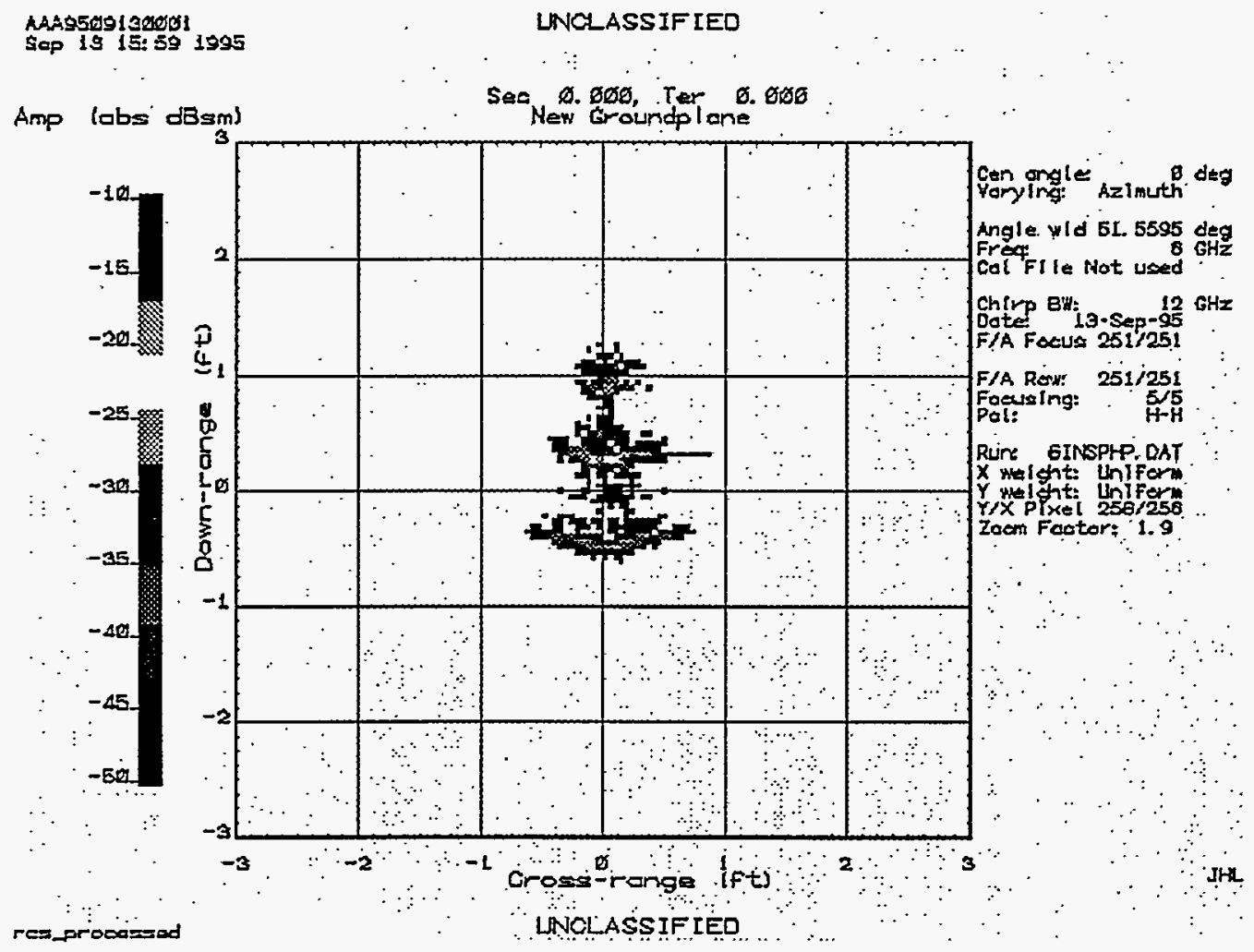

Fig. 9 ISAR Image of Sphere High-frequency Response H-H Polarization

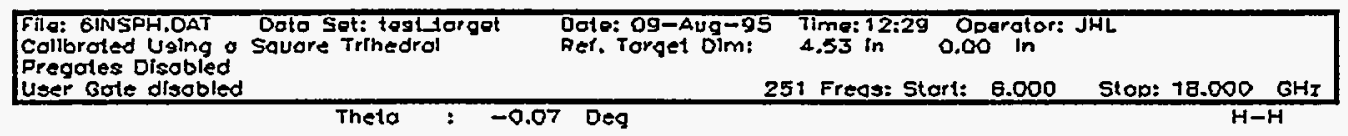
New Groundolone

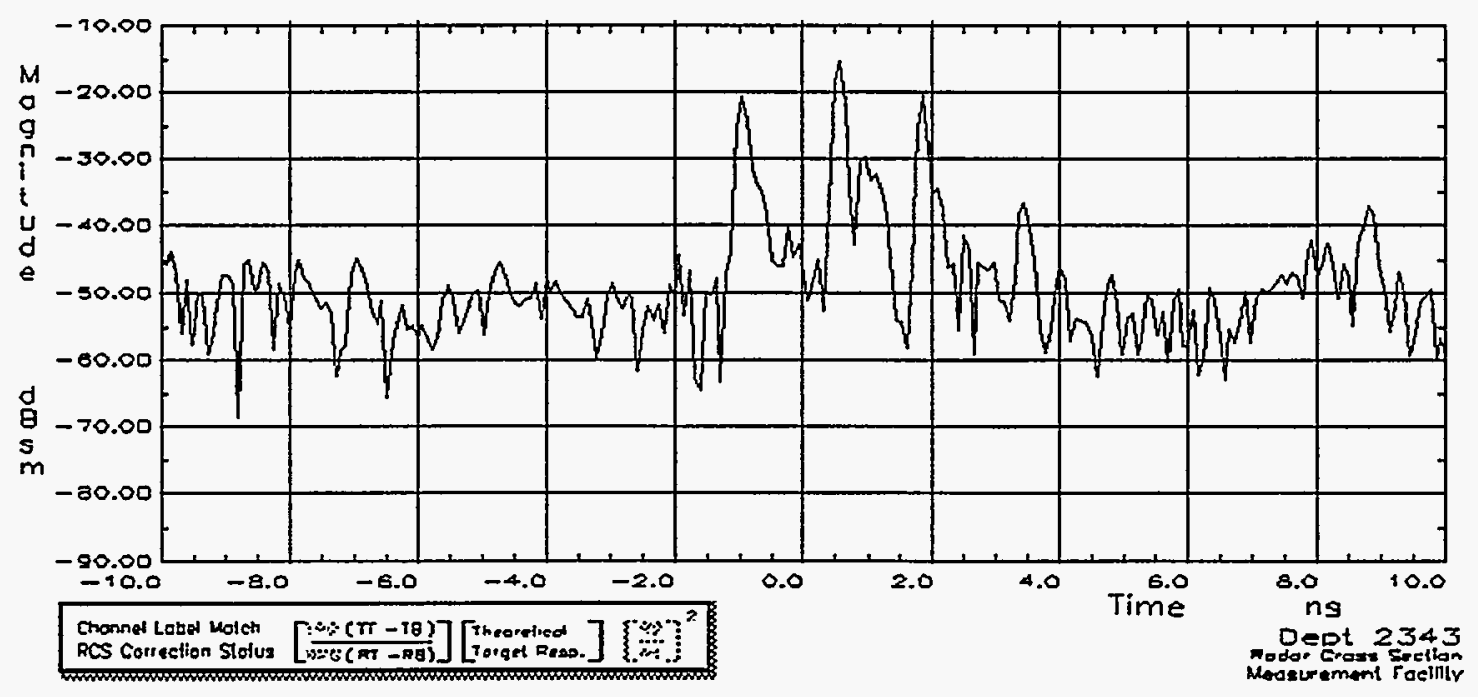

Fig. 10 Sphere Down-range High-frequency Response V-V Polarization 


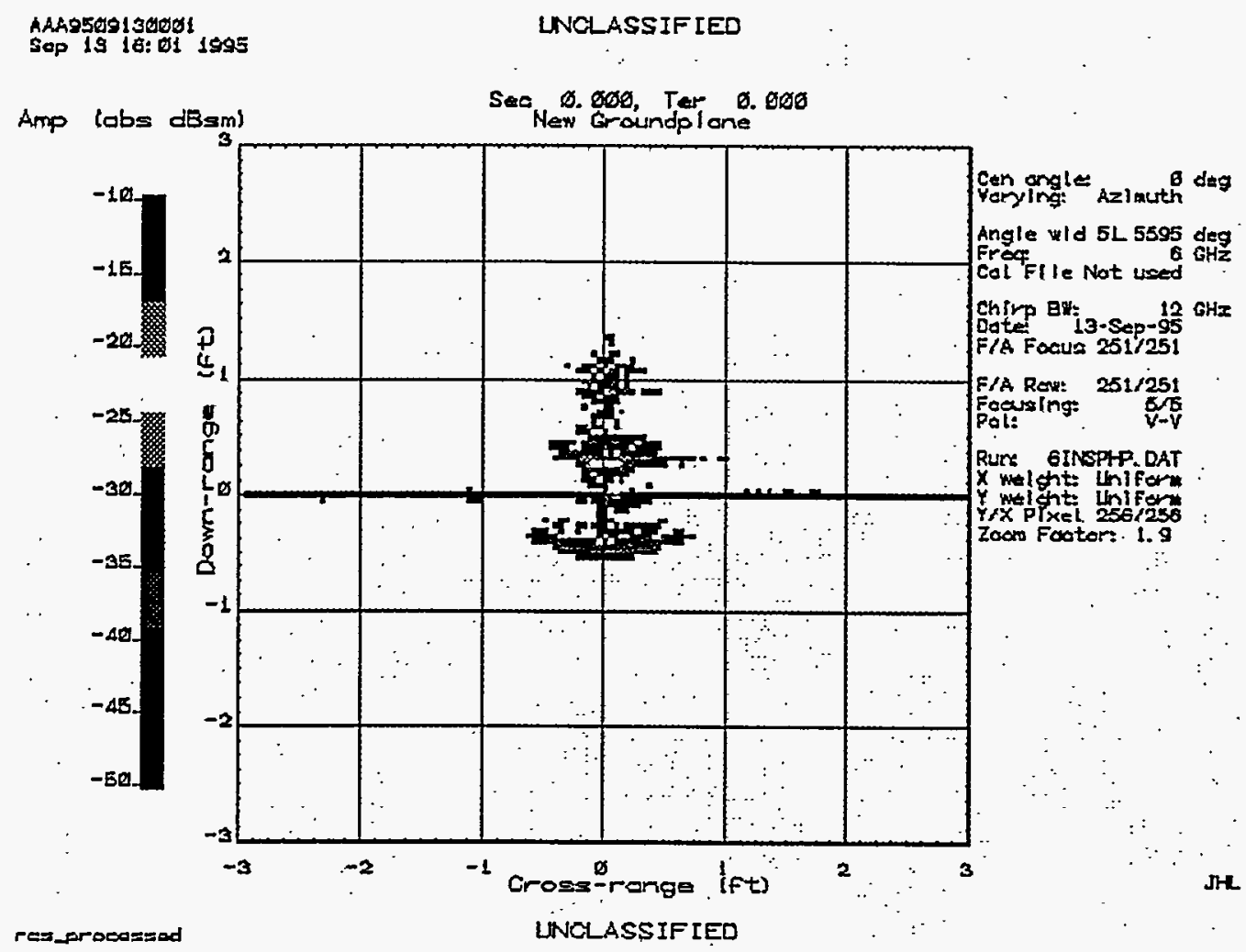

Fig. 11 ISAR Image of Sphere High-frequency Response V-V Polarization

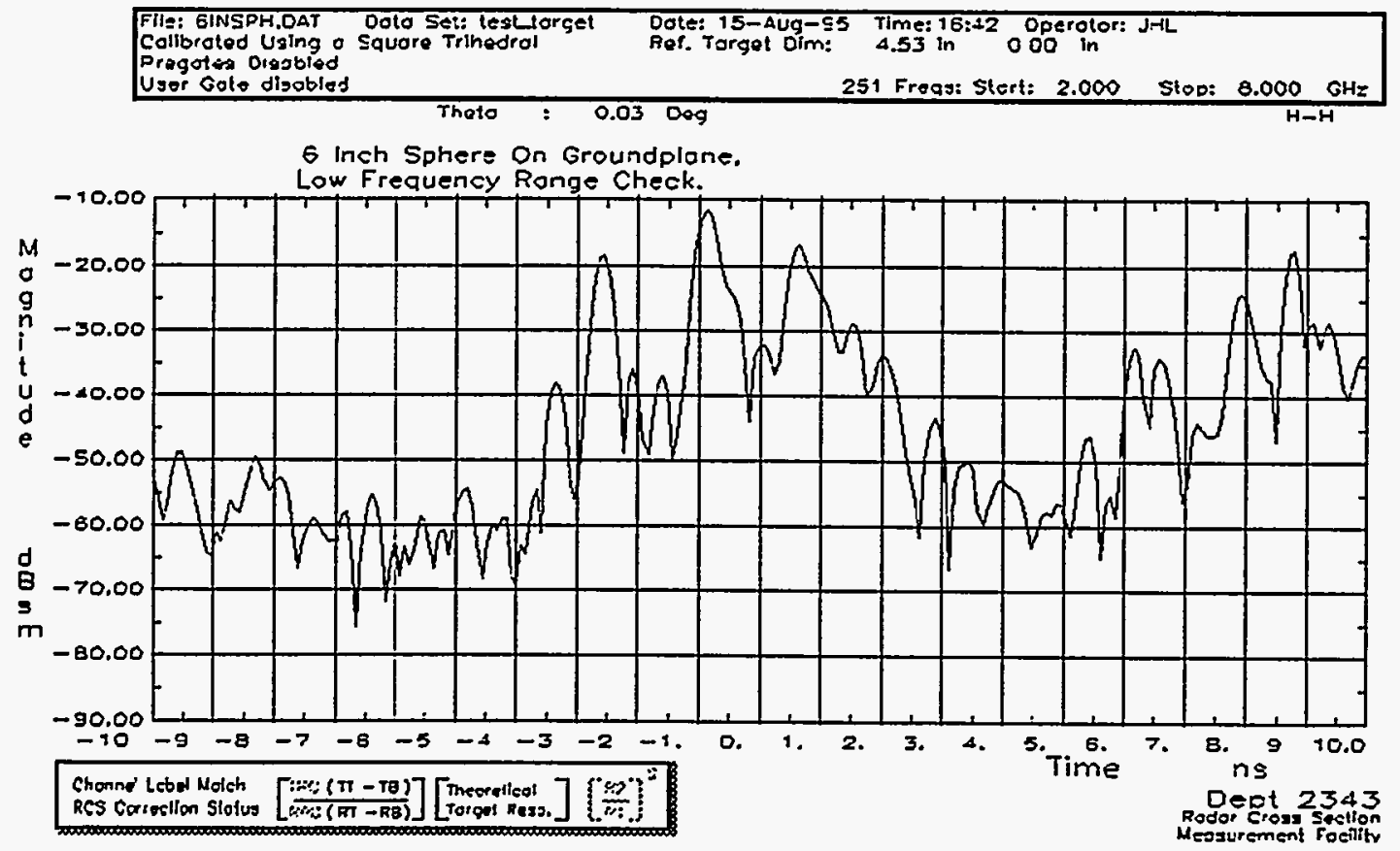

Fig. 12 Sphere Down Range Low-frequency Response H-H Polarization 


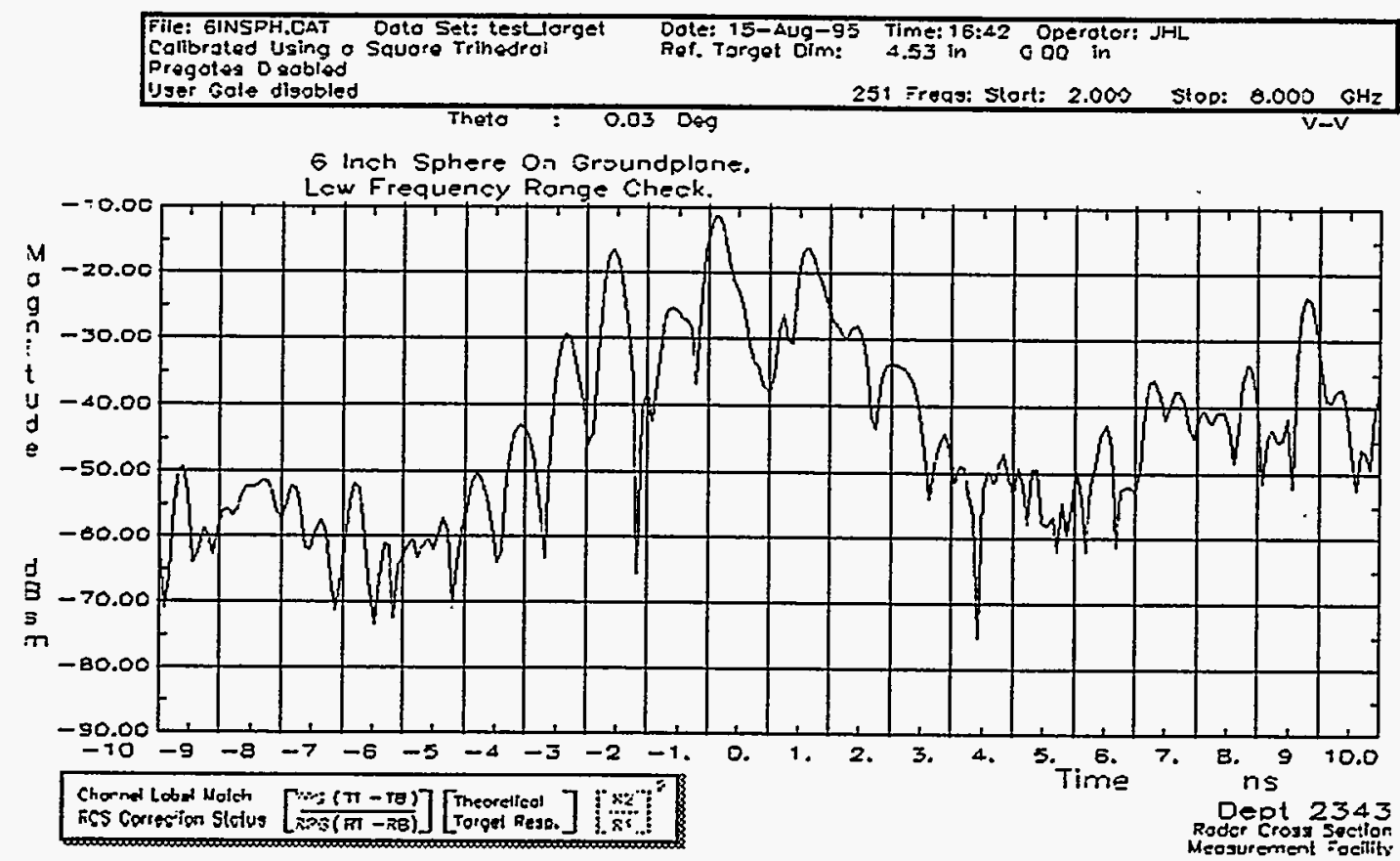

Fig. 13 Sphere Down Range Low-frequency Response V-V Polarization

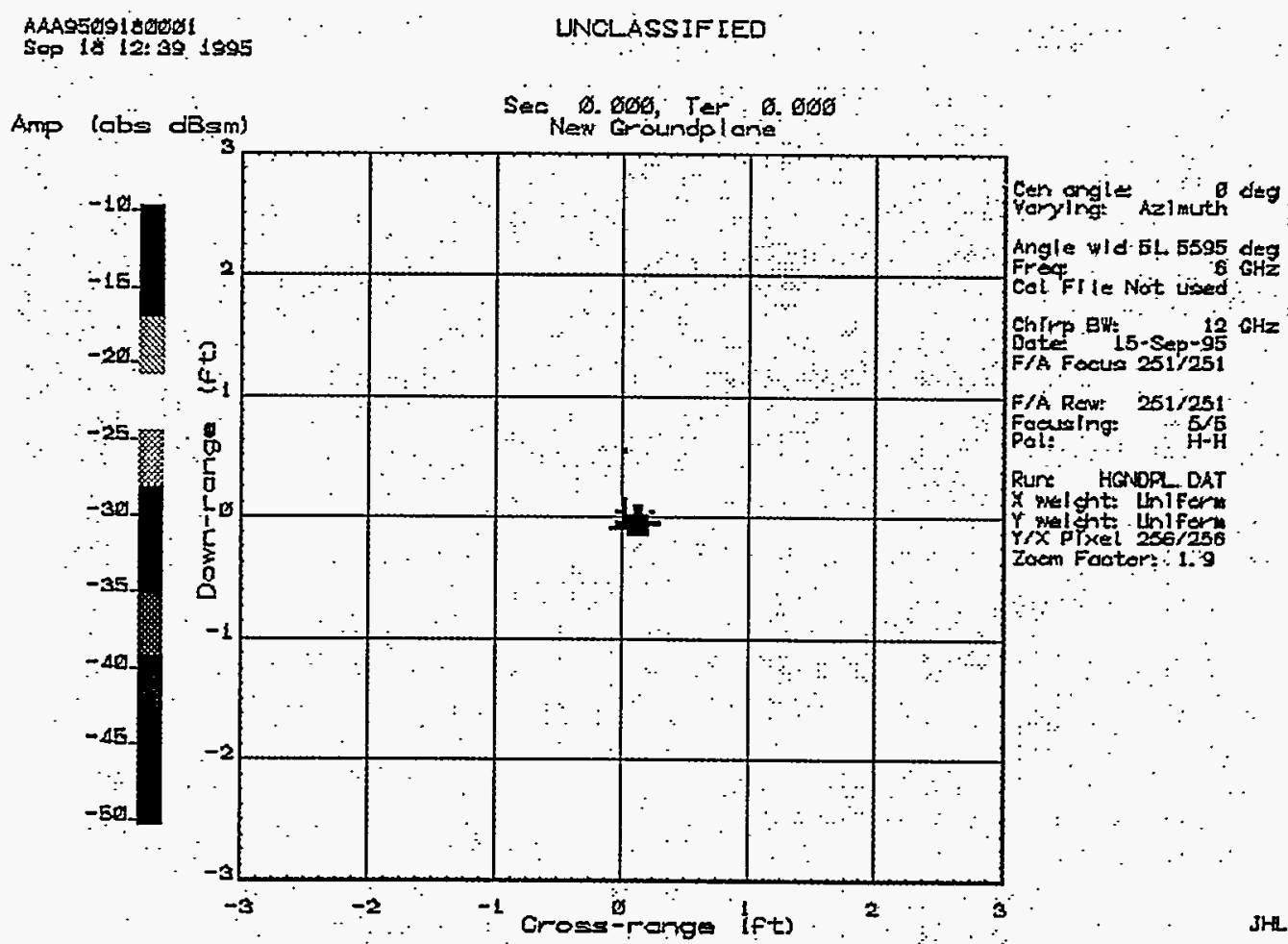

resprosasead LNCLASSIFIED

Fig. 14 High Frequency ISAR Image of Ground Plane H-H Polarization 


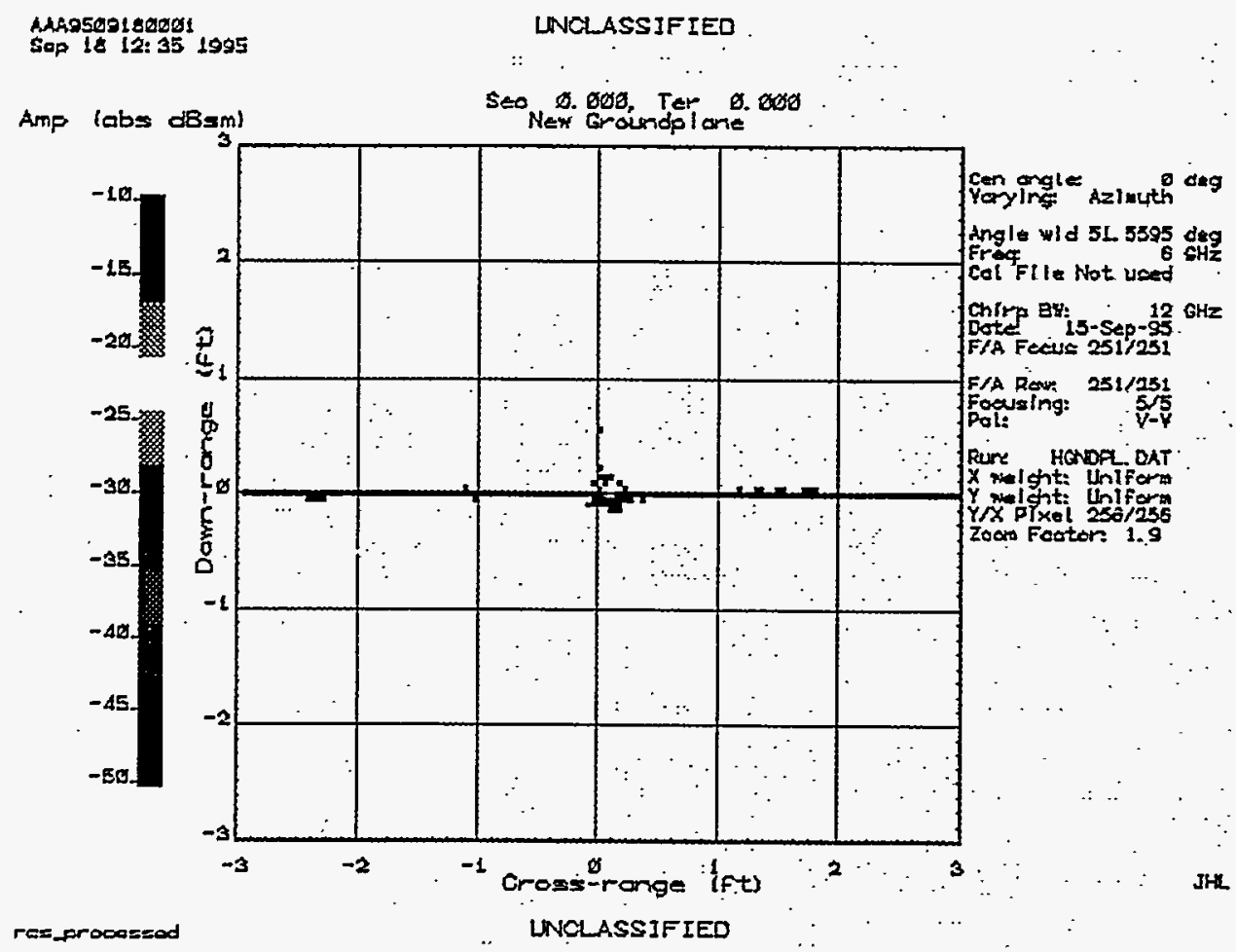

Fig. 15 High Frequency ISAR Image of Ground Plane V-V Polarization

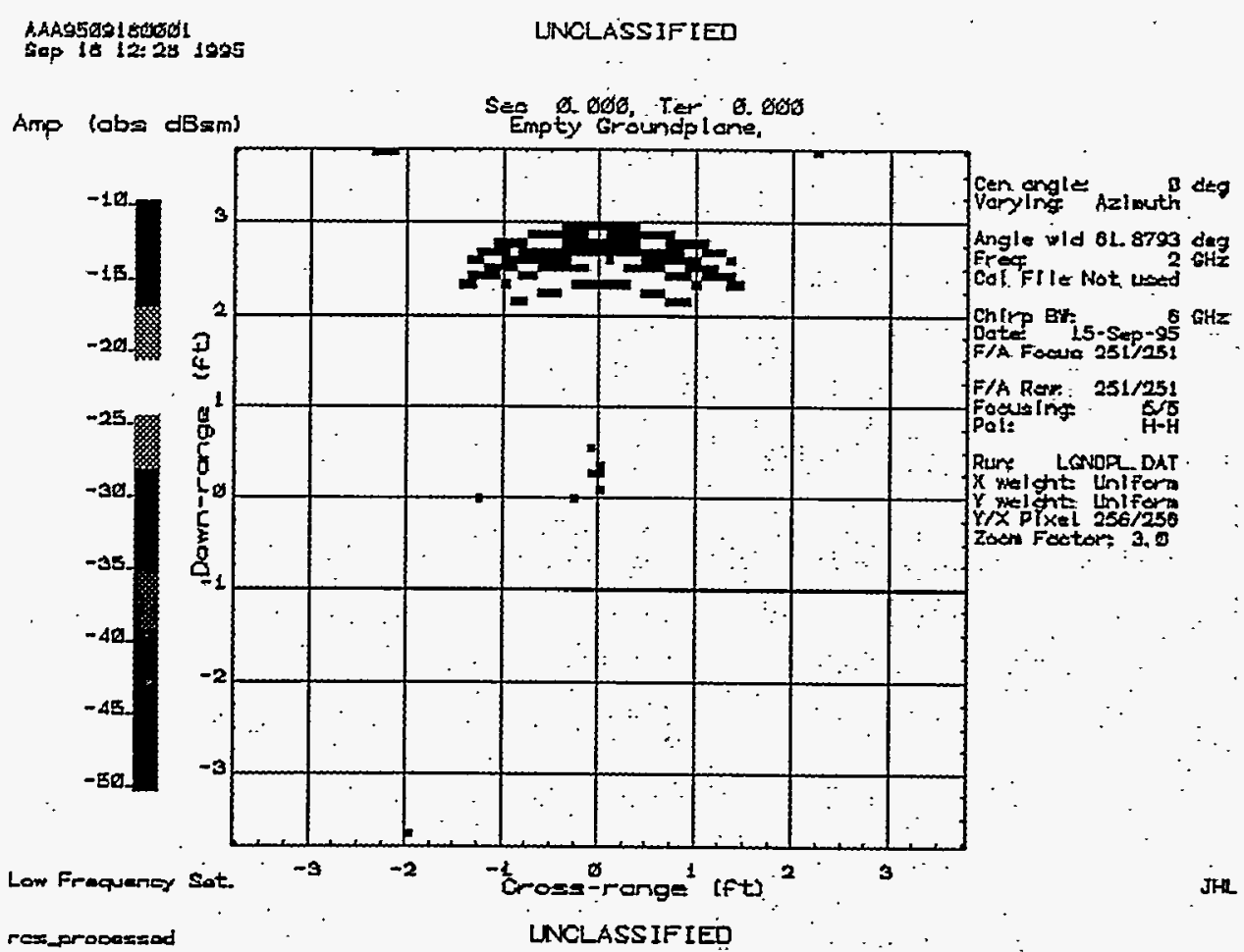

Fig. 16 Low Frequency ISAR Image of Ground Plane H-H Polarization 


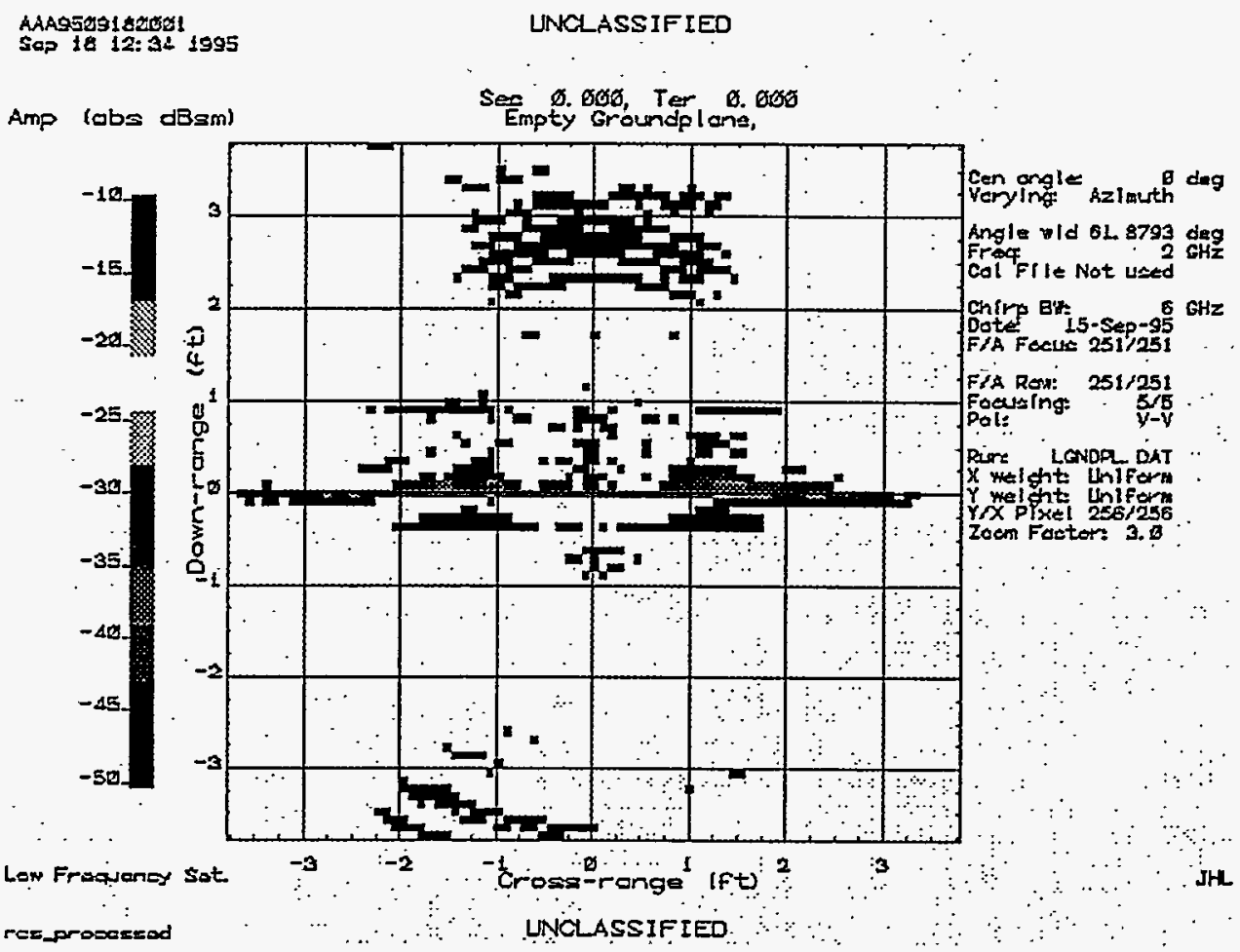

Fig. 17 Low Frequency ISAR Image of Ground Plane V-V Polarization

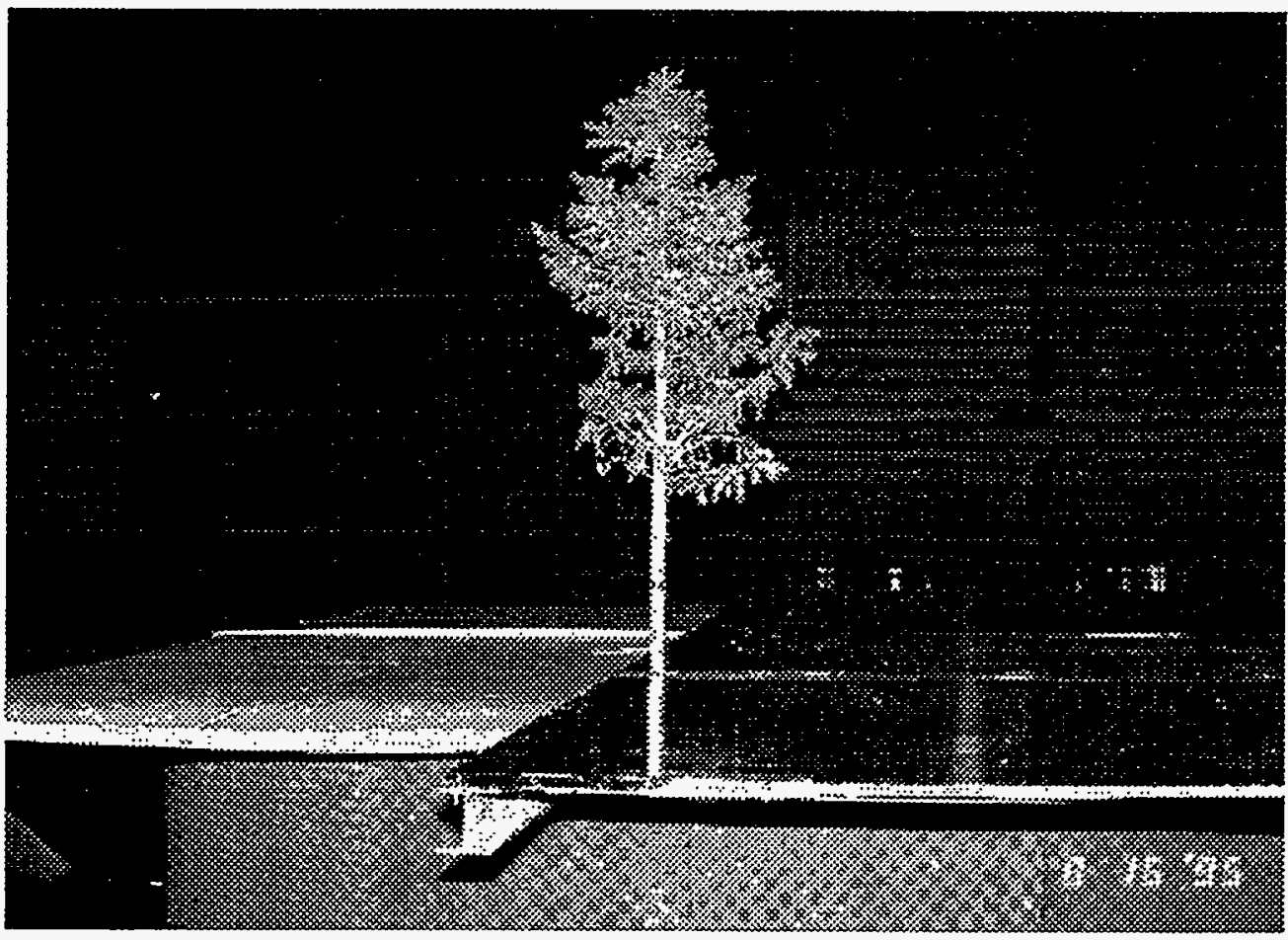

Fig. 18 Black Hills Spruce Tree 


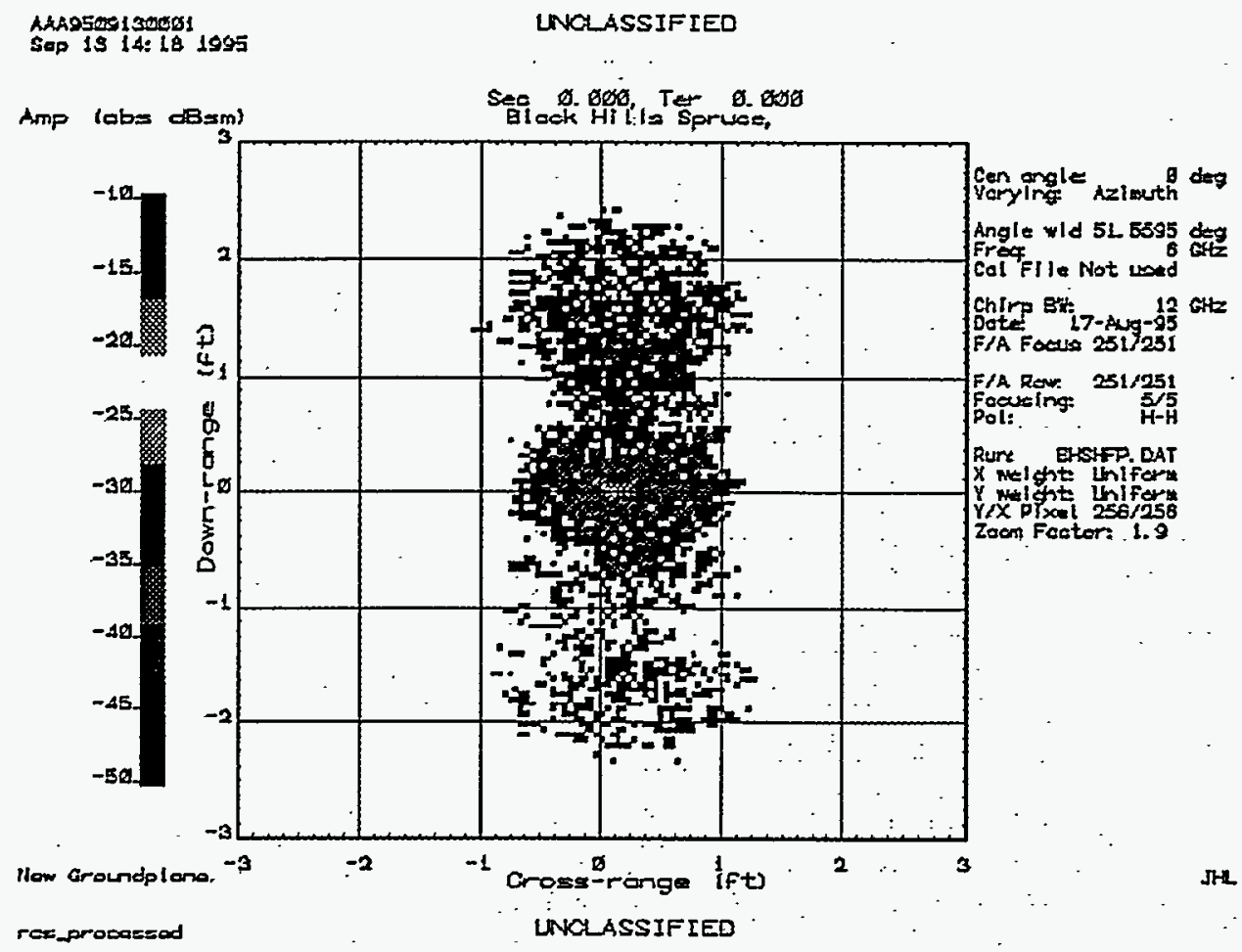

Fig. 19 High Frequency ISAR Image of Black Hills Spruce Tree H-H Polarization

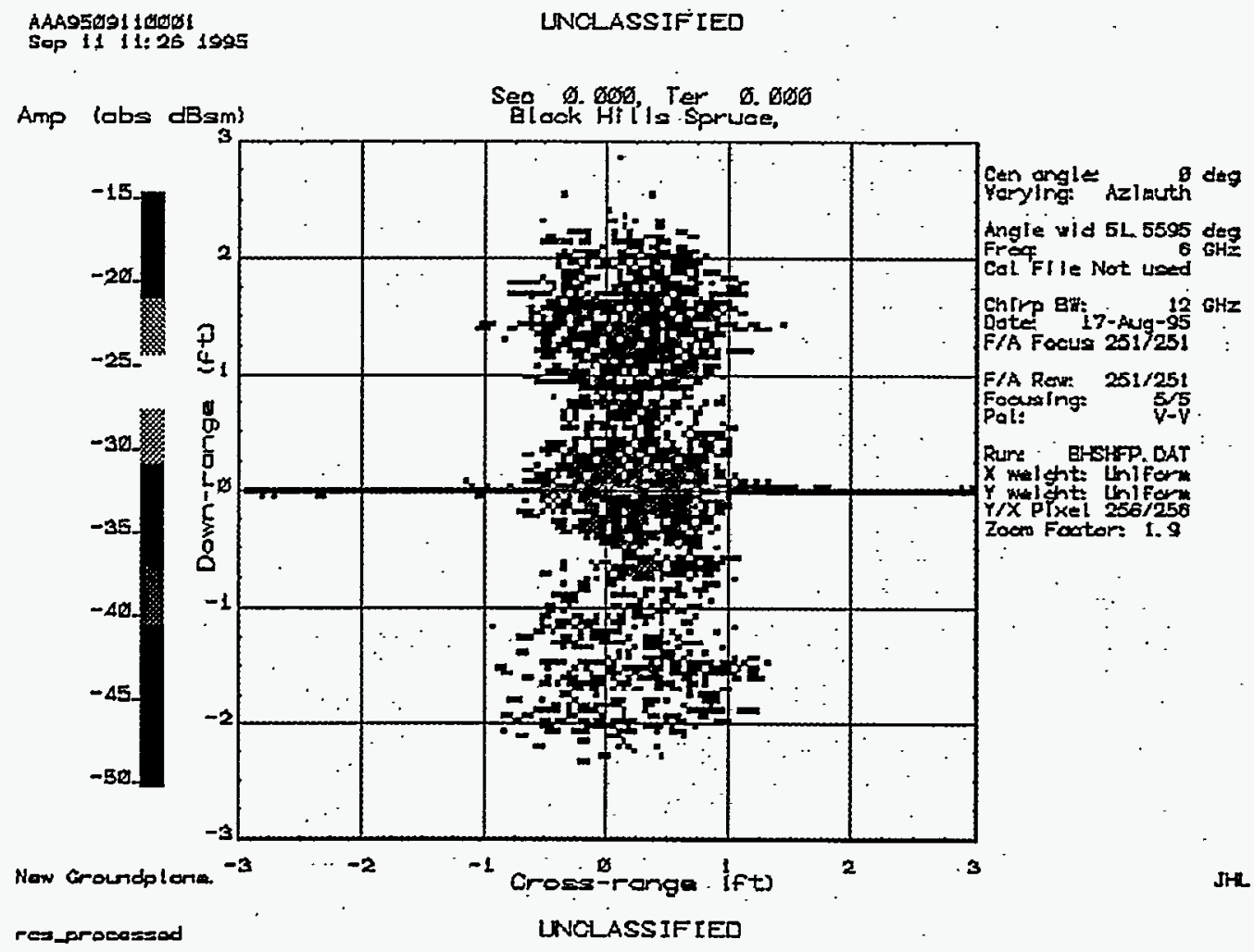

Fig. 20 High Frequency ISAR Image of Black Hills Spruce Tree V-V Polarization 


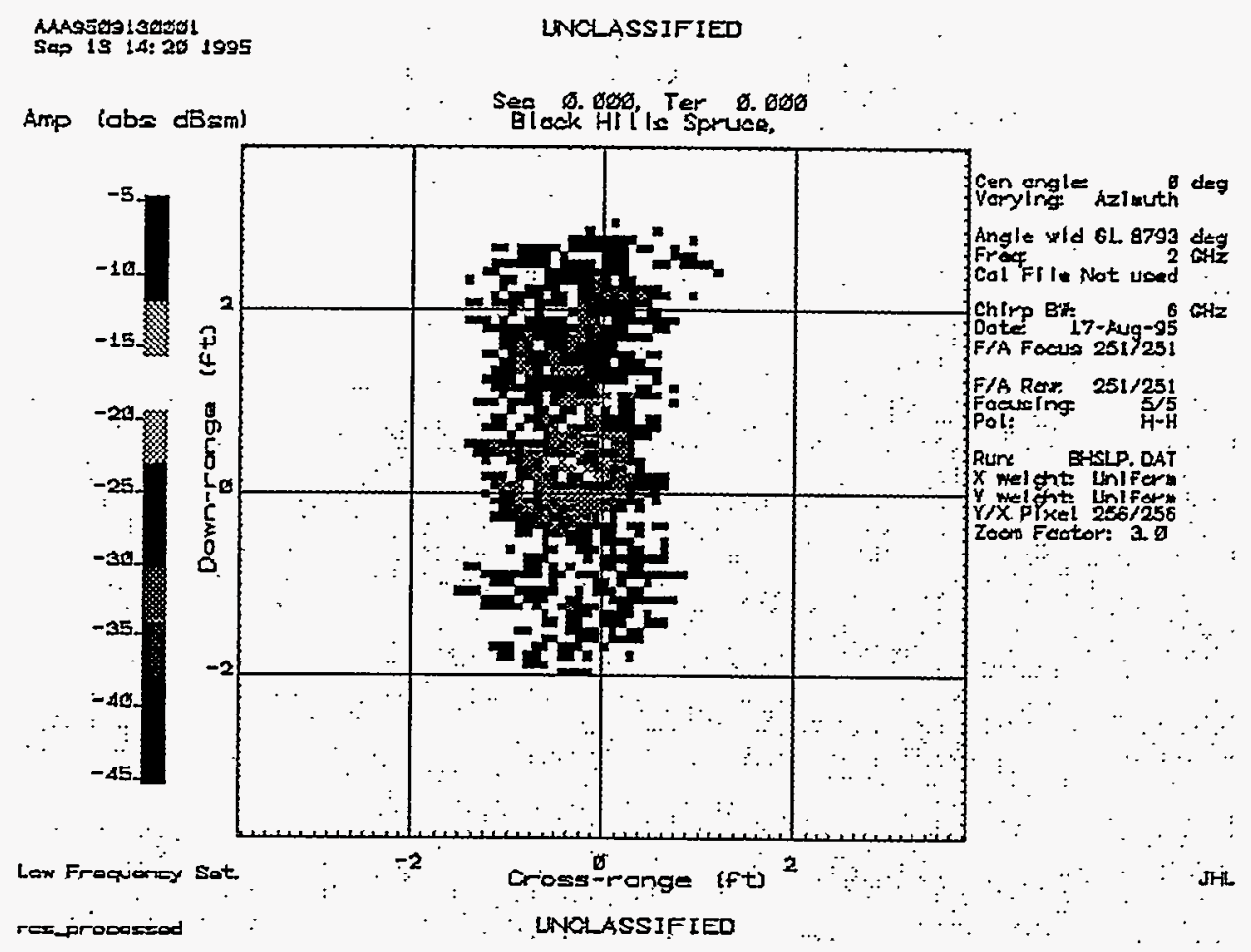

Fig. 21 Low Frequency ISAR Image of Black Hills Spruce Tree H-H Polarization

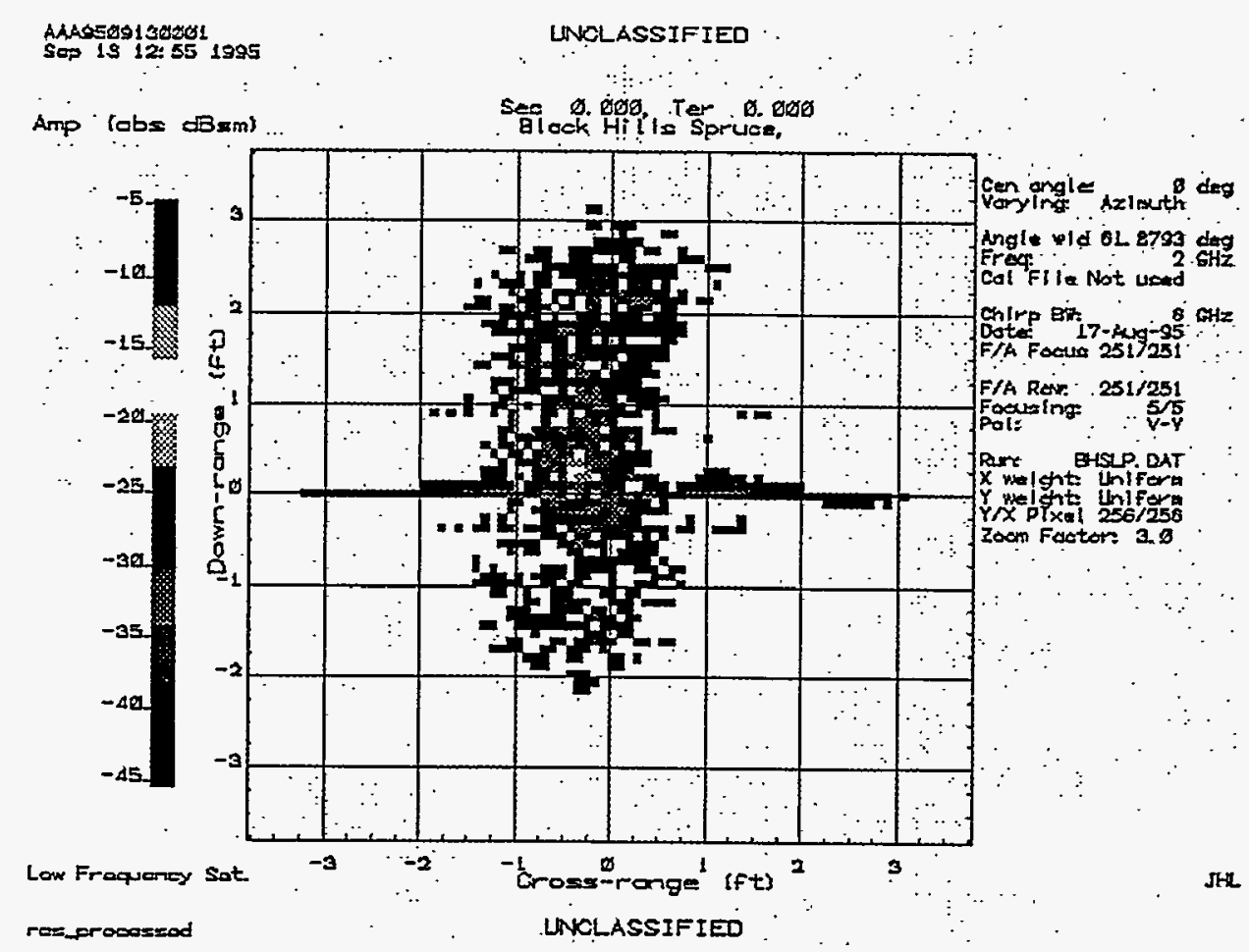

Fig. 22 Low Frequency ISAR Image of Black Hills Spruce Tree V-V Polarization 


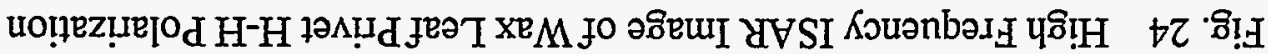

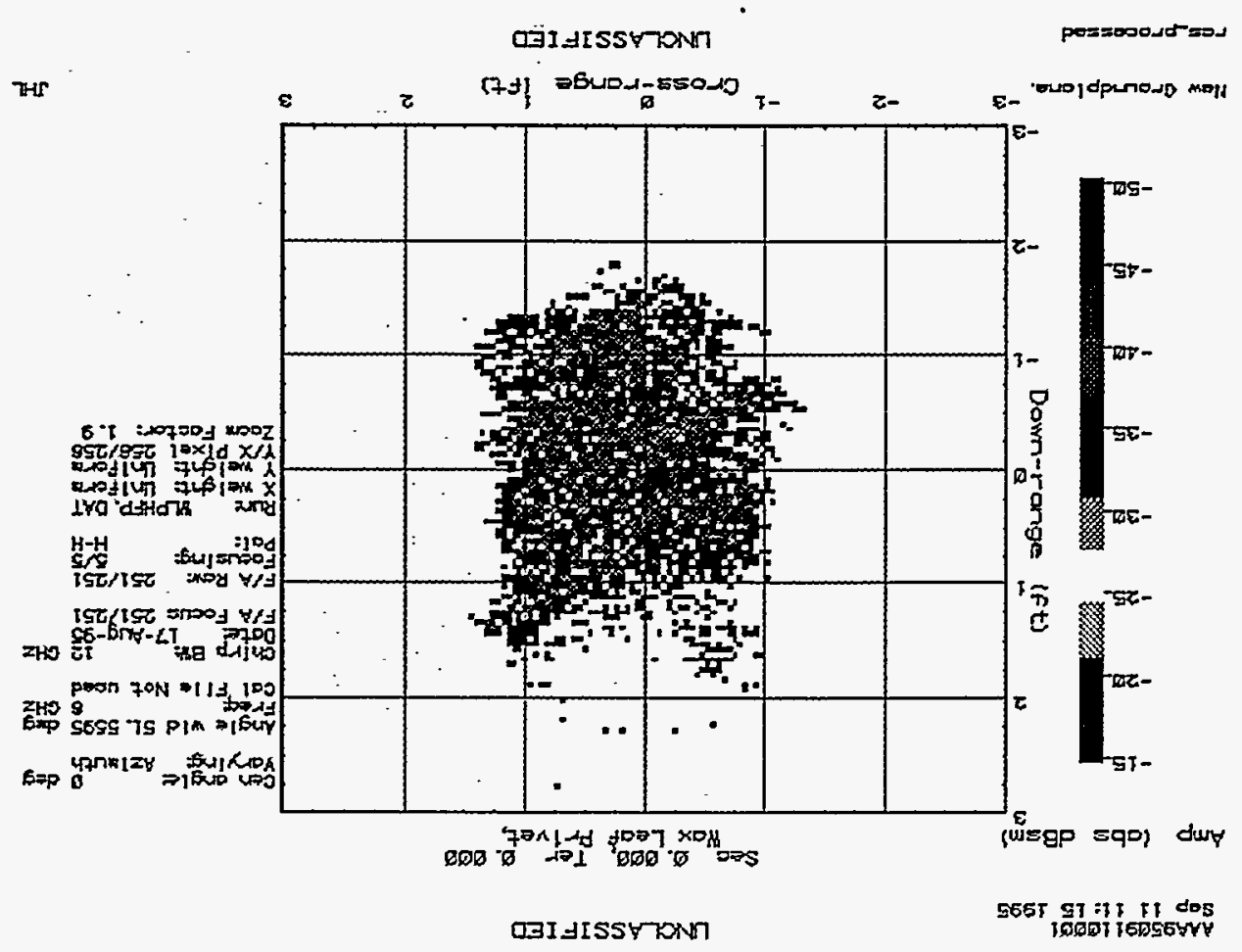

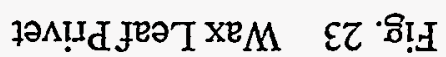

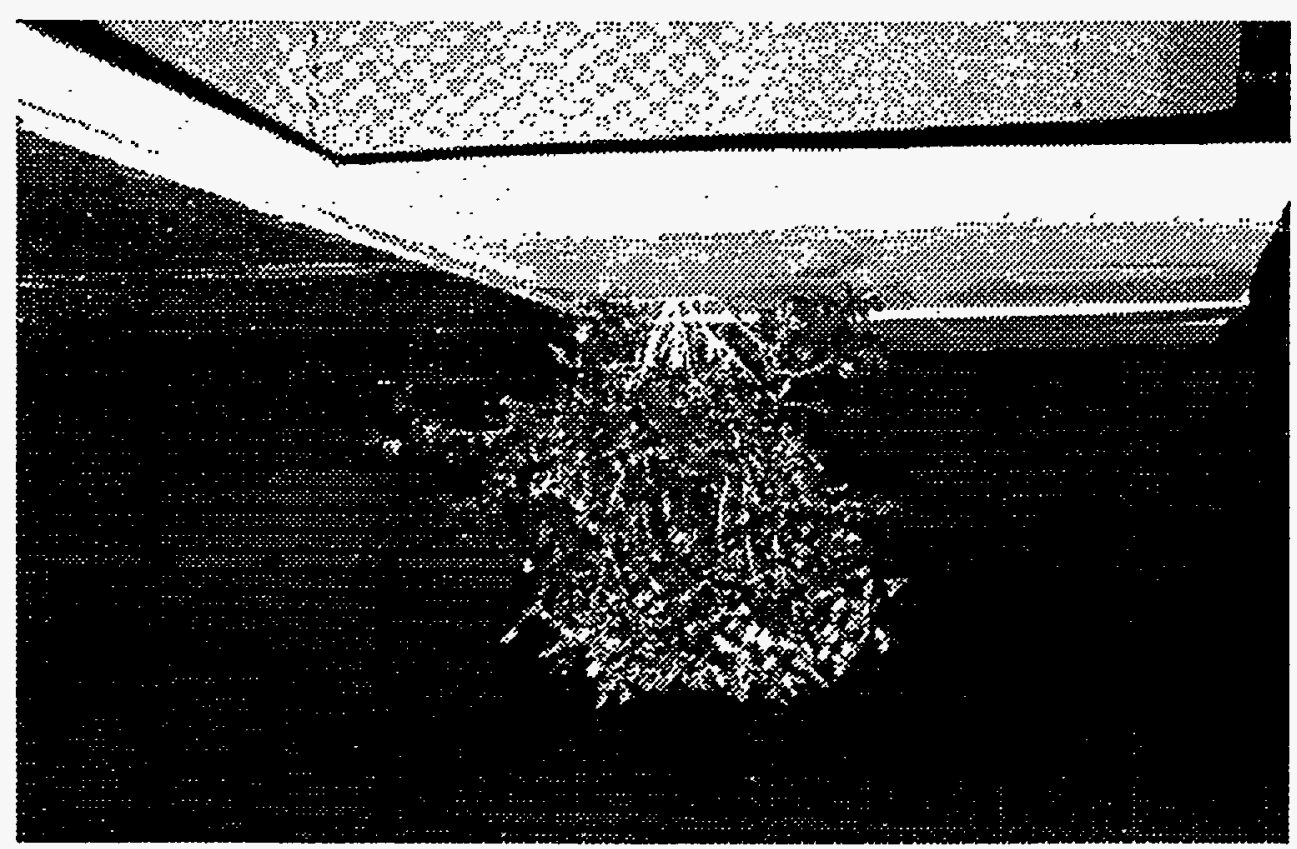




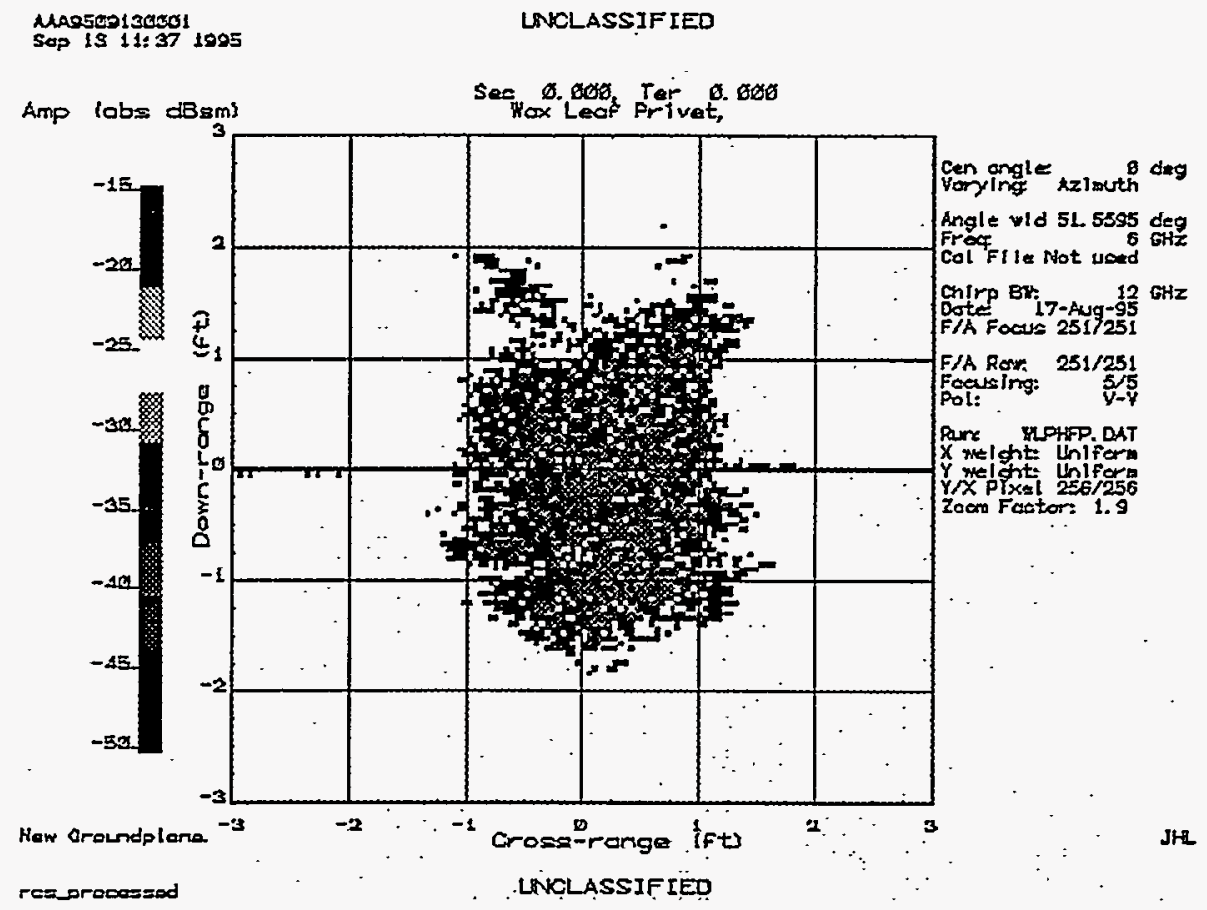

Fig. 25 High Frequency ISAR Image of Wax Leaf Privet V-V Polarization

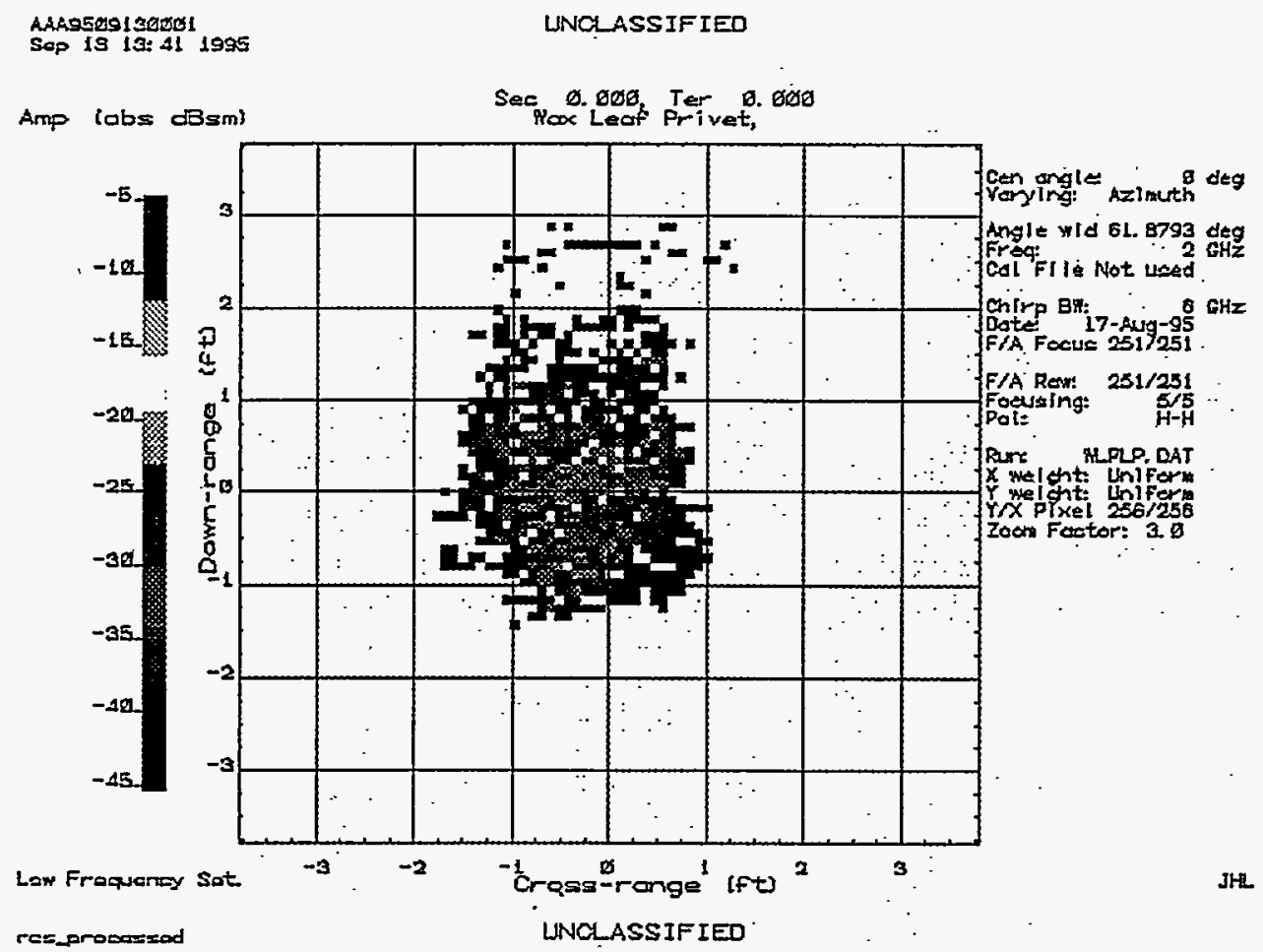

Fig. 26 Low Frequency ISAR Image of Wax Leaf Privet H-H Polarization 


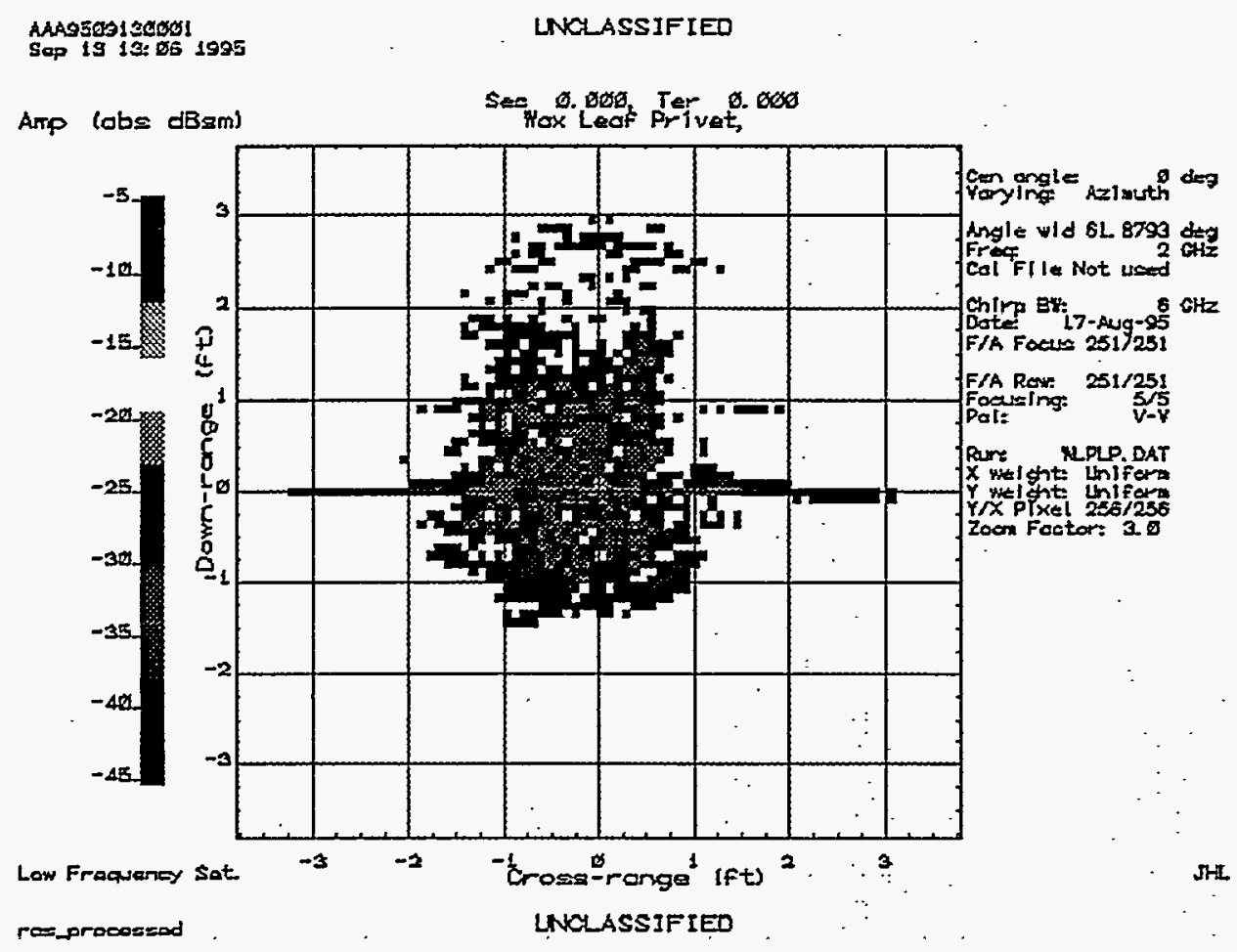

Fig. 27 Low Frequency ISAR Image of Wax Leaf Privet V-V Polarization

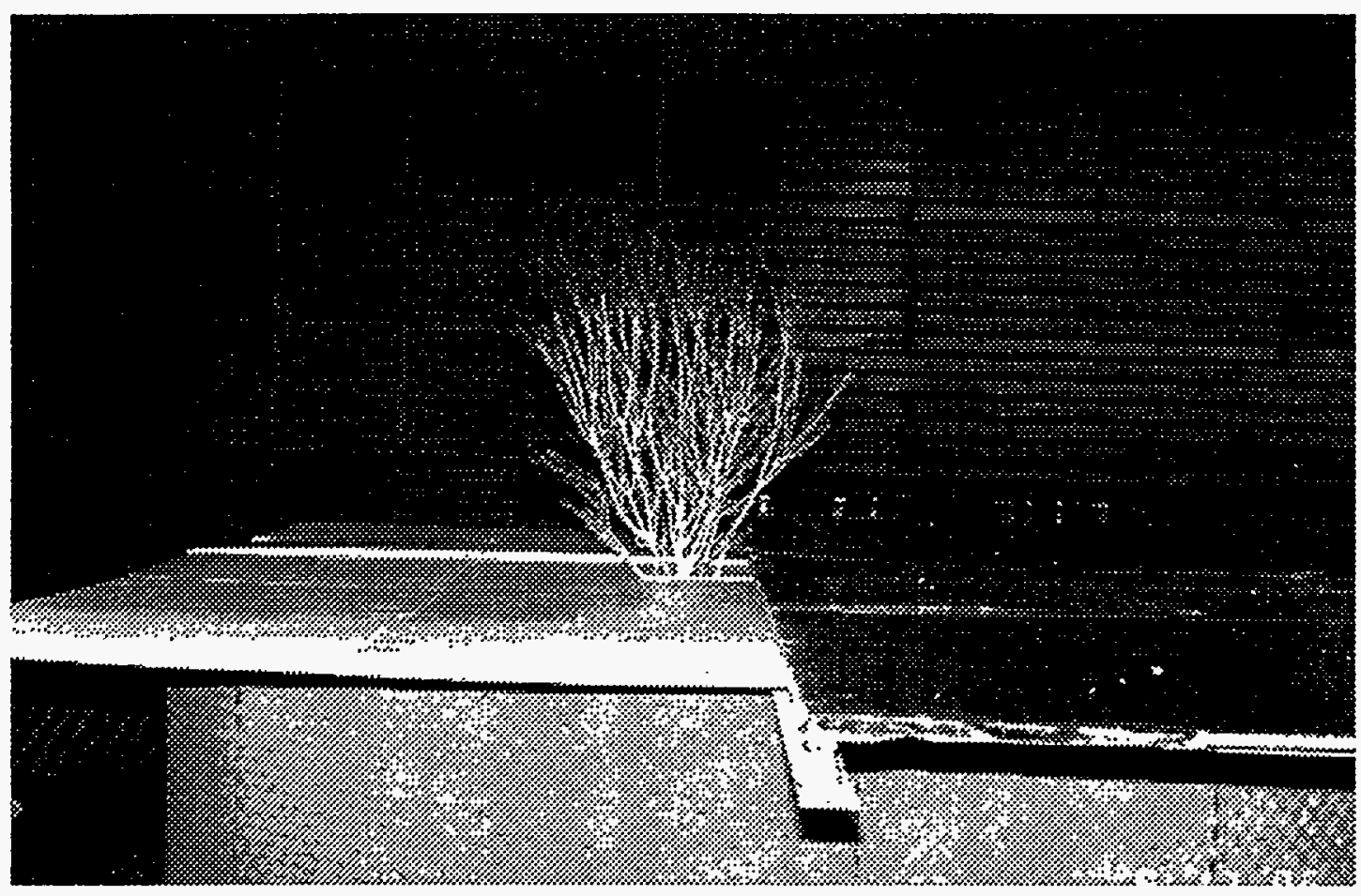

Fig. 28 Wax Leaf Privet Leaves Removed 


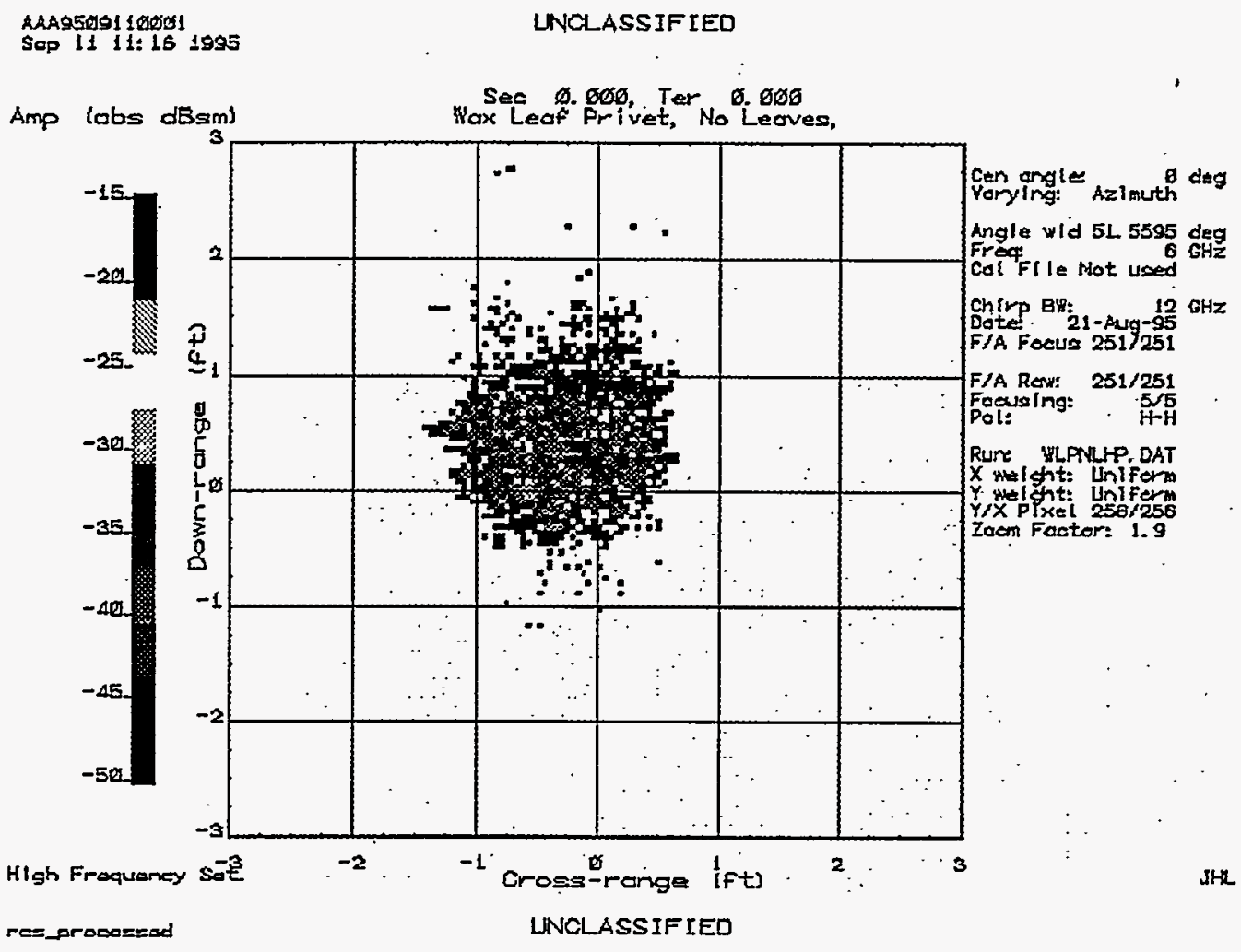

Fig. 29 High Frequency ISAR Image of Wax Leaf Privet Leaves Removed H-H Polarization

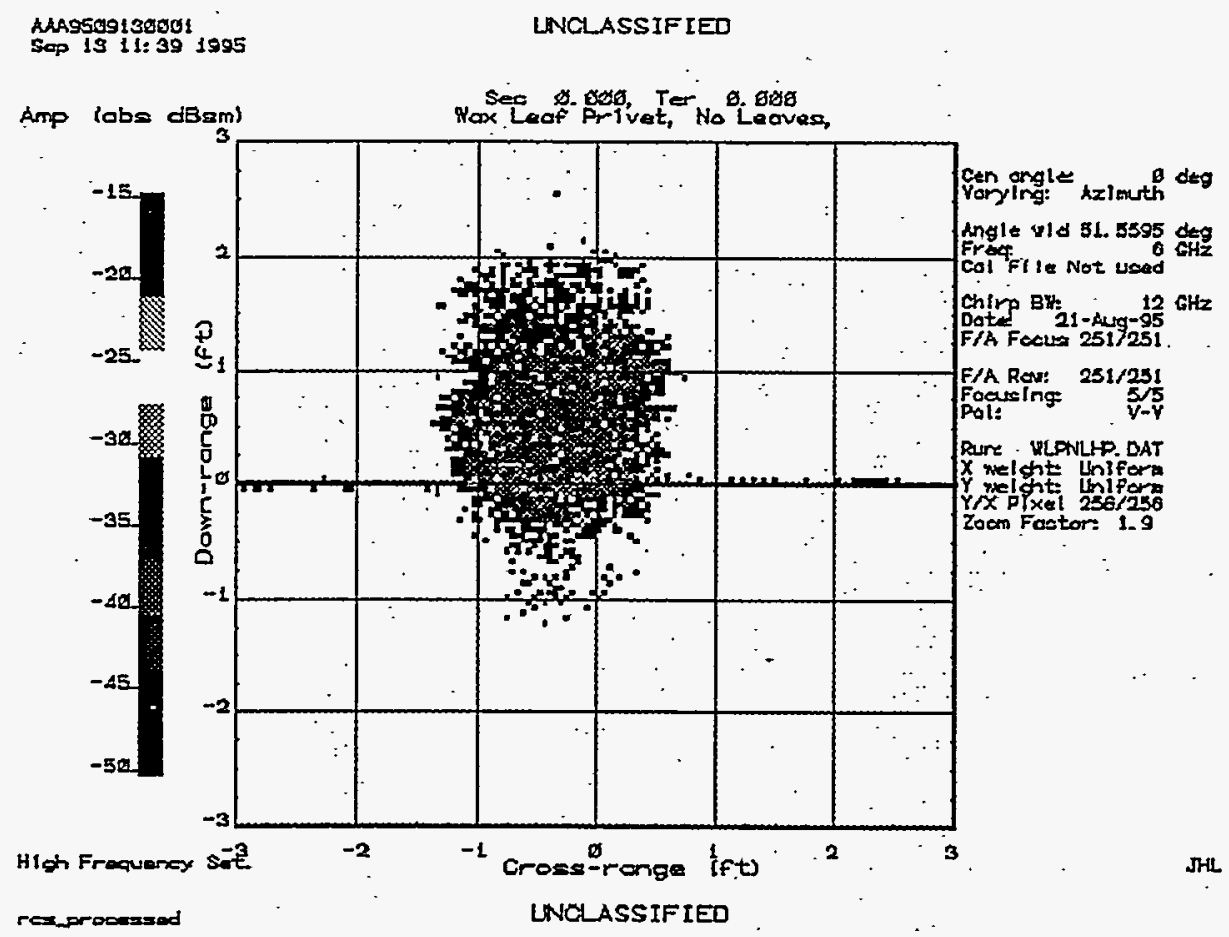

Fig. 30 High Frequency ISAR Image of Wax Leaf Privet Leaves Removed V-V Polarization 


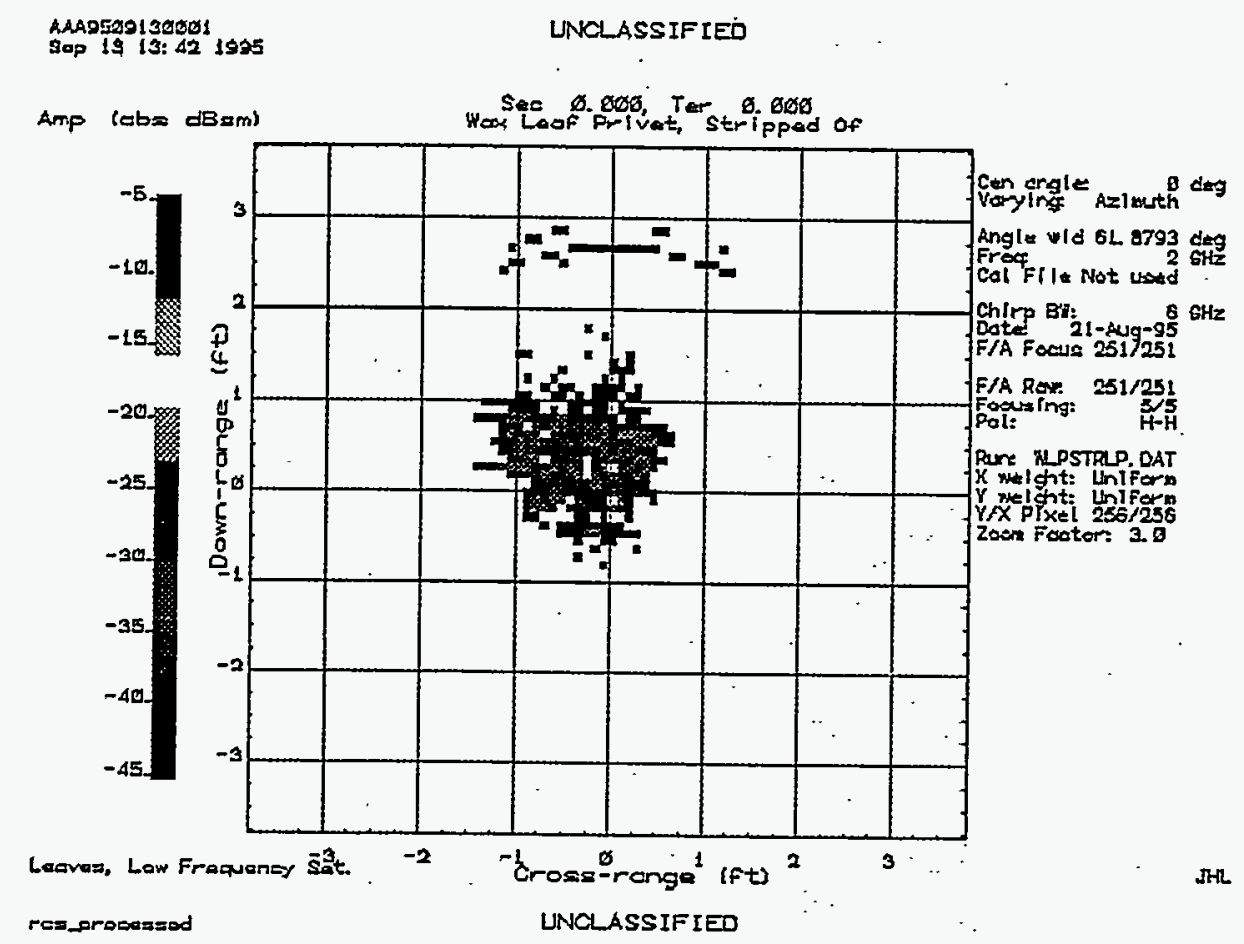

Fig. 31 Low Frequency ISAR Image of Wax Leaf Privet Leaves Removed H-H Polarization

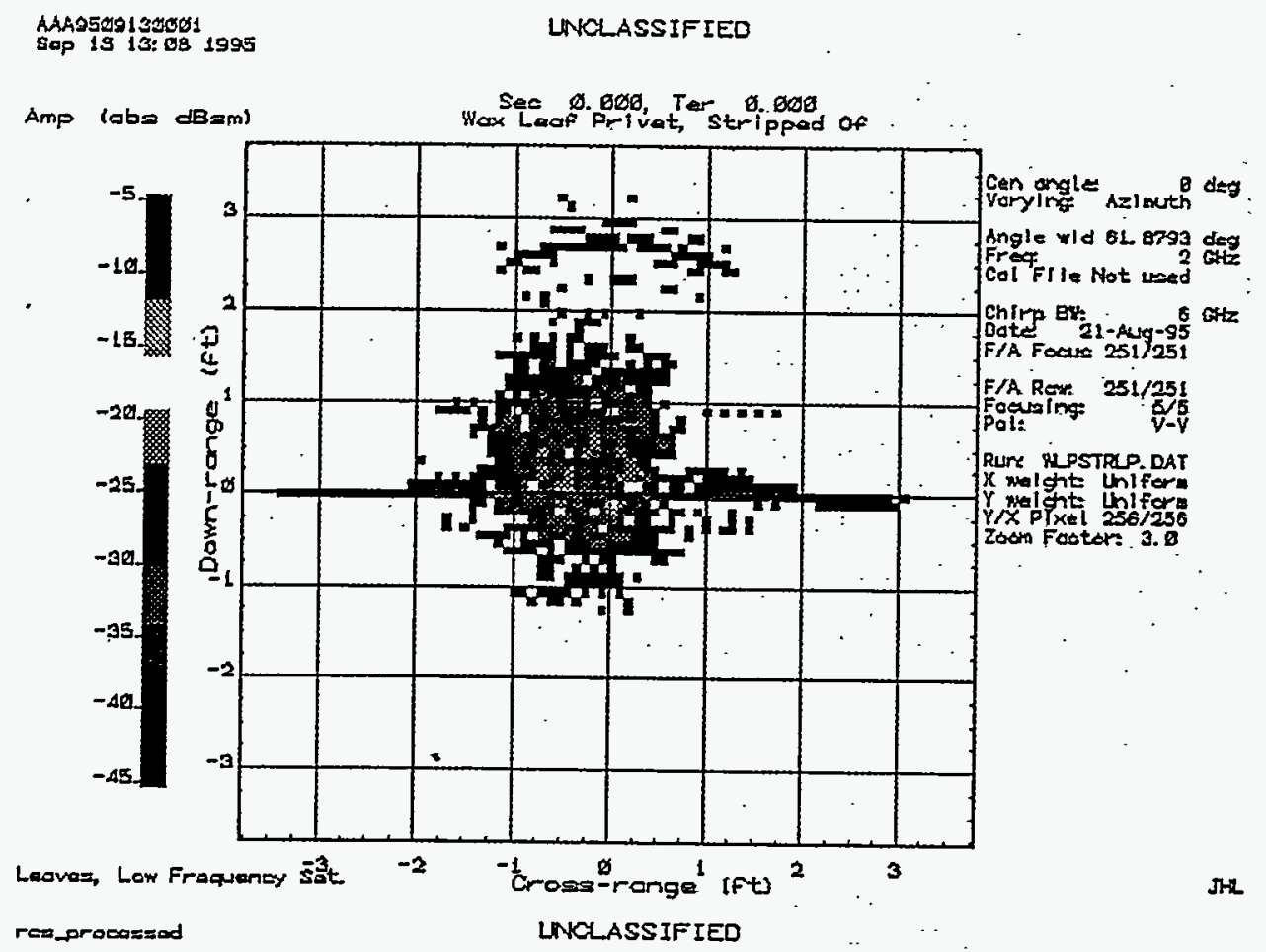

Fig. 32 Low Frequency ISAR Image of Wax Leaf Privet Leaves Removed V-V Polarization 


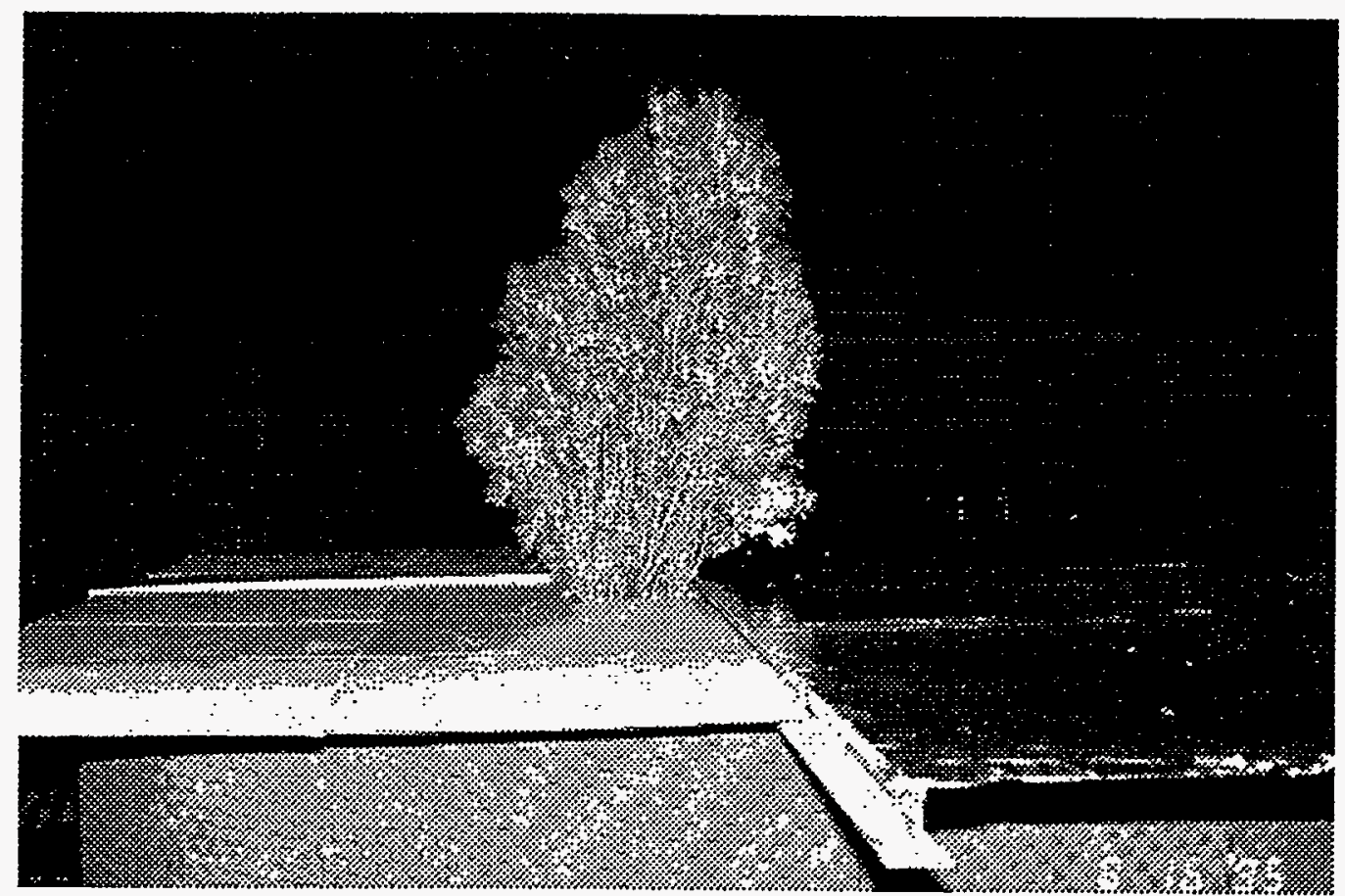

Fig. 33 Juniper Tree

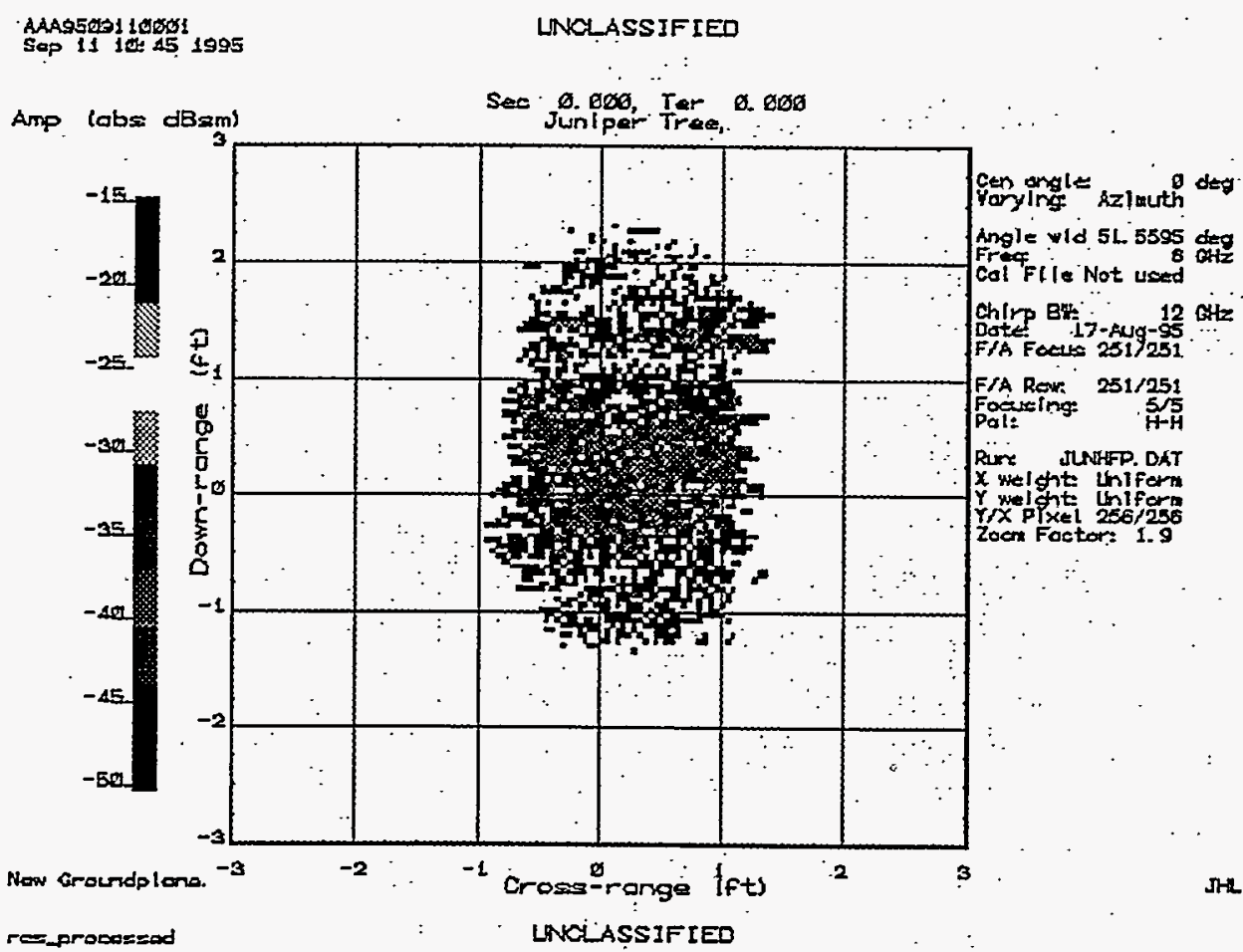

Fig. 34 High Frequency ISAR Image of Juniper Tree H-H Polarization 


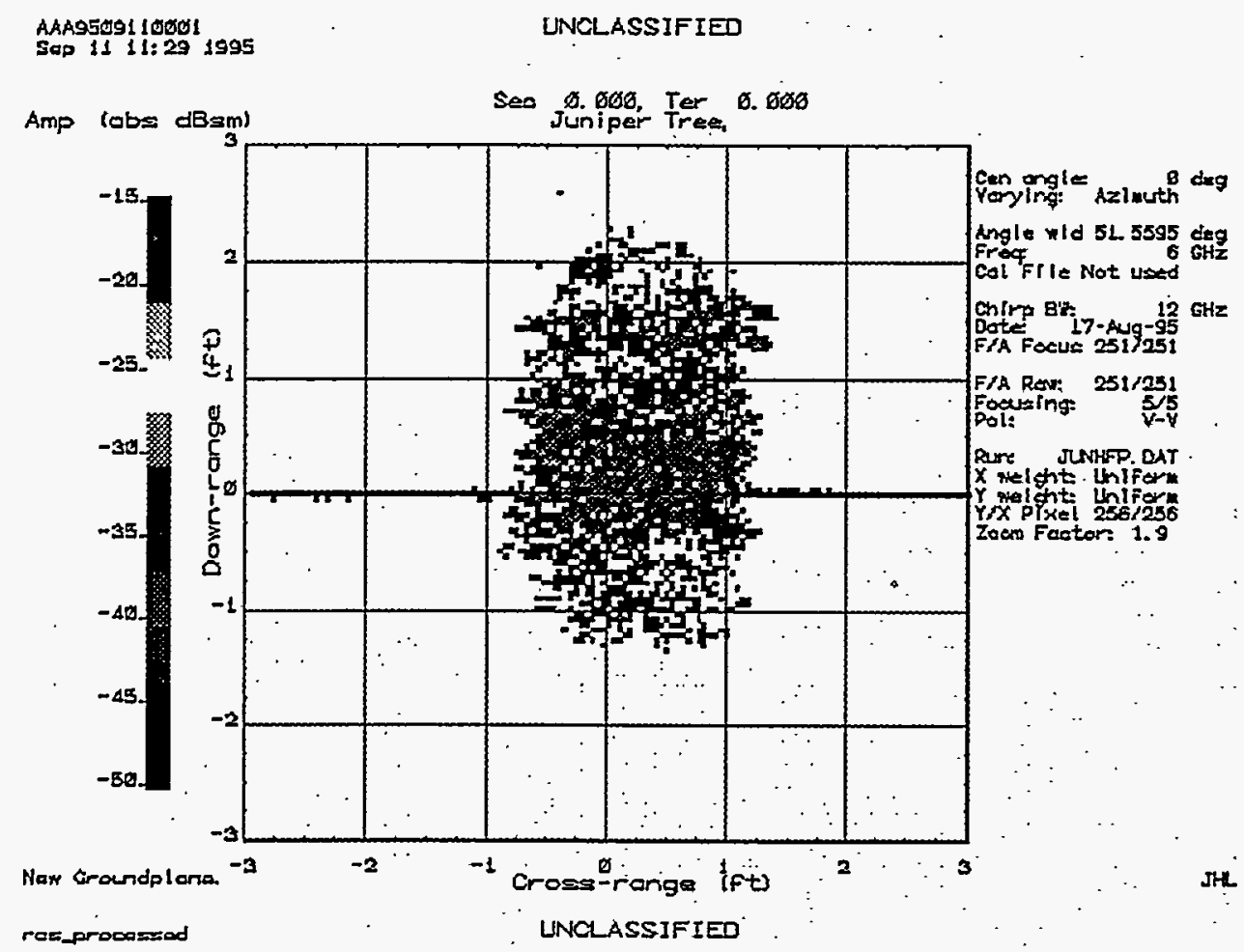

Fig. 35 High Frequency ISAR Image of Juniper Tree V-V Polarization AAR95091309g1
Sap 19 13: 34 1995

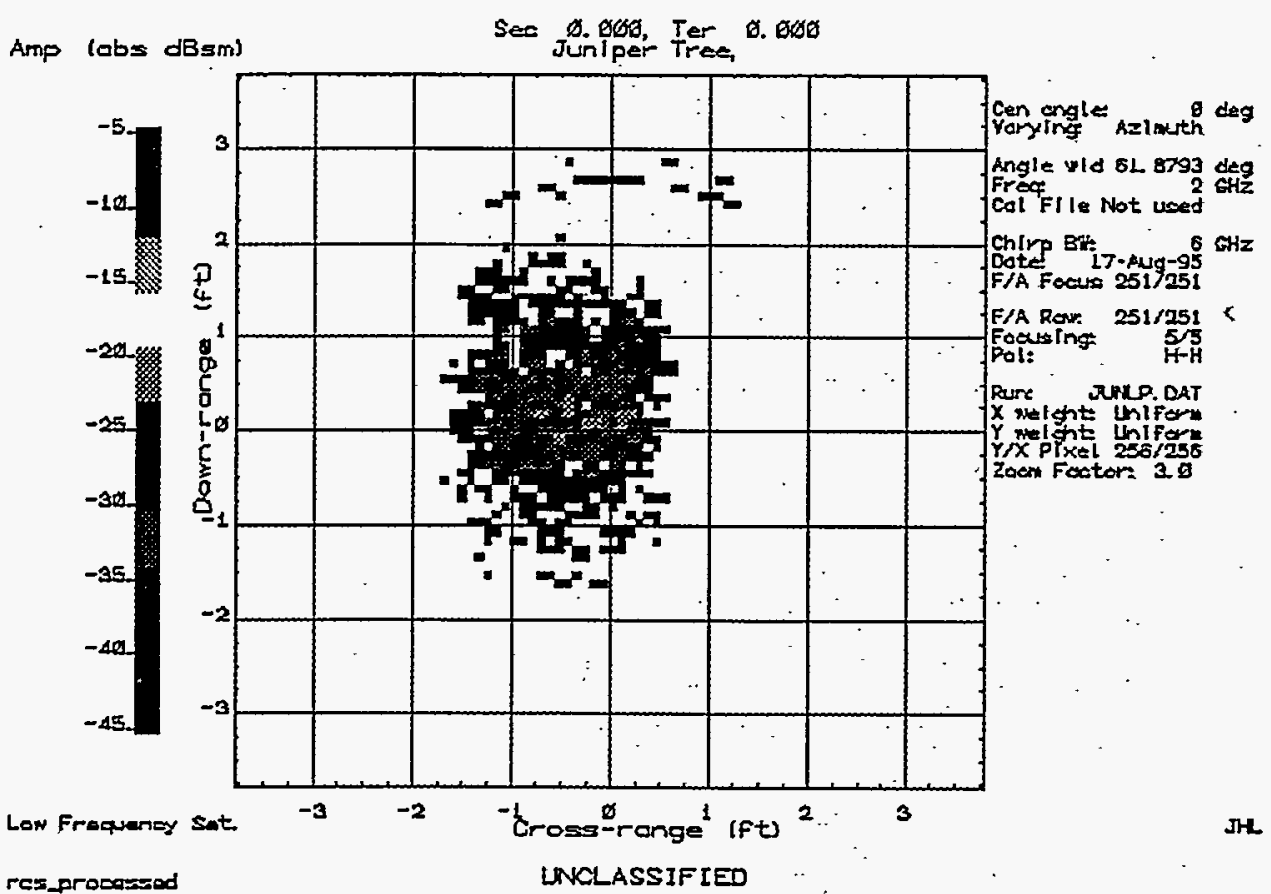

Fig. 36 Low Frequency ISAR Image of Juniper Tree H-H Polarization 


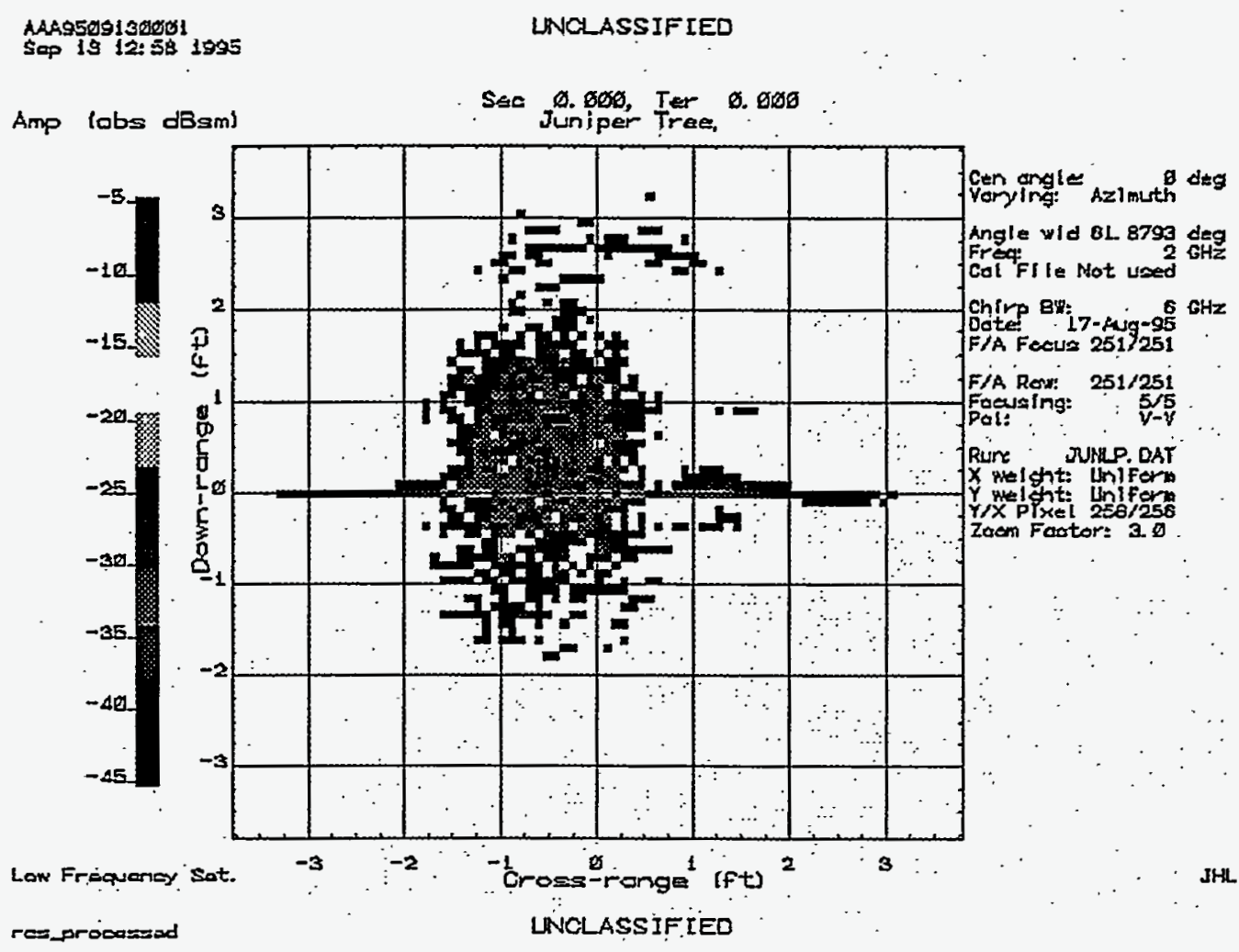

Fig. 37 Low Frequency ISAR Image of Juniper Tree V-V Polarization

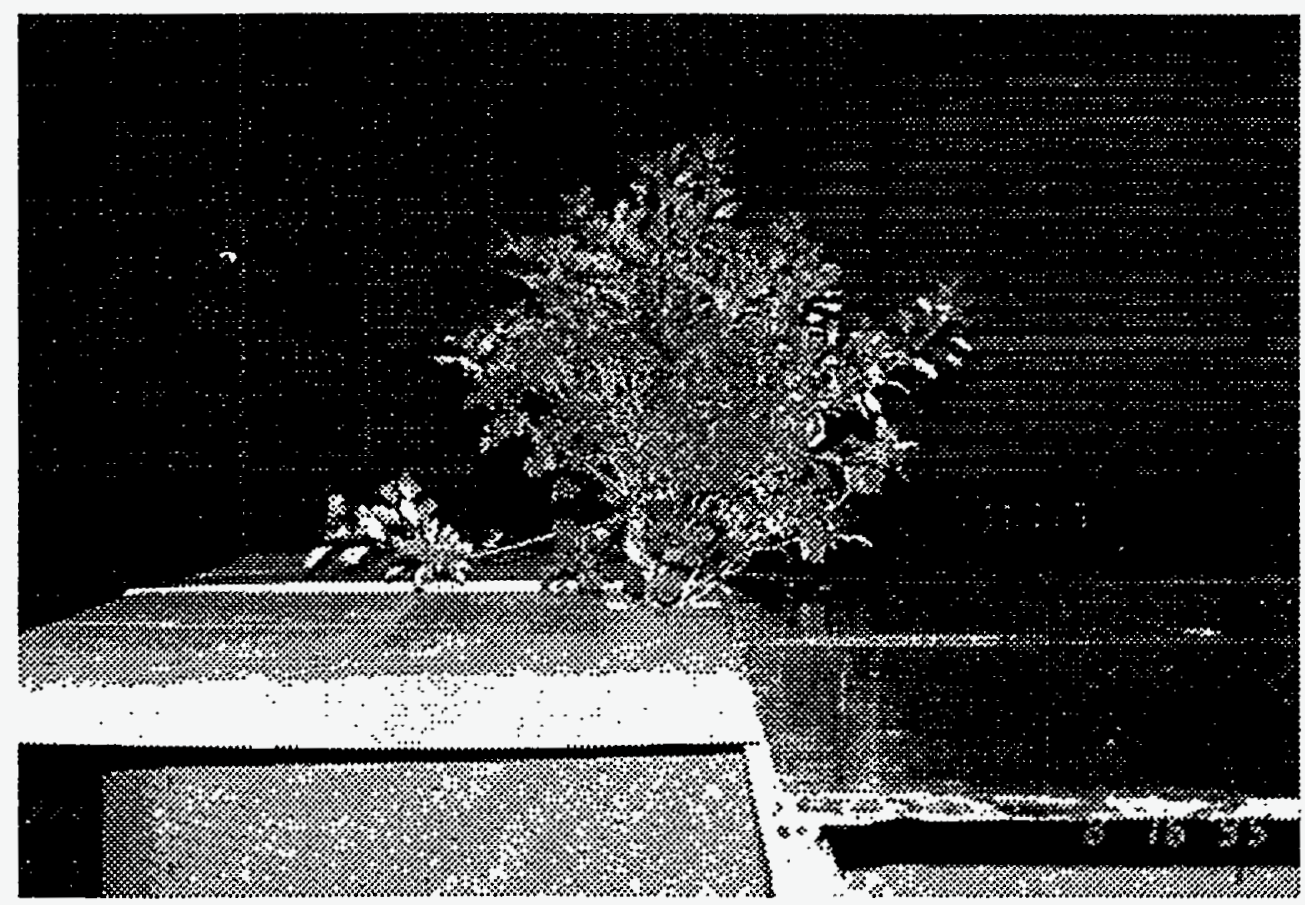

Fig. 38 Royal Purple Smoke Tree 


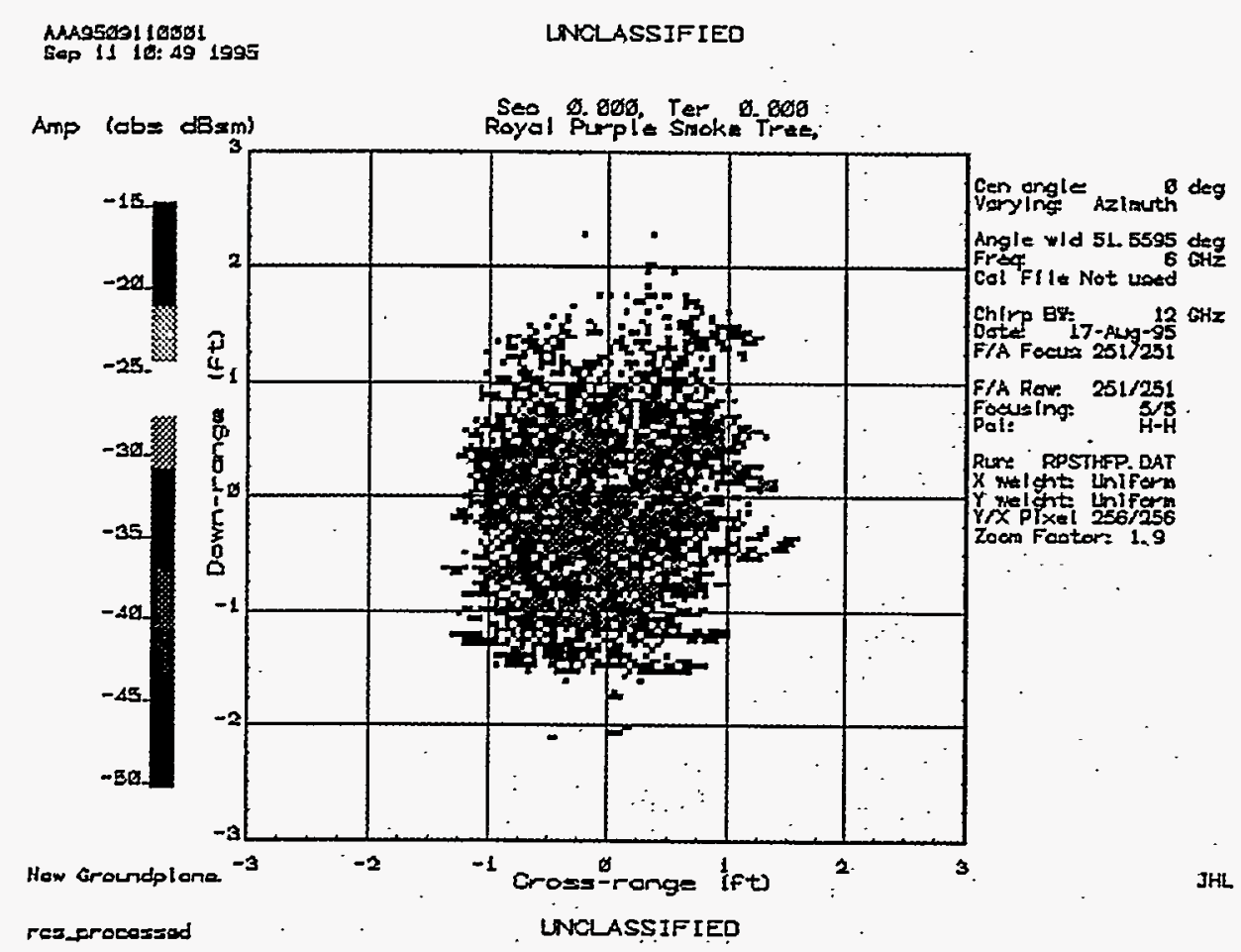

Fig. 39 High Frequency ISAR Image of Royal Purple Smoke Tree H-H Polarization

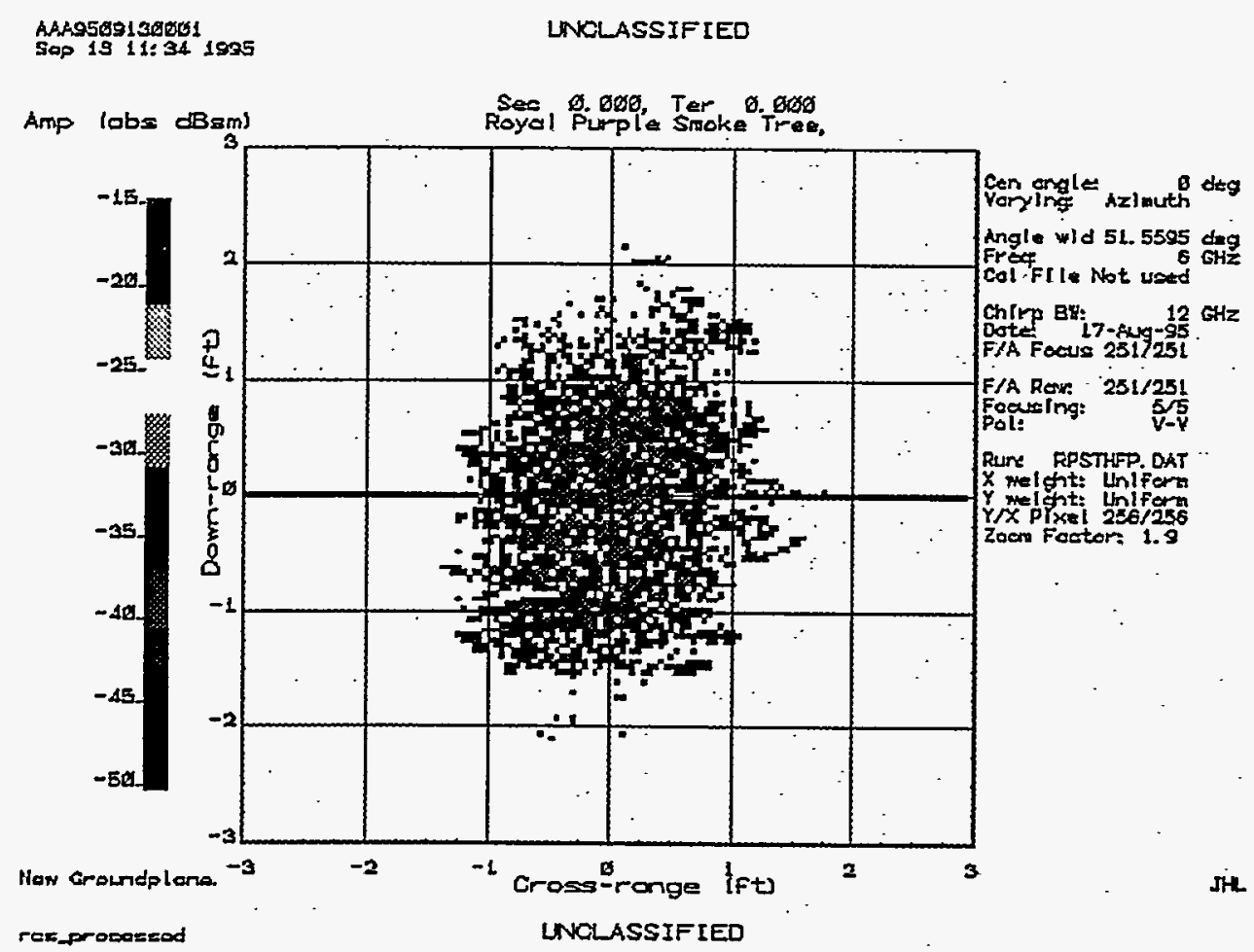

Fig. 40 High Frequency ISAR Image of Royal Purple Smoke Tree V-V Polarization 


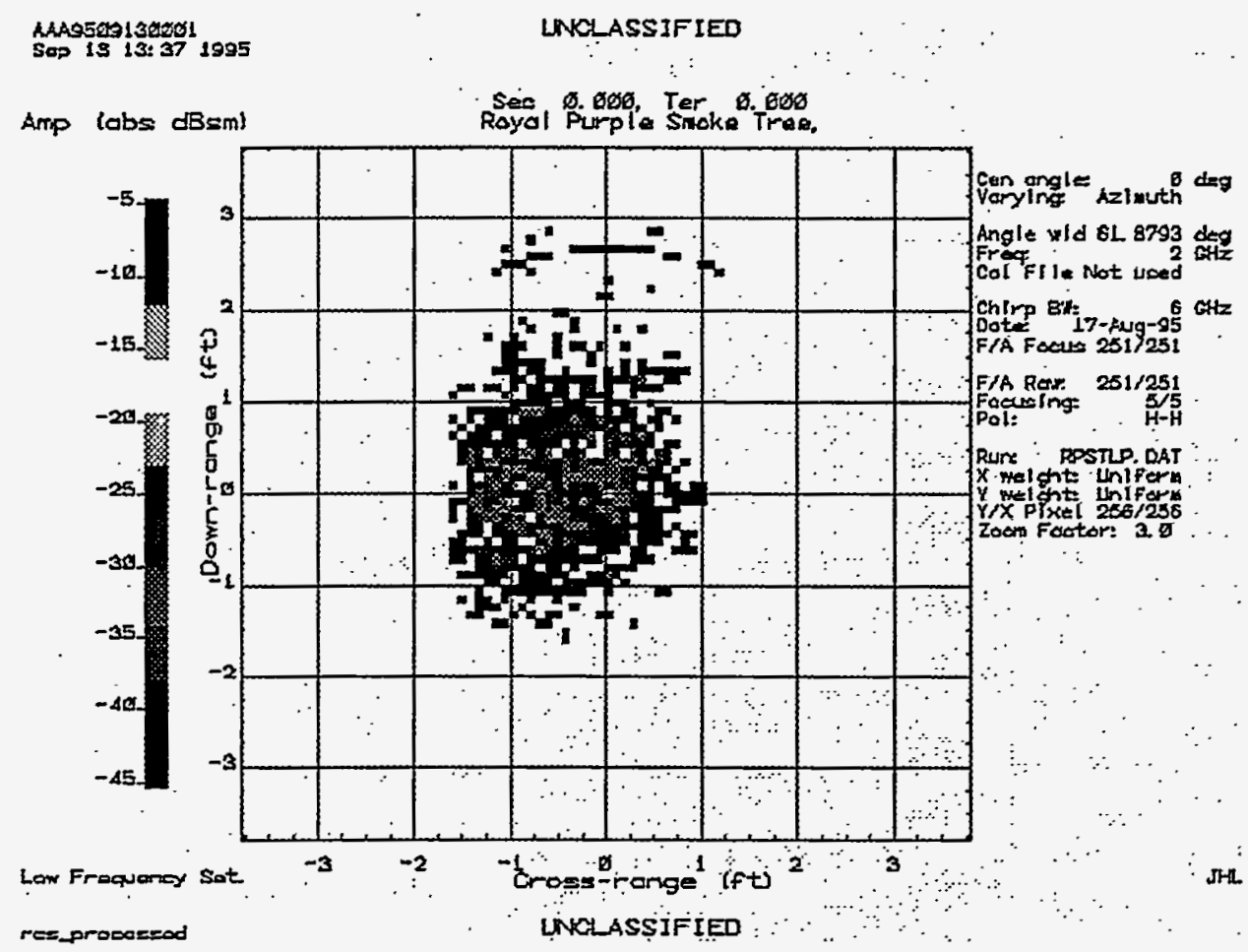

Fig. 41 Low Frequency ISAR Image of Royal Purple Smoke Tree H-H Polarization

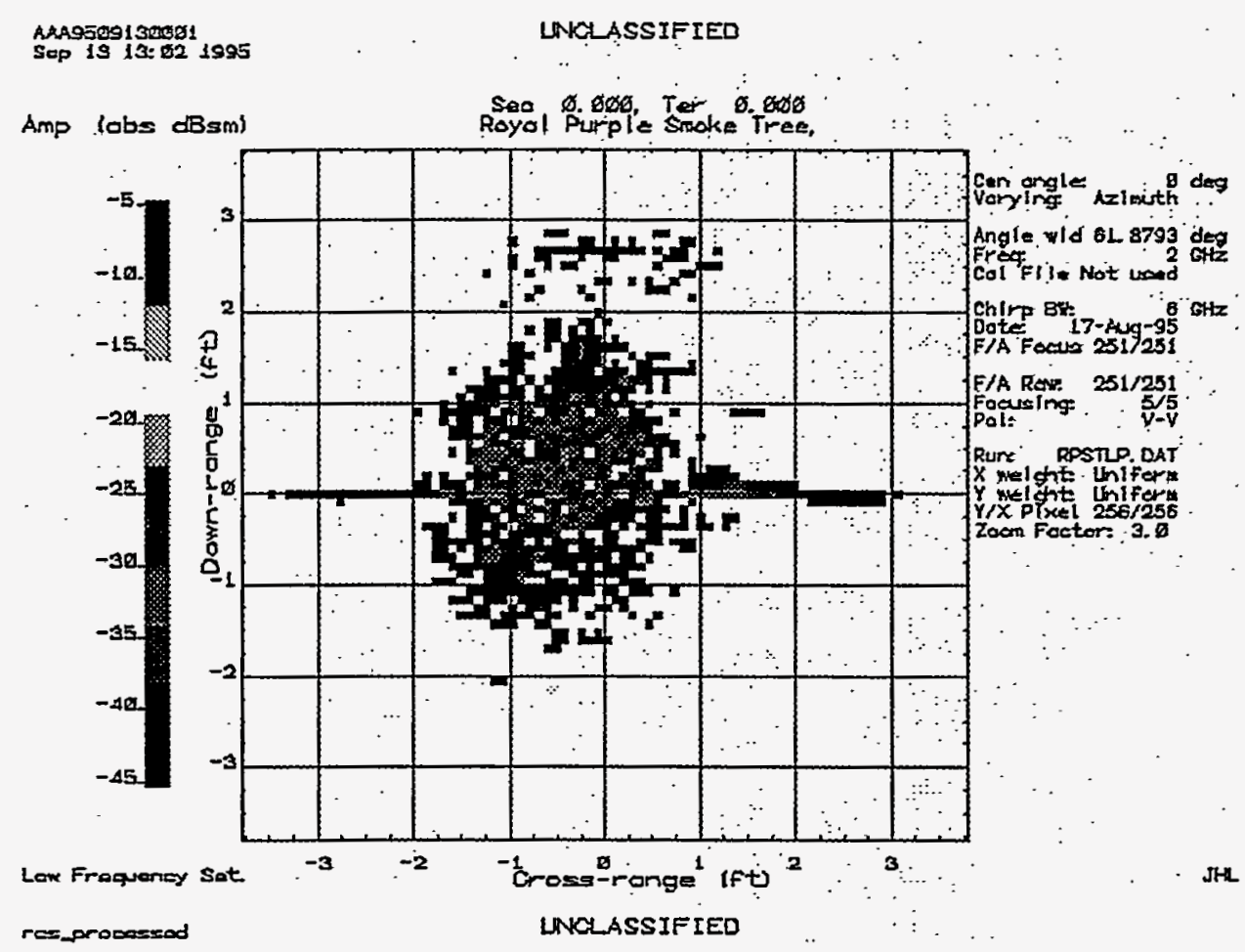

Fig. 42 Low Frequency ISAR Image of Royal Purple Smoke Tree V-V Polarization 


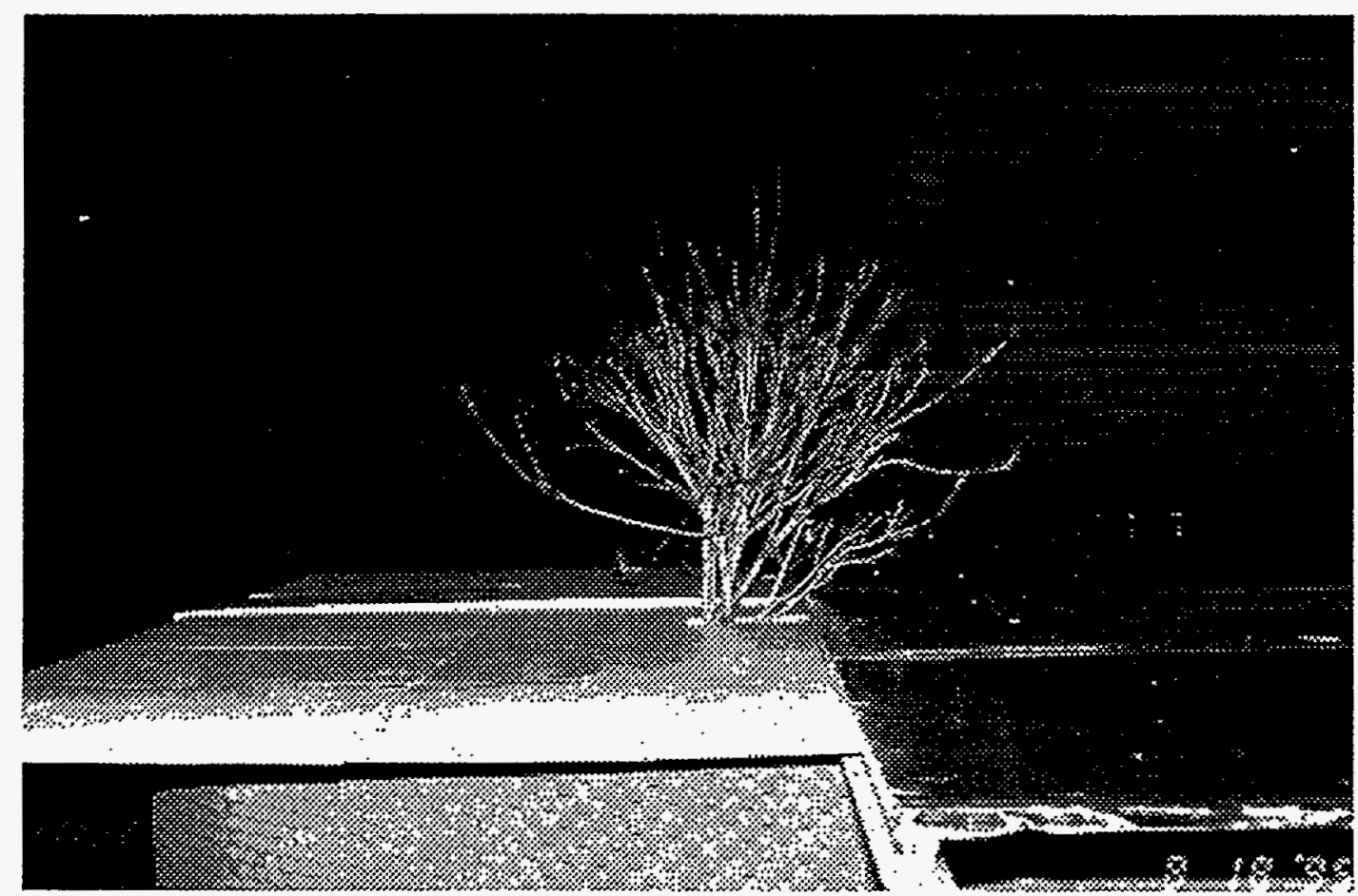

Fig. 43 Royal Purple Smoke Tree, Leaves Removed

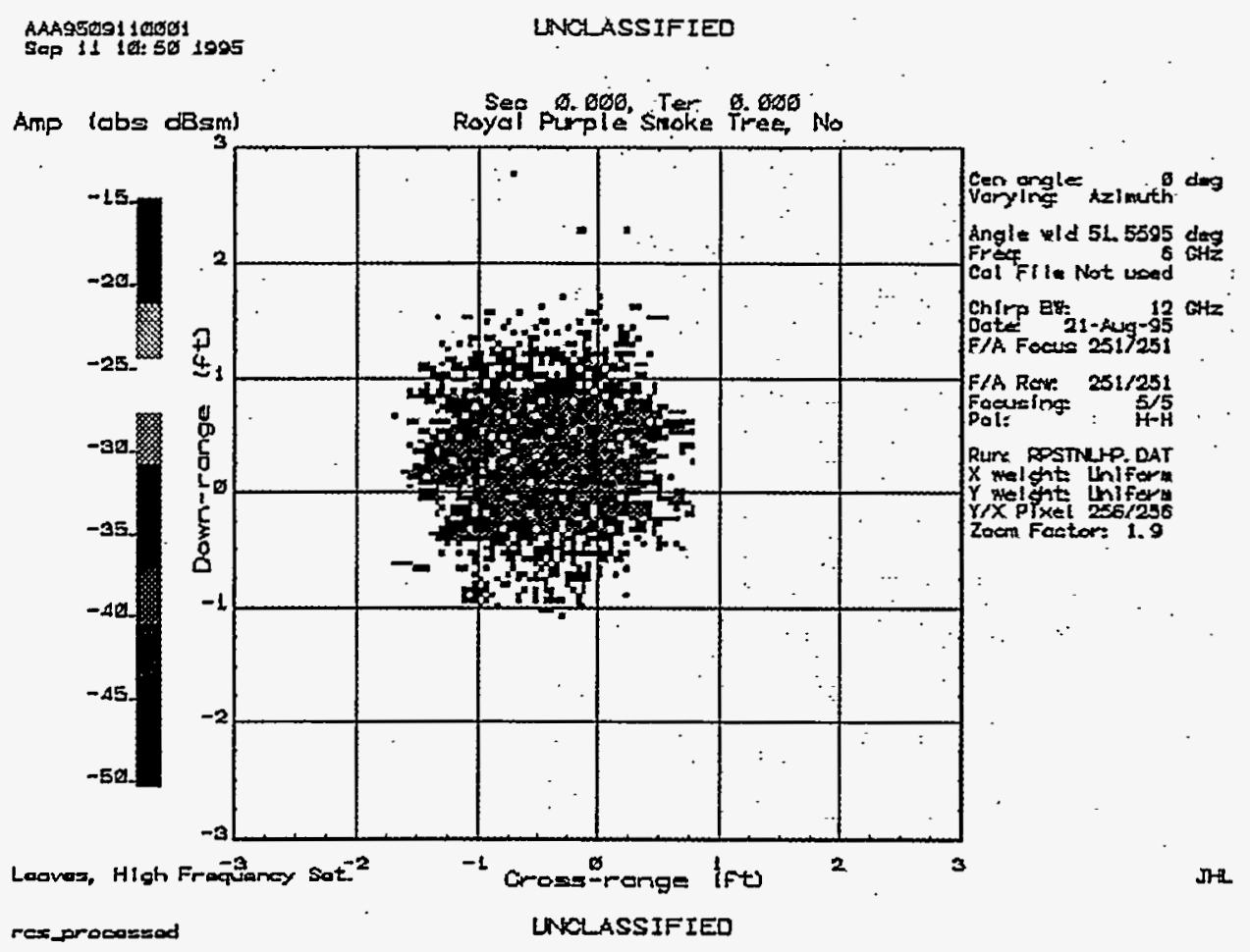

Fig. 44 High Frequency ISAR Image of Royal Purple Smoke Tree No Leaves H-H Polarization 


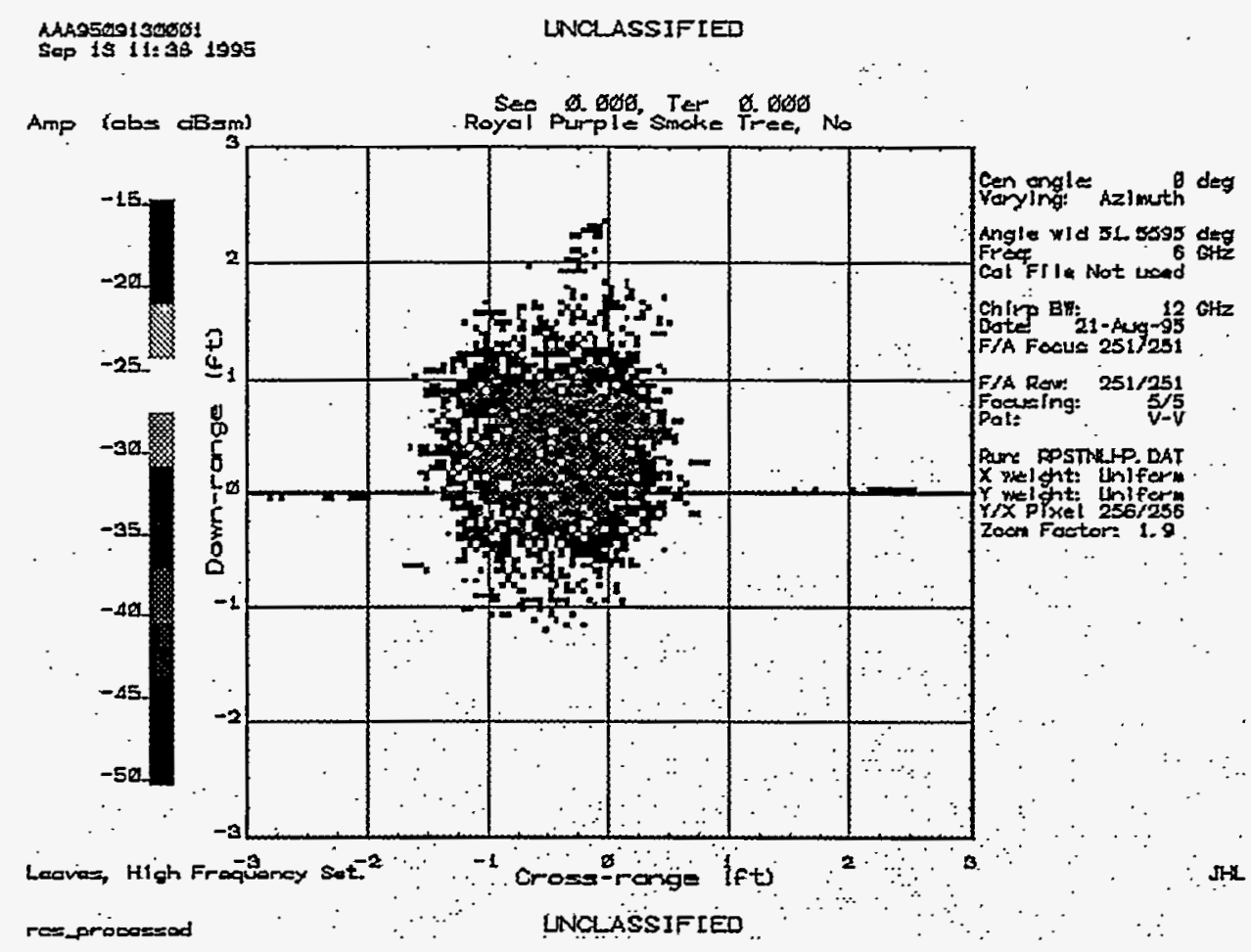

Fig. 45 High Frequency ISAR Image of Royal Purple Smoke Tree No Leaves V-V Polarization

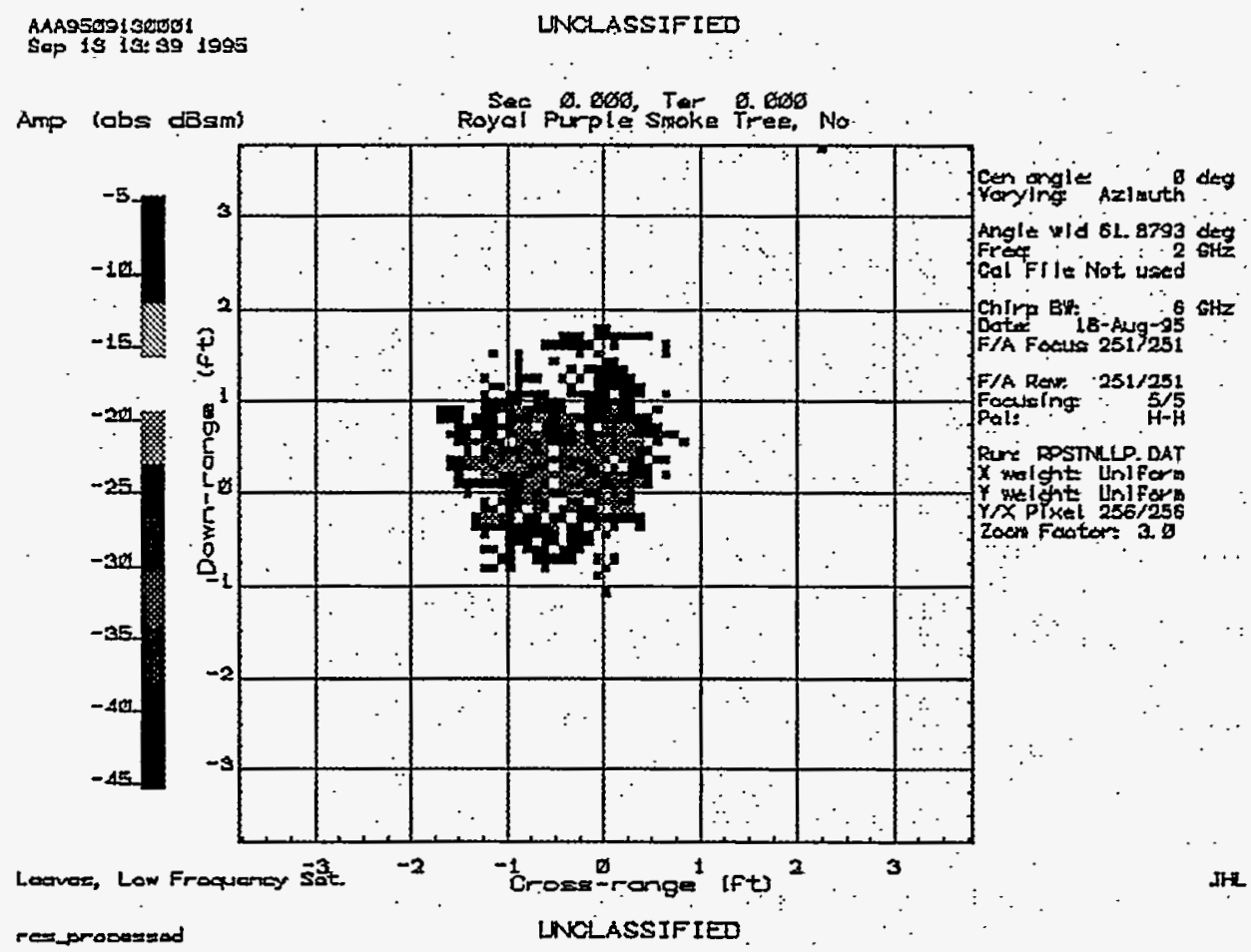

Fig. 46 Low Frequency ISAR Image of Royal Purple Smoke Tree No Leaves H-H Polarization 


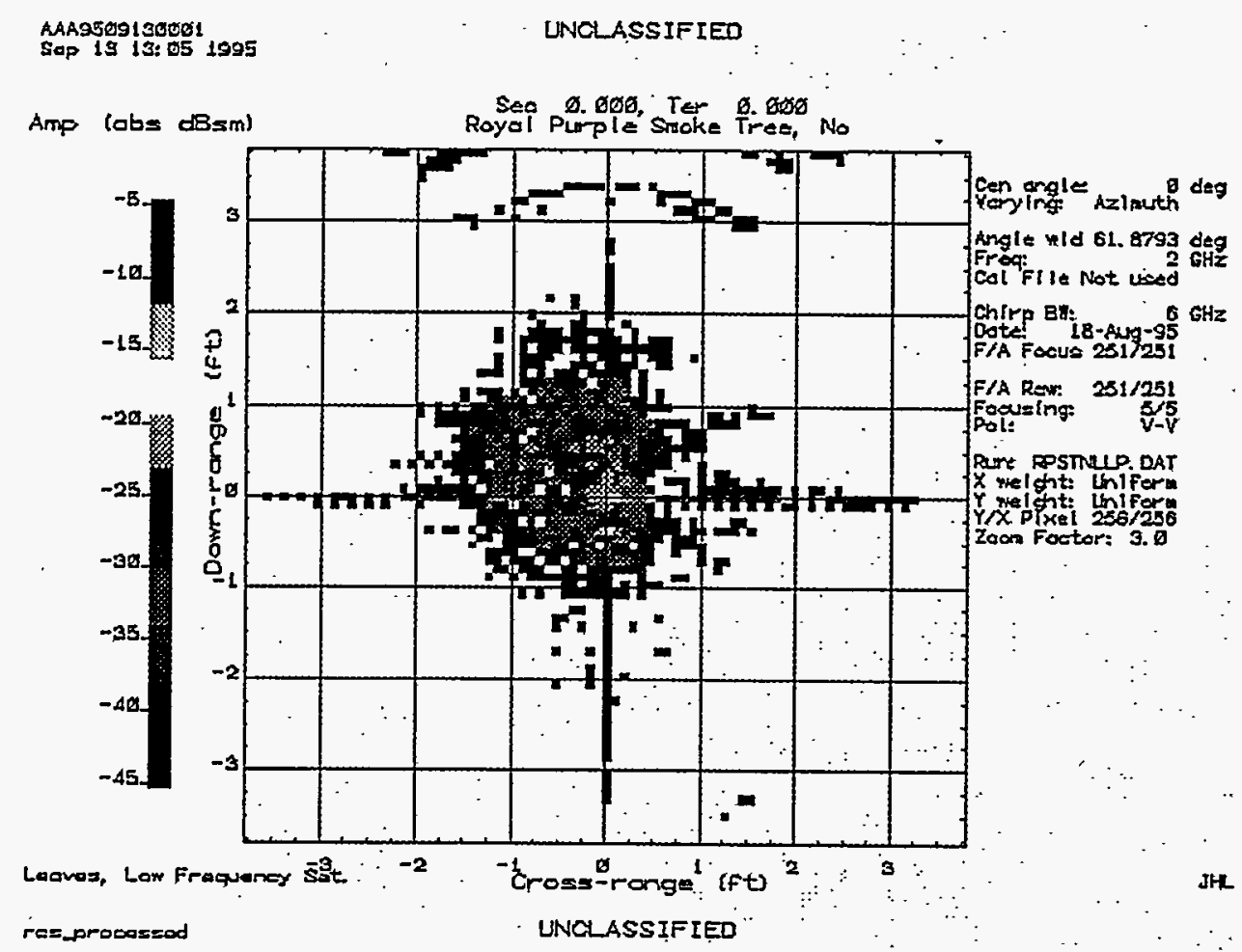

Fig. 47 Low Frequency ISAR Image of Royal Purple Smoke Tree No Leaves V-V Polarization

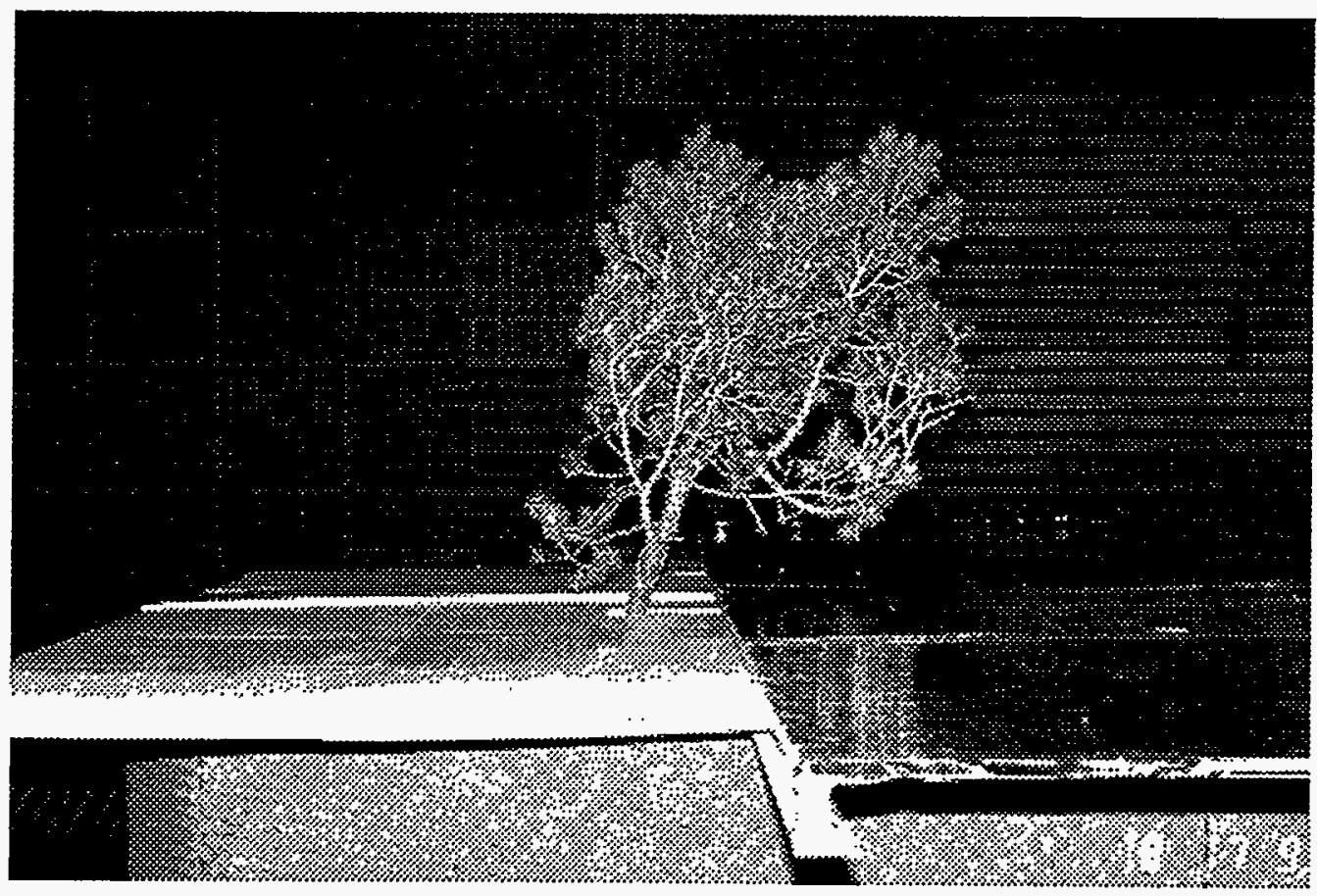

Fig. 48 Piñon Tree 


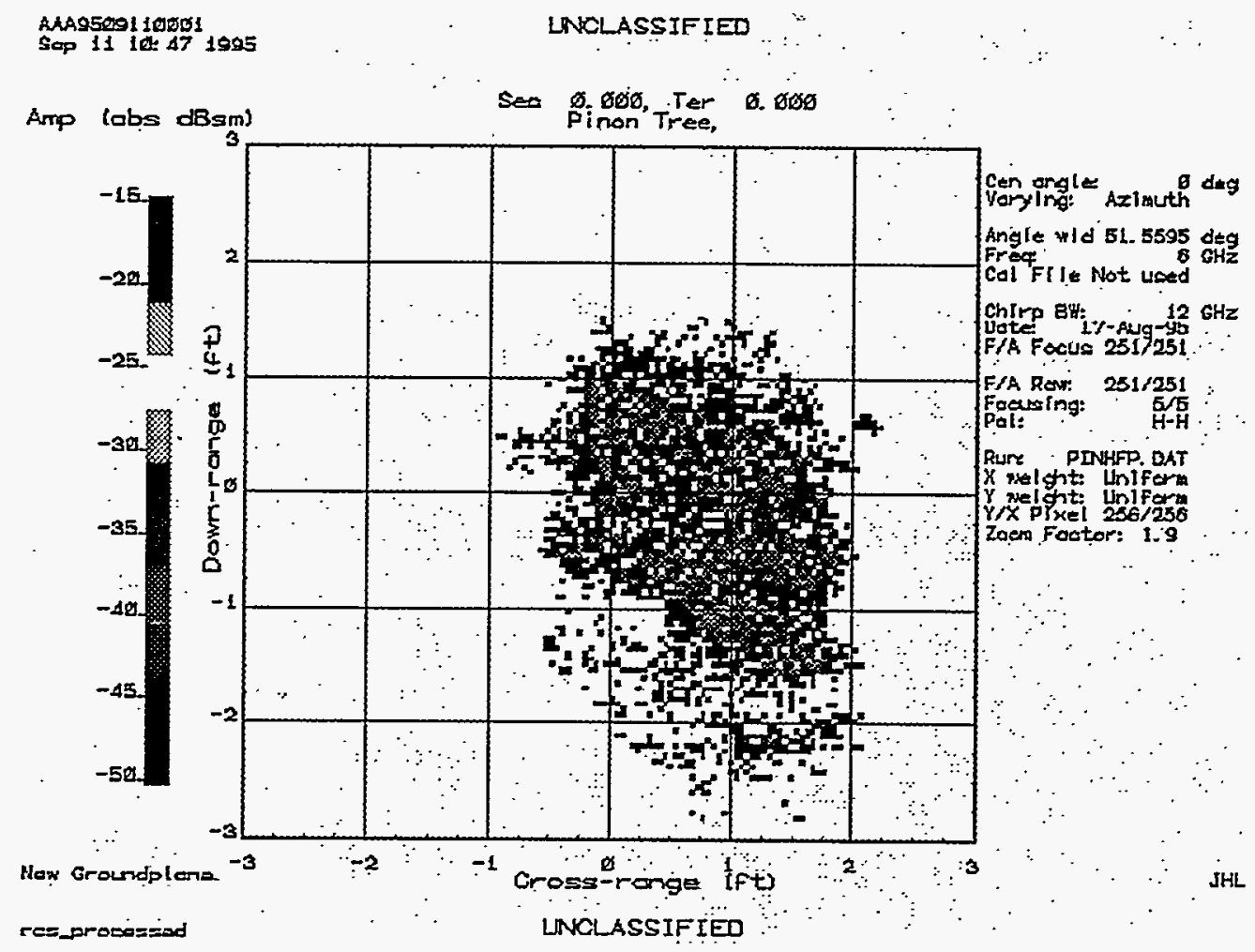

Fig. 49 High Frequency ISAR Image of Piñon Tree H-H Polarization

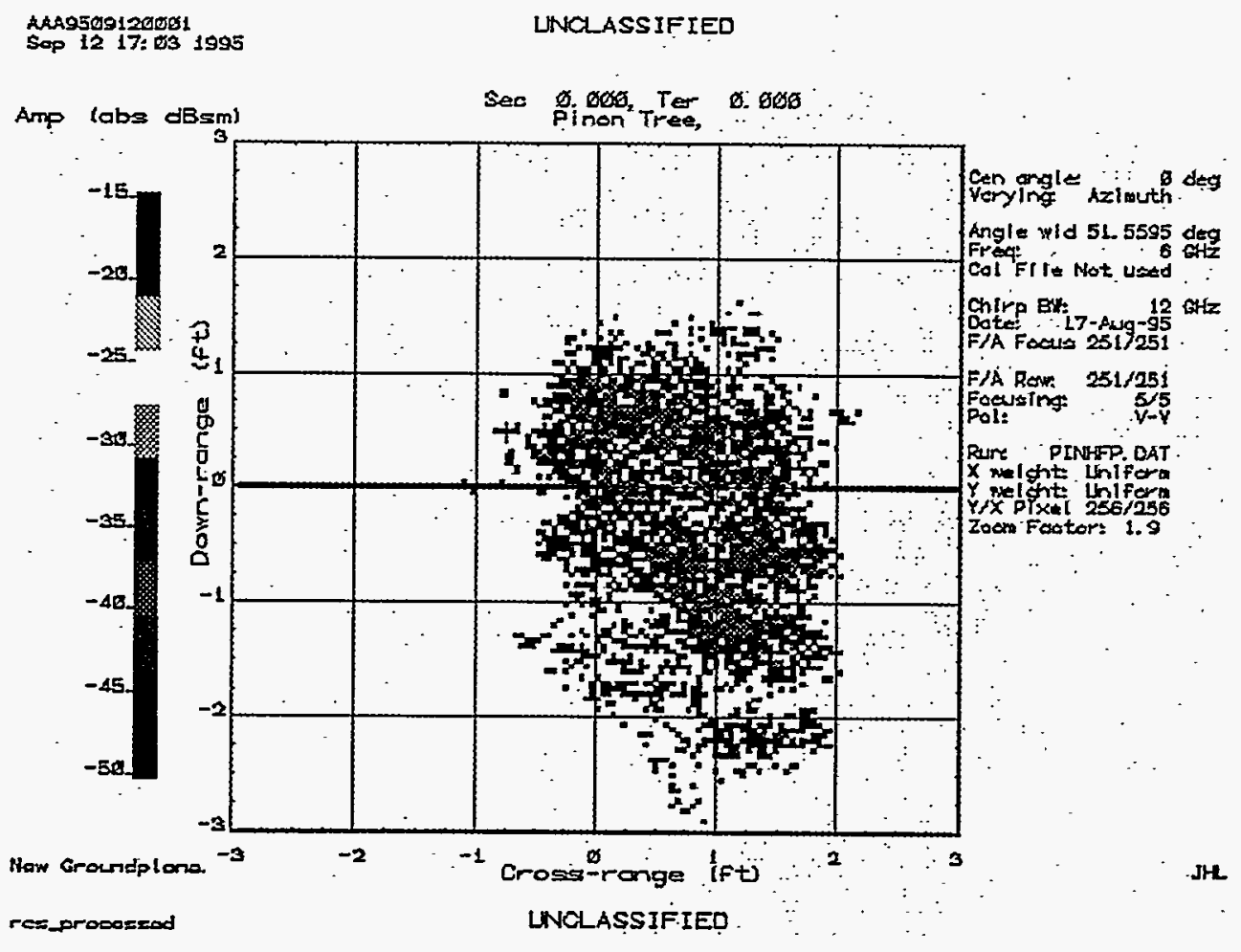

Fig. 50 High Frequency ISAR Image of Piñon Tree V-V Polarization 


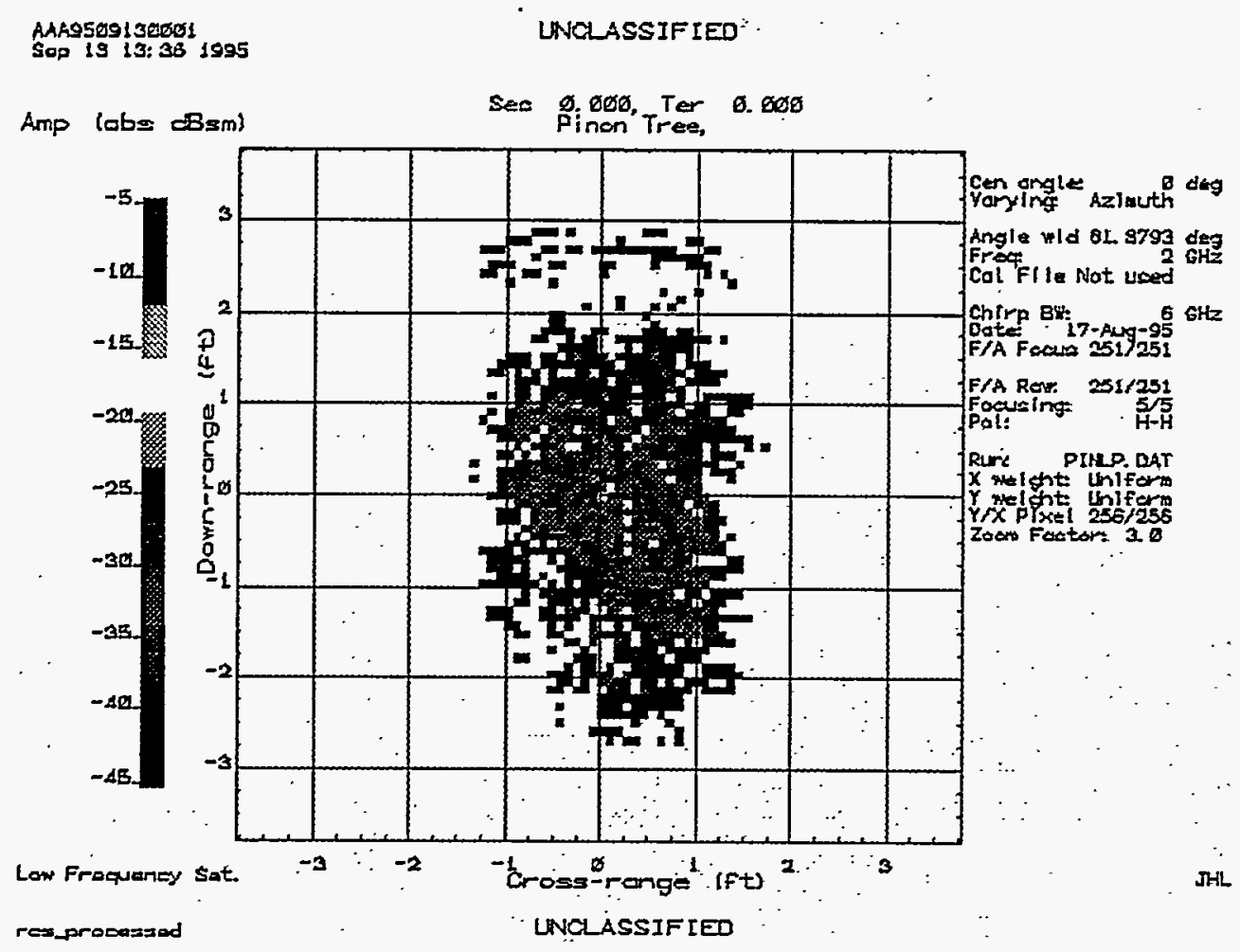

Fig. 51 Low Frequency ISAR Image of Piñon Tree H-H Polarization

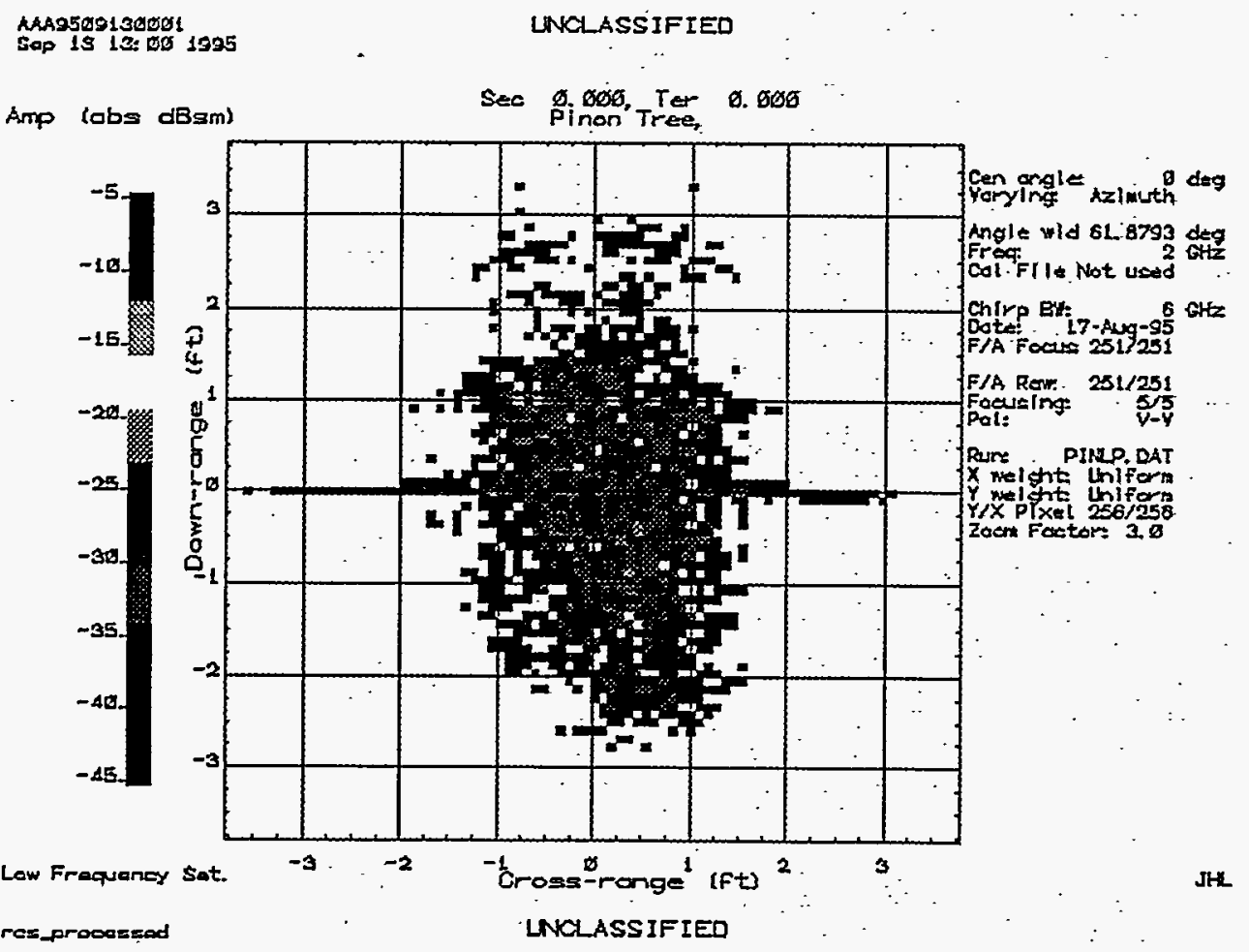

Fig. 52 Low Frequency ISAR Image of Piñon Tree V-V Polarization 


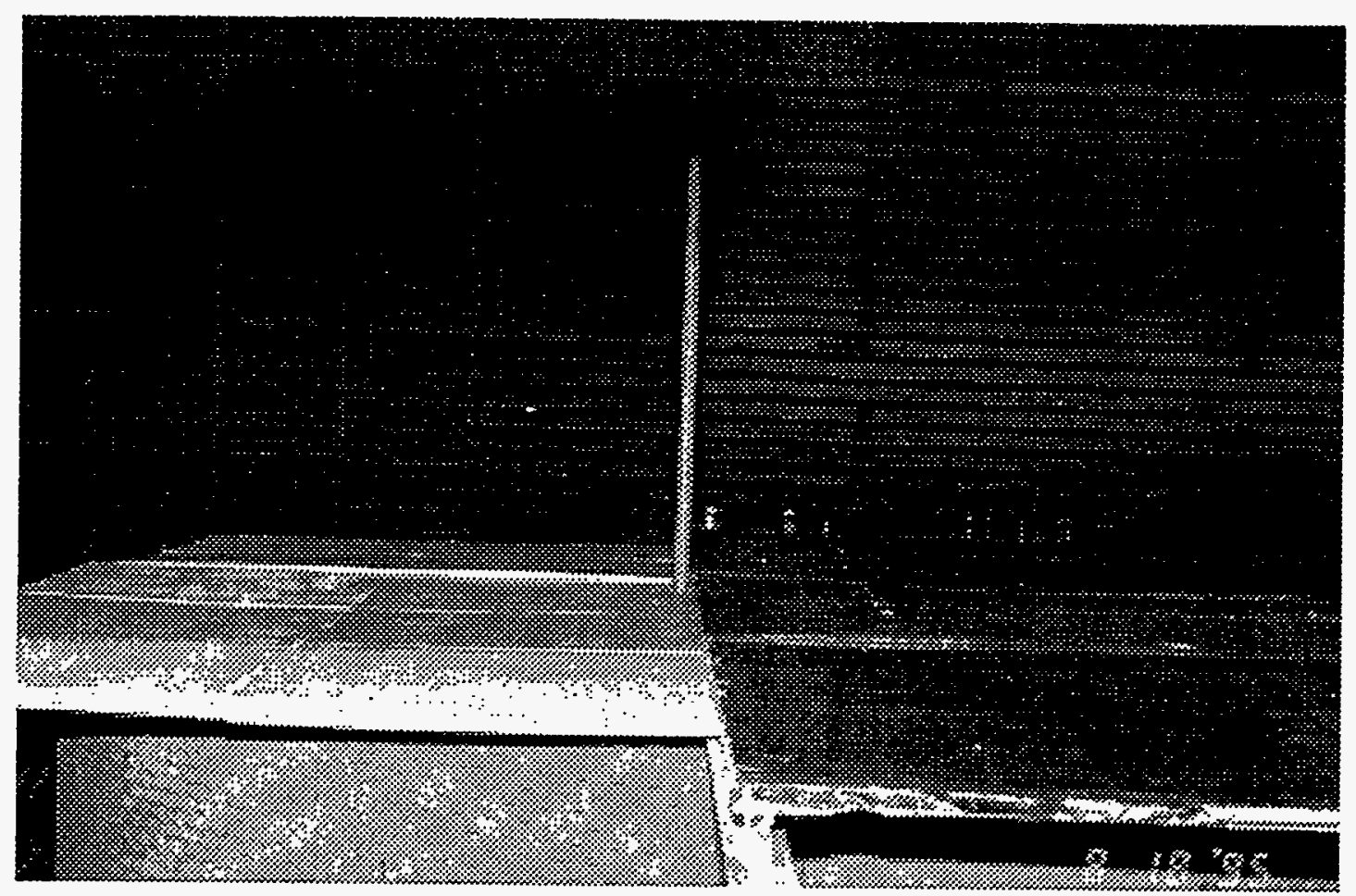

Fig. 53 Walking Stick

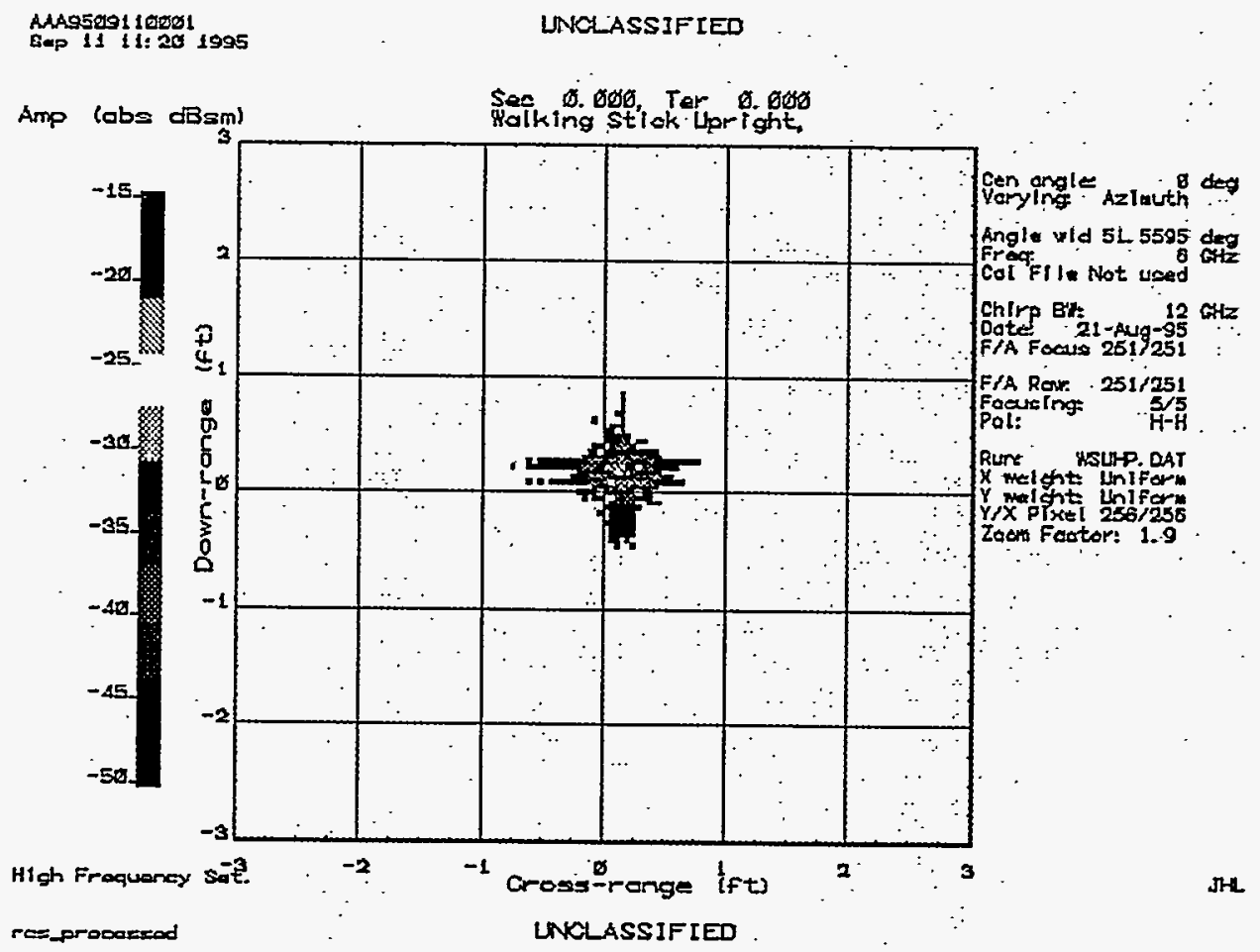

Fig. 54 High Frequency ISAR Image of Walking Stick, Vertical Position, H-H Polarization 


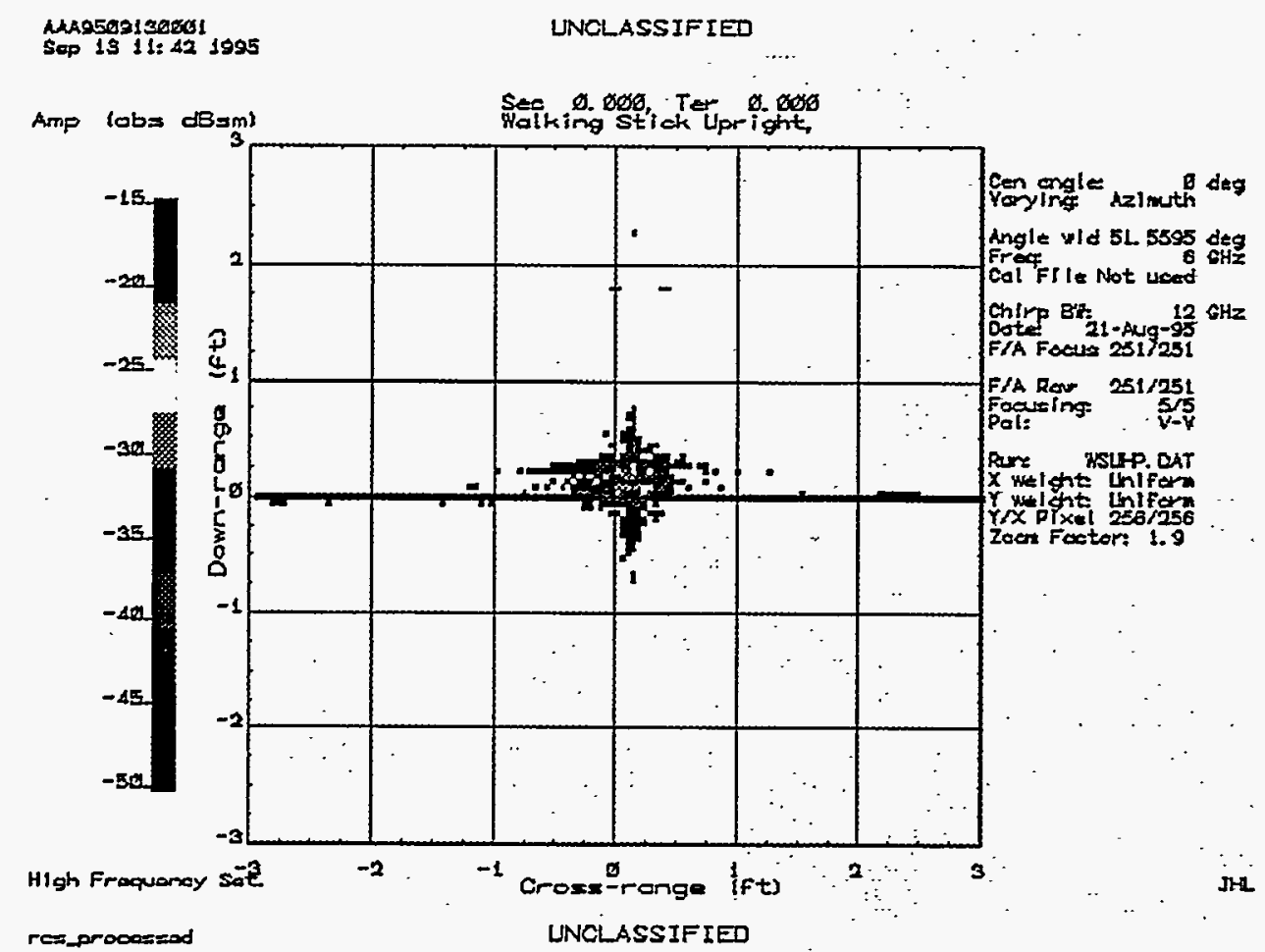

Fig. 55 High Frequency ISAR Image of Walking Stick, Vertical Position, V-V Polarization

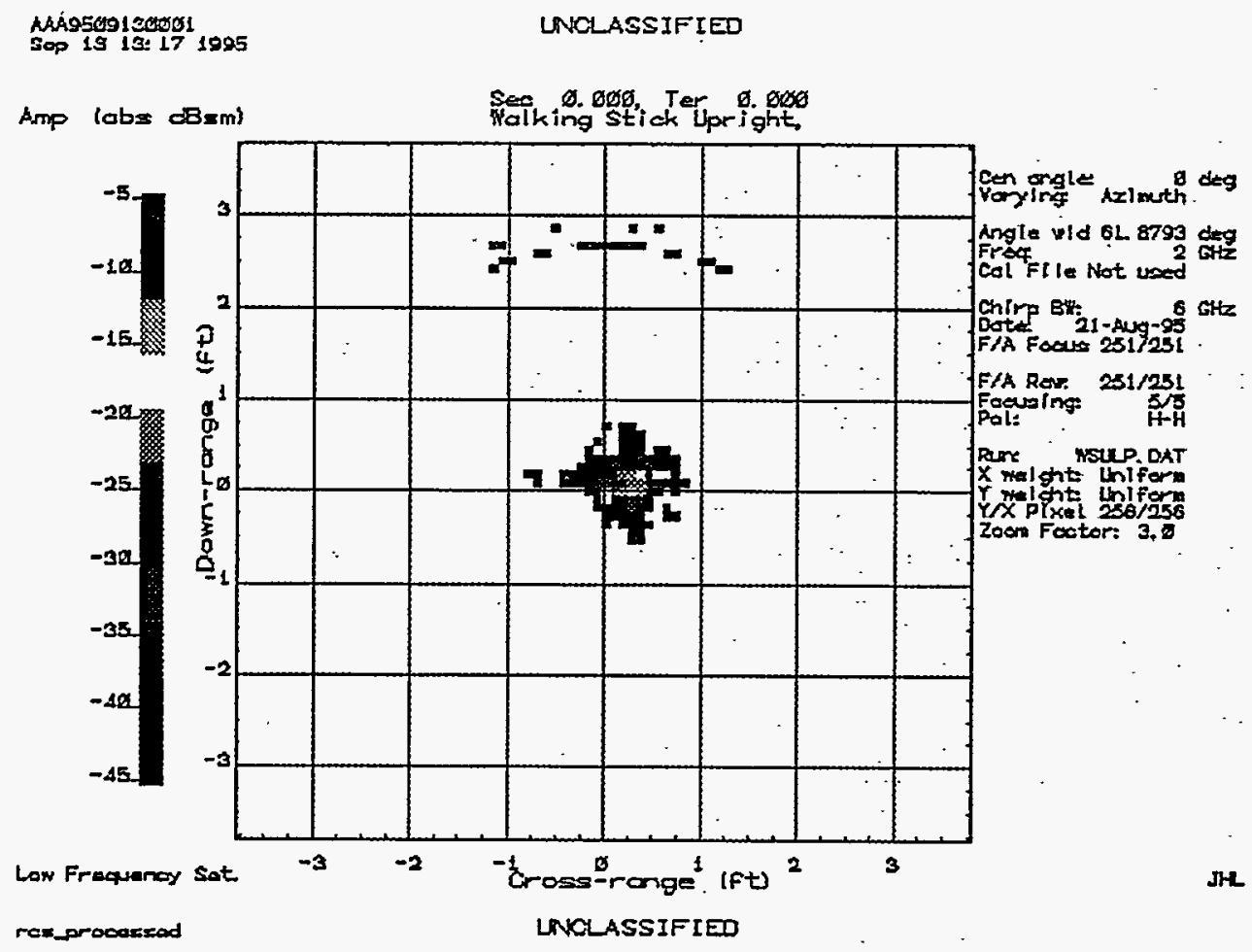

Fig. 56 Low Frequency ISAR Image of Walking Stick, Vertical Position, H-H Polarization 


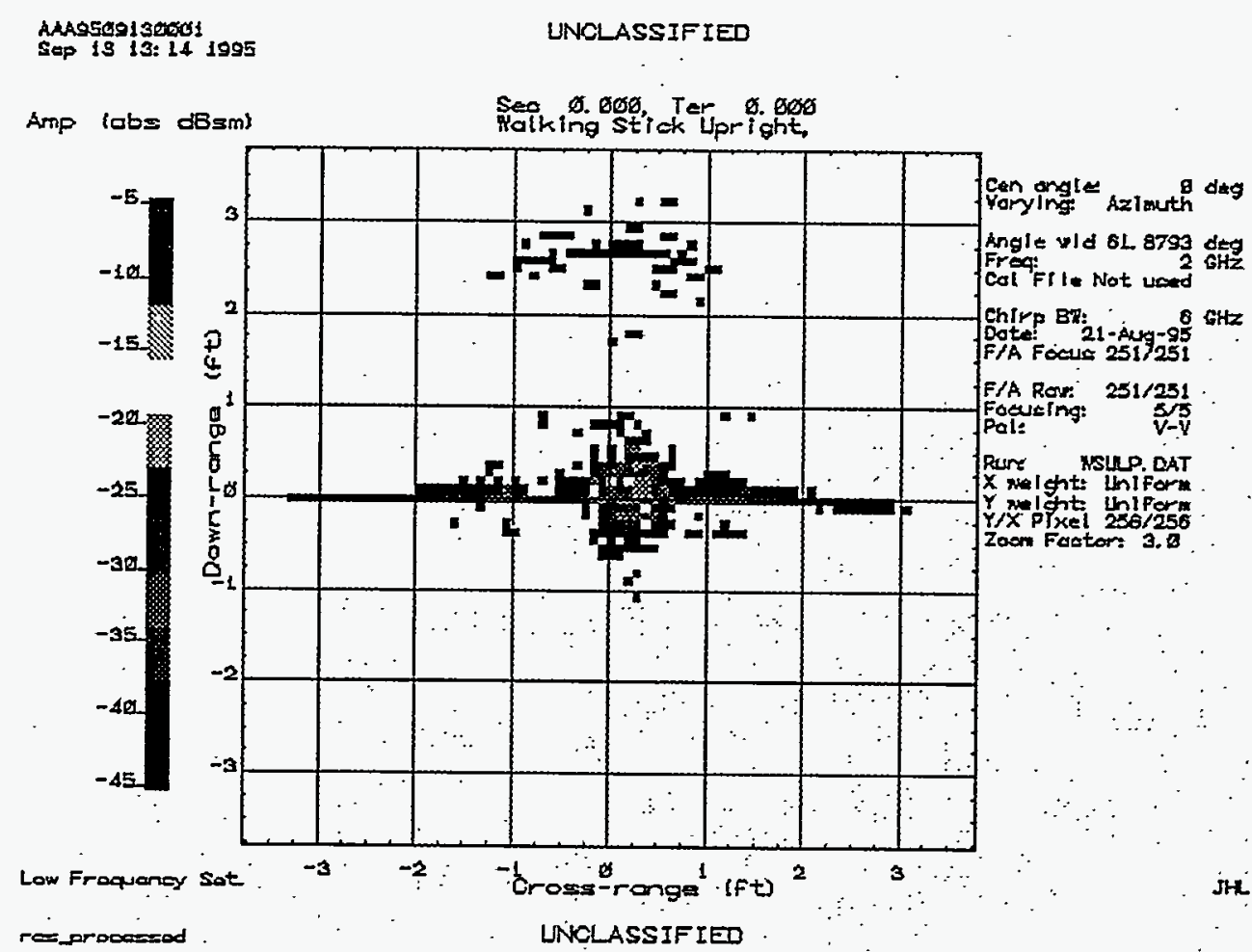

Fig. 57 Low Frequency ISAR Image of Walking Stick, Vertical Position, V-V Polarization AAASSOSI 1 1 ERES Sep 11 il: 101995

UNCLASSIFIED

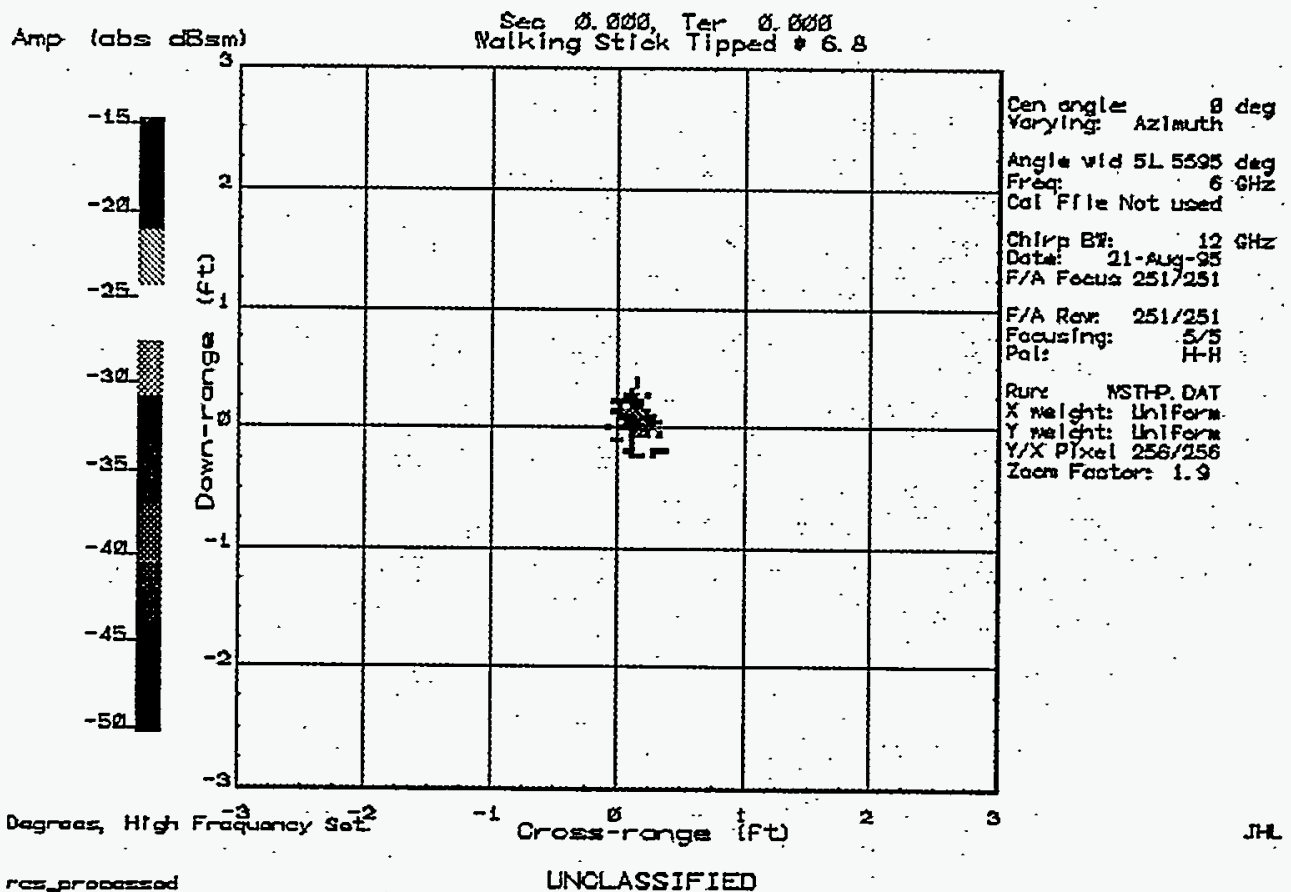

Fig. 58 High Frequency ISAR Image of Walking Stick, Tilted 6.8 Degrees, H-H Polarization 


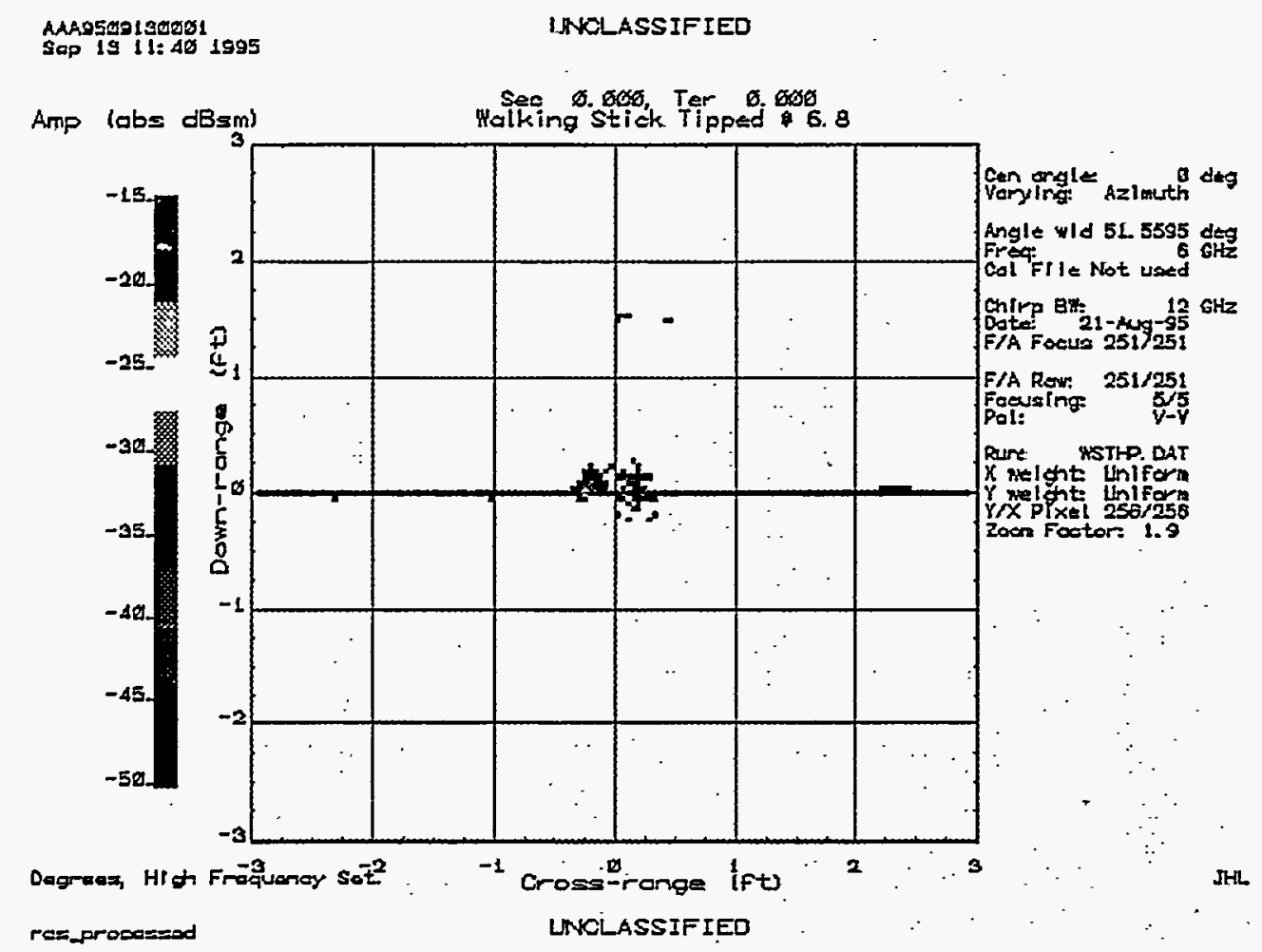

Fig. 59 High Frequency ISAR Image of Walking Stick, Tilted 6.8 Degrees, V-V Polarization ARA9509130601
SAP 19 I3: 44 1925

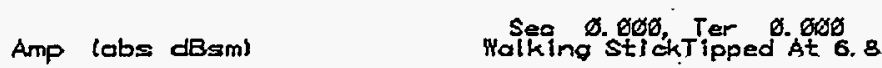

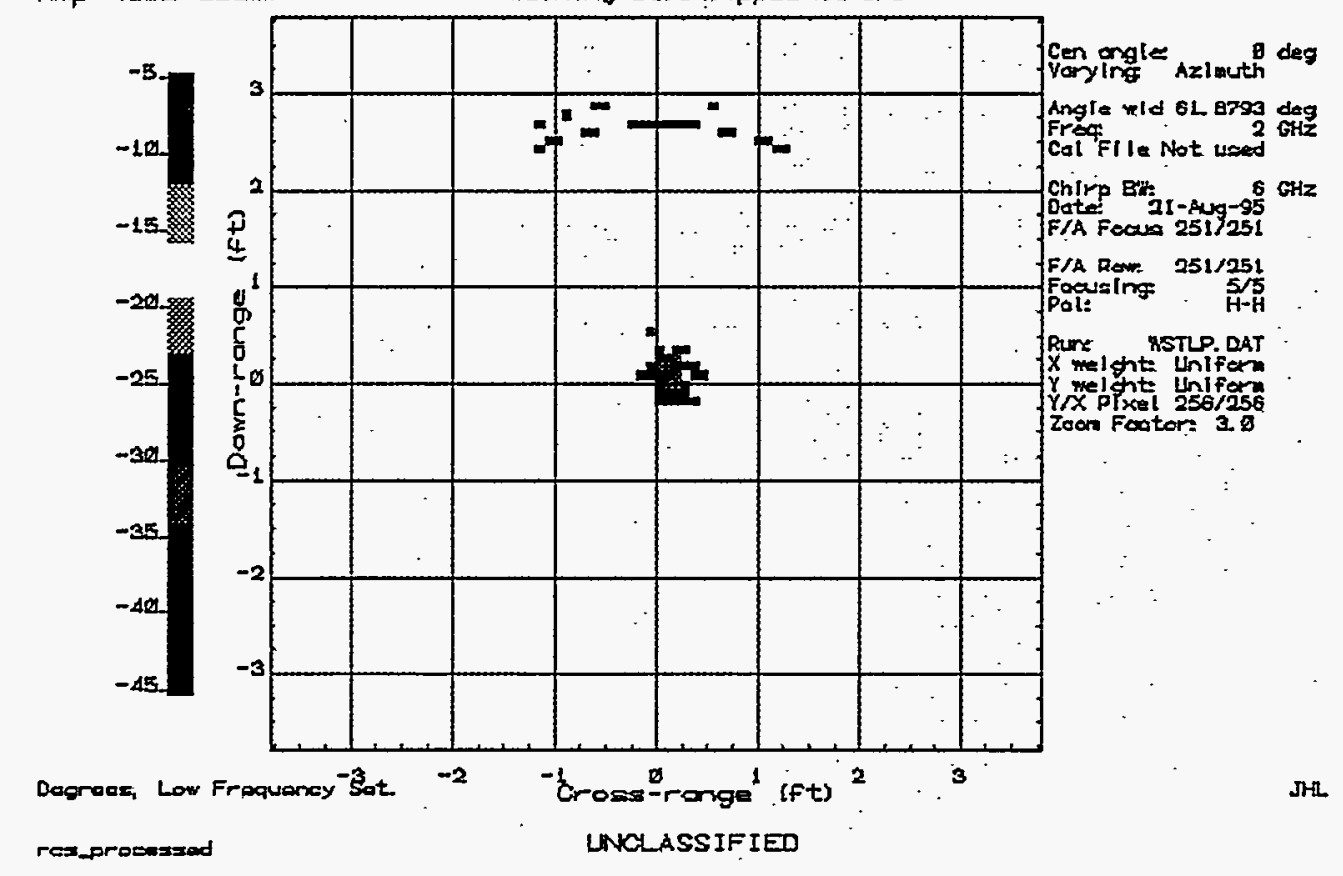

Fig. 60 Low Frequency ISAR Image of Walking Stick, Tilted 6.8 Degrees, H-H Polarization 


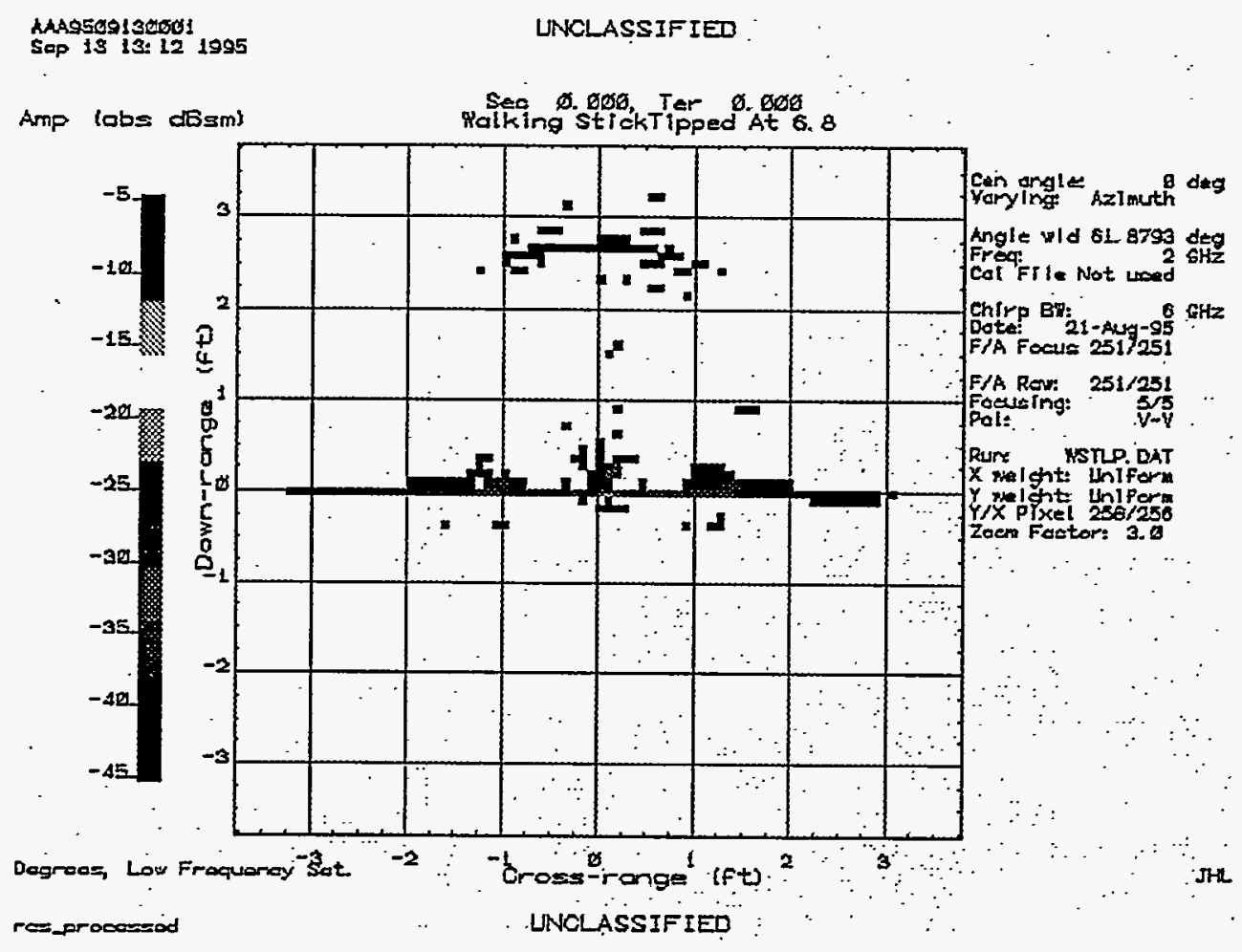

Fig. 61 Low Frequency ISAR Image of Walking Stick, Tilted 6.8 Degrees, V-V Polarization 


\section{References}

[1] D. F. Dubbert, R. B. Hurley, A. W. Doerry, B. L. Burns, B. C. Brock, T. J. Flynn, "A VHF/UHF SAR for Imaging Buried Targets:, Proceedings of the $41^{\text {st }}$ Annual Tri-Service Radar Symposium, Applied Physics Laboratory, Johns Hopkins University, Laural, Maryland, June 1995, SECRET.

[2] Kurt W. Sorensen, Folded Compact Range Development and Coherent Change Detection Measurement Project, SAND95-0389, Sandia National Laboratories, Albuquerque, March, 1995. 


\section{Distribution}

$1 \quad$ MS-0529

$1 \quad$ MS 0529

$1 \quad$ MS 0529

$1 \quad$ MS 0529

1 MS-0531

1 MS-0531

1 MS-0531

10 MS 0533

$1 \quad$ MS 0533

$1 \quad$ MS 0533

$1 \quad$ MS 0533

$1 \quad$ MS 0533

$1 \quad$ MS 0572

$1 \quad$ MS 0572

$1 \quad$ MS 0572

$1 \quad$ MS 0843

$1 \quad$ MS 0860

$1 \quad$ MS 0860

1 MS 0860

$1 \quad$ MS 9018

$5 \quad$ MS 0899

$1 \quad$ MS 0619

2 MS 0100
B. L. Burns, 2345

A. W. Doerry, 2345

D. F. Dubbert, 2345

B. C. Walker, 2345

J. T. Cordaro, 2344

W. H. Hensley, 2344

D. L. Bickel, 2344

B. C. Brock, 2343

J. H. Littlejohn, 2343

W. E. Patitz, 2343

W. H. Schaedla, 2343

D. H. Zittel, 2343

C. V. Jakowatz, 5912

T. S. Prevender, 5912

T. J. Flynn, 5912

J. R. Fellerhoff, 9131

C. C. Carson, 9122

D. H. Cress, 9122

R. O. Nellums, 9122

Central Technical Files, 8523-2

Technical Library, 4414

Print Media, 12615

Document Processing, 7613-2

For DOE/OSTI 